Issued by Sandia National Laboratories, operated for the United States Department of Energy by Sandia Corporation.

NOTICE: This report was prepared as an account of work sponsored by an agency of the United States Government. Neither the United States Government nor any agency thereof, nor any of their employees, nor any of their contractors, subcontractors, or their employees, makes any warranty, express or implied, or assumes any legal liability or responsibility for the accuracy, completeness, or usefulness of any information, apparatus, product, or process disclosed, or represents that its use would not infringe privately owned rights. Reference herein to any specific commercial product, process, or service by trade name, trademark, manufacturer, or otherwise, does not necessarily constitute or imply its endorsement, recommendation, or favoring by the United States Government, any agency thereof or any of their contractors or subcontractors. The views and opinions expressed herein do not necessarily state or reflect those of the United States Government, any agency thereof or any of their contractors.

Printed in the United States of America. This report has been reproduced directly from the best available copy.

Available to DOE and DOE contractors from Office of Scientific and Technical Information PO Box 62

Oak Ridge, TN 37831

Prices available from (615) 576-8401, FTS 626-8401

Available to the public from

National Technical Information Service

US Department of Commerce

5285 Port Royal RD

Springfield, VA 22161

NTIS price codes

Printed copy: A04

Microfiche copy: A06 


\section{DISCLAIMER}

Portions of this document may be illegible in electronic image products. Images are produced from the best available original document. 
Distribution

Category UC-704

SAND 94-0691

Unlimited Distribution

\title{
Analysis of Physiochemical Processes During Solder Aging
}

\author{
Kenneth L. Erickson \\ Energetic Materials and Fluid Mechanics Department 1512 \\ Polly L. Hopkins \\ Computational Fluid Dynamics Department 1511 \\ Paul T. Vianco \\ Physical and Joining Metallurgy Department 1831 \\ Sandia National Laboratories \\ Albuquerque, New Mexico 87185
}

\begin{abstract}
A model describing the diffusion-controlled growth of multiple intermetallic layers and the displacement of the interfaces between layers was developed and implemented in a one-dimensional computer code based on the method-of-lines. The model can accomodate cases involving: (1) finite initial layer thicknesses, (2) rate-limiting interfacial reactions, (3) multiple and variable diffusion coefficients, and (4) finite material boundaries. Additionally, the effects of nucleation can be modeled empirically. A transformation of the spatial coordinate circumvented the need to remesh the growing and (or) shrinking layers. Results from the one-dimensional code were verified by comparing the numerical results with analytical solutions for simple systems involving two, three, and five layers. The computer code was applied to analysis of the intermetallic layer growth that occurred in solder aging experiments that were done with $100 \mathrm{Sn}$ and $63 \mathrm{Sn}-37 \mathrm{~Pb}$ solders. The analyses indicated that intermetallic layer growth was consistent with a bulk diffusion mechanism involving $\mathrm{Cu}$ and (or) $\mathrm{Sn}$ and variable diffusion coefficients that should reflect some enhanced diffusion during early layer growth. The enhanced diffusion can be accounted for empirically using a variable diffusion coefficient that is a function of layer thickness.
\end{abstract}




\section{Table of Contents}

1.0 INTRODUCTION $\ldots \ldots \ldots \ldots \ldots \ldots \ldots \ldots \ldots \ldots \ldots \ldots \ldots \ldots \ldots \ldots$

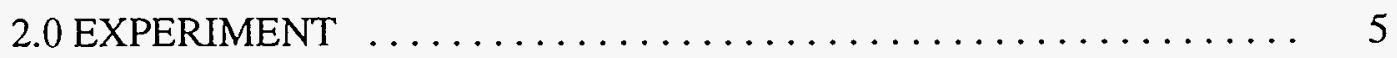

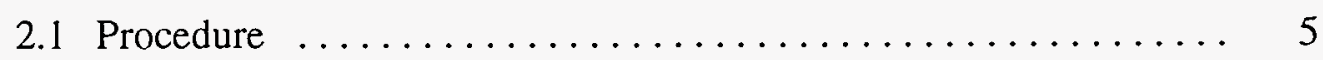

2.2 Results ................................ 6

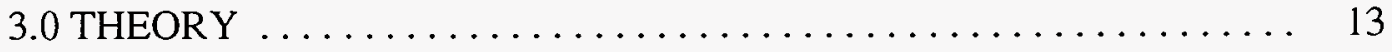

4.0 NUMERICAL APPROACH $\ldots \ldots \ldots \ldots \ldots \ldots \ldots \ldots \ldots \ldots . . \ldots \ldots$

4.1 Equation Transformation $\ldots \ldots \ldots \ldots \ldots \ldots \ldots \ldots \ldots \ldots \ldots \ldots \ldots$

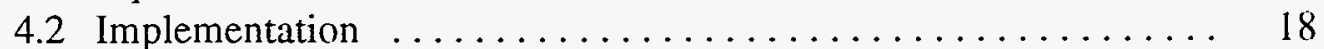

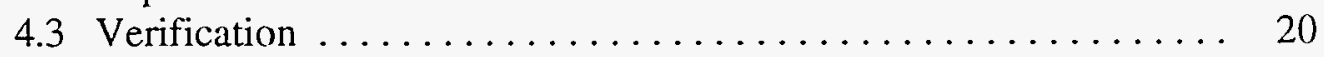

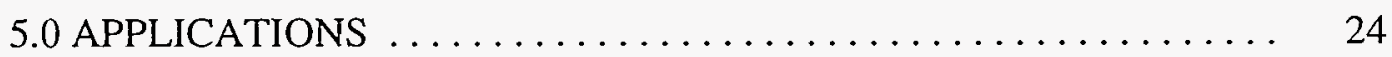

6.0 RECOMMENDATIONS FOR FURTHER WORK $\ldots \ldots \ldots \ldots \ldots \quad 40$

7.0 CONCLUSIONS ............................... 43

ACKNOWLEDGMENTS $\ldots \ldots \ldots \ldots \ldots \ldots \ldots \ldots \ldots \ldots \ldots \ldots \ldots \ldots$

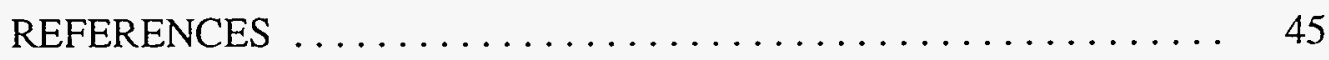

APPENDIX A: Marker Layers $\ldots \ldots \ldots \ldots \ldots \ldots \ldots \ldots \ldots \ldots \ldots \ldots \ldots \ldots$

APPENDIX B: The Interface as the Frame of Reference $\ldots \ldots \ldots \ldots \quad 49$

APPENDIX C: Program ILaG Flow Chart $\ldots \ldots \ldots \ldots \ldots \ldots \ldots \quad 52$

APPENDIX D: ILaG Input File Description $\ldots \ldots \ldots \ldots \ldots \ldots . \quad 53$

APPENDIX E: Sample Input File $\ldots \ldots \ldots \ldots \ldots \ldots \ldots \ldots \ldots . \quad 56$ 


\subsection{INTRODUCTION}

The reliability of mechanical and electronic systems can be acutely dependent on the integrity of the soldered joints used in those assemblies. During manufacture and service, intermetallic layers form in reaction zones between the dissimilar materials forming the joints. The thermal and mechanical properties of the intermetallic layers can be substantially different from those of the initial bulk materials. The properties of the intermetallic layers can seriously affect wetting characteristics during manufacturing, and reliability during service in a variety of defense applications and commercial products in the electronics, automotive, aircraft, nuclear, and power industries.

Because thermal cycling during service can result in chemical and physical changes to the microstructure of the joint (for example, intermetallic layer growth), analytical models describing these changes can contribute to improved predictions of the long-term reliability of soldered joints. The objective of this work was to develop the numerical tools for analyzing the multiphase, multicomponent, solid-state diffusion-controlled growth of intermetallic layers in soldered joints during service conditions and aging experiments at elevated temperatures. The software provides a new analysis capability for materials researchers to examine intermetallic growth mechanisms and for design engineers to predict manufacturing defects and joint failure during service for a wide variety of defense and commercial applications involving both traditional and advanced materials. Although the work primarily addresses processes occurring during service conditions after joints are formed, the modeling capabilities developed are amenable to analysis of several physiochemical processes associated with formation of soldered joints.

The research approach consisted of two complementary tasks: (1) the development of mathematical models and numerical tools and (2) the acquisition of data for intermetallic layer growth in solder-aging experiments using copper substrates with tin and tin-lead solders. The experimental work was intended to provide data for determining relevant mechanisms, in addition to chemical diffusion, that should be included in the models and software, and to quantitatively describe mechanisms and rates in real solder systems of interest in both defense and commercial applications.

The formation and growth of intermetallic layers is shown schematically in Fig. 1. In general, contact between a metal substrate and molten solder results in a chemical reaction between the metal and constituents of the solder, and an intermetallic phase nucleates at the metal-solder interface. As the reaction continues, nuclei coalesce to form a continuous intermetallic layer. If the solder material is an alloy, such as $63 \mathrm{Sn}-37 \mathrm{~Pb}$, the reaction of one constituent (for example $\mathrm{Sn}$ ) to form the intermetallic layer causes the composition of the solder to become richer in the nonreacting constituent $(\mathrm{Pb})$. The non-reacting constituent may precipitate as a dispersed phase in the bulk solder or may form a second layer ahead of the intermetallic layer. Growth of the intermetallic layer is controlled by the interfacial reaction rate and the diffusion of reacting constituents in the layer. Growth of the intermetallic layer continues while the temperature of the system remains elevated, but becomes negligible as the material cools to ambient temperature. During service, solder joints may be heated due to thermal cycling of the assemblies in which the joints are used. Reaction between solder and substrate can occur, causing additional growth of the intermetallic layer. Furthermore, additional intermetallic phases can nucleate and form layers adjacent to the initial layer.

After an intermetallic layer forms, growth of that layer is described by the diffusion equations 
(a)

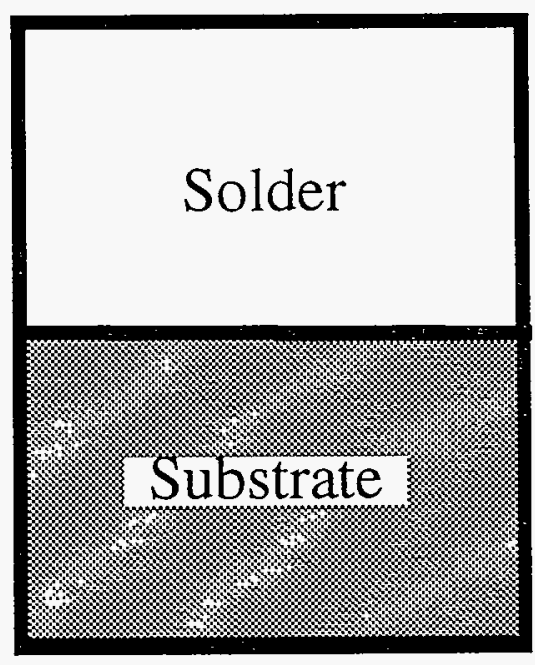

(d)

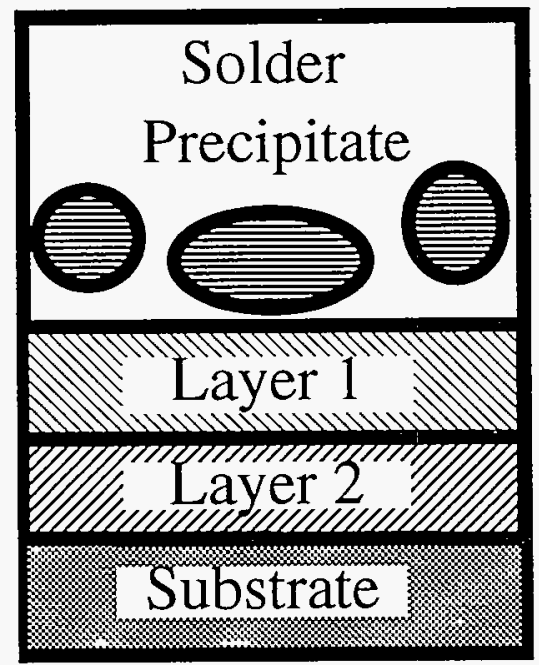

(b)

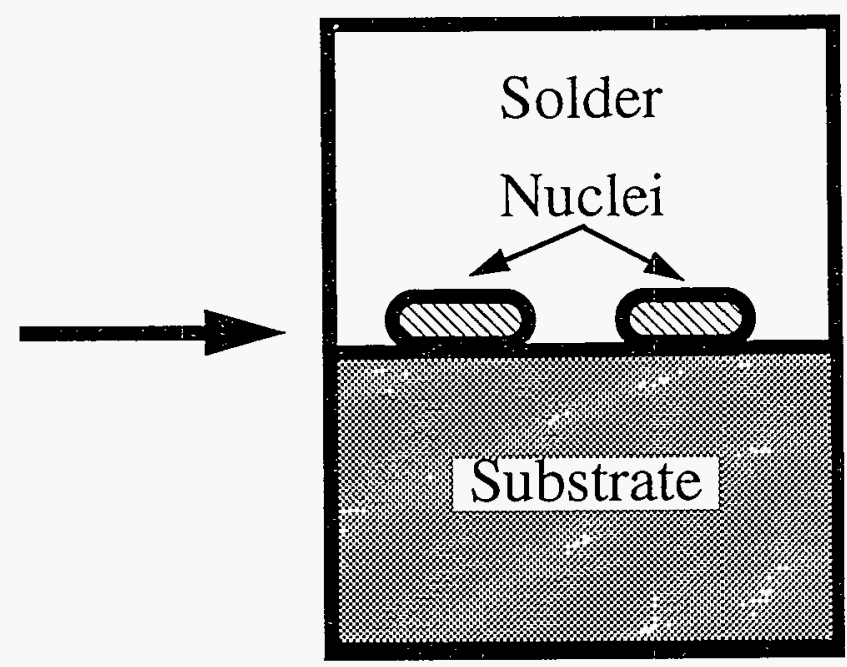

(c)
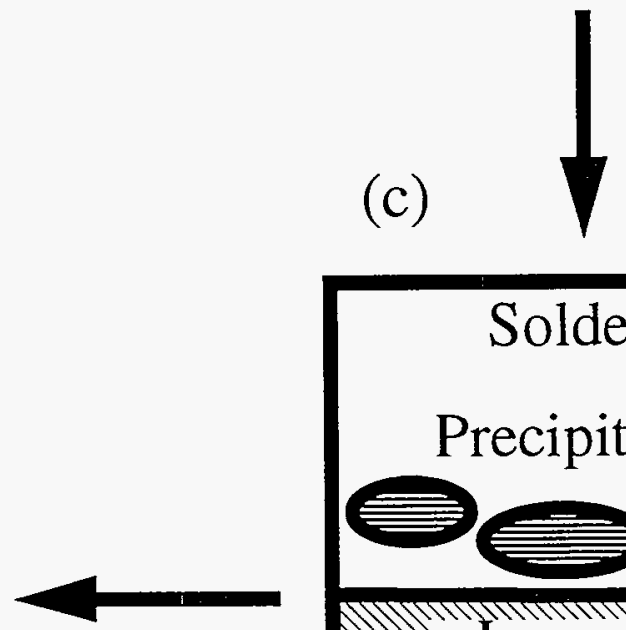

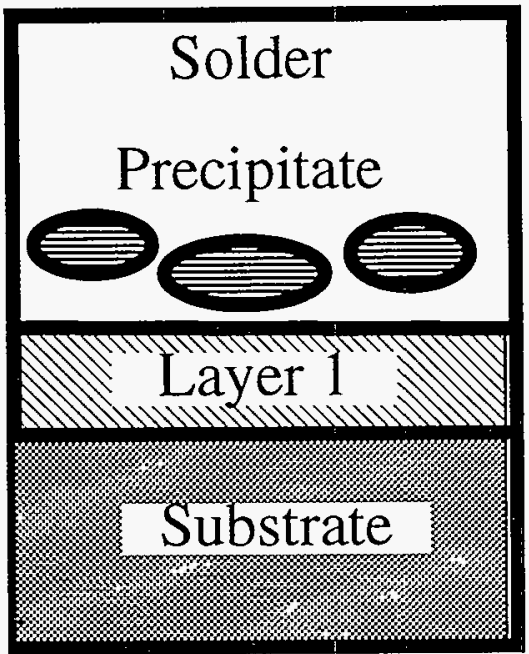

Figure 1. Schematic diagram illustrating (a) initial solder and substrate, (b) intermetallic nucleation, (c) intermetallic layer growth and dispersed phase precipitation, and (d) growth of an additional intermetallic layer. 
for the reacting constituents in the layer, the reaction rates at each interface bounding the layer, and the equations for the displacement of each interface bounding the layer. Mathematical problems of this type are often referred to as "Stefan Problems" and have been discussed by several authors. The preponderance of the literature addresses heat transfer problems. An introduction to moving boundary, or Stefan, problems is given in the books by Carslaw and Jaeger (1959), Jost (1960), and Crank (1975). A much more detailed discussion of the analytical theory and existence of solutions to Stefan problems is given by Friedman (1964) and by Rubenstein (1971). Analytical solutions also are discussed in Friedman (1959 and 1960), Miranker and Keller (1960), and Cannon, et al. (1967). Various numerical approaches have been developed and are summarized by Crank (1988). These include front-tracking, front-fixing, and enthalpy methods, which are primarily applied to one-dimensional, one- or two-phase heat transfer problems. The enthalpy method has been particularly useful in heat transfer problems, for example, Shamsunder and Sparrow (1975), Meyer (1973), and Meyer (1978). The latter also discusses some transformation techniques applicable to limited classes of problems. Unfortunately, in mass transfer problems, an analogy to the enthalpy method does not exist, because the latent heat does not have an analogy in mass transfer. The use of an "immobilizing" transformation for a two-phase solidification problem is discussed by Duda, et al. (1975), and an application of the method-of-lines to one-dimensional, single-phase problems is discussed in Meyer (1977). Additional applications in which Stefan problems occur are discussed in Ockendon and Hodgkins (1974) and Chadam and Rasmussen (1993a and 1993b).

A numerical model describing the diffusion-controlled growth of multiple intermetallic layers and the displacement of the interfaces between layers was developed and implemented in a onedimensional computer code based on the method-of-lines. A transformation of the spatial coordinate circumvented the need to remesh the growing and (or) shrinking layers. The model can accommodate problems involving: (1) finite initial layer thicknesses, (2) rate-limiting interfacial reactions, (3) multiple and variable diffusion coefficients, and (4) finite material boundaries. Additionally, the effects of nucleation can be modeled empirically. Results from the one-dimensional code were verified by comparing the numerical results with analytical solutions for simple systems involving two, three, and five layers. The analytical solutions assumed zero initial thickness of the intermetallic layers, although the process being modeled begins with small but finite thickness of these layers. The initial thickness of the layers is represented in the computational solution.

The computer code was applied to the analysis of the intermetallic layer growth that occurred in solder aging experiments performed with $100 \mathrm{Sn}$ and $63 \mathrm{Sn}-37 \mathrm{~Pb}(\mathrm{wt} . \%)$ solders. The $\mathrm{Cu}-63 \mathrm{Sn}-$ $37 \mathrm{~Pb}$ couples were aged for 1 to 400 days at temperatures of $70,100,135$, and $170^{\circ} \mathrm{C}$. The $\mathrm{Cu}-$ $100 \mathrm{Sn}$ samples were aged similarly, except that heat treatments were also performed at $205^{\circ} \mathrm{C}$. Two intermetallic layers, $\mathrm{Cu}_{3} \mathrm{Sn}$ and $\mathrm{Cu}_{6} \mathrm{Sn}_{5}$, were observed for both alloys. Some differences between the thickness of the intermetallic layers that formed with $100 \mathrm{Sn}$ and $63 \mathrm{Sn}-37 \mathrm{~Pb}$ solders were also observed. At higher temperatures, the total thickness of the layers was similar, but the ratio of the thicknesses of the $\mathrm{Cu}_{3} \mathrm{Sn}$ to the $\mathrm{Cu}_{6} \mathrm{Sn}_{5}$ layer differed. The analyses indicated that intermetallic layer growth was consistent with a bulk diffusion mechanism involving $\mathrm{Cu}$ and (or) Sn and variable diffusion coefficients that probably should reflect some enhanced diffusion during early layer growth. Furthermore, the enhanced diffusion can be accounted for empirically using a variable diffusion coefficient that is a function of layer thickness. A satisfactory explanation for the difference between intermetallic layer growth that was observed with $100 \mathrm{Sn}$ and $63 \mathrm{Sn}-37 \mathrm{~Pb}$ 
solder was not established. With $63 \mathrm{Sn}-37 \mathrm{~Pb}$ samples, diffusion in the $\mathrm{Cu}_{6} \mathrm{Sn}_{5}$ layer appeared to be faster than with $100 \mathrm{Sn}$ samples. The higher diffusion rates may have been due to trace amounts of $\mathrm{Pb}$ perturbing the layer crystal structure, but the presence of $\mathrm{Pb}$ could not be confirmed by electron microprobe analysis or Auger depth profiling.

In the text below, the experimental procedures used in the solder aging experiments are described, and the data for intermetallic layer growth in the $\mathrm{Cu}-100 \mathrm{Sn}$ and $\mathrm{Cu}-63 \mathrm{Sn}-37 \mathrm{~Pb}$ systems are summarized. Then, the physiochemical mechanisms controlling intermetallic layer growth, the governing equations used in this work, and the model for intermetallic layer growth are described. Next, implementation of the model in a computer code, and verification of the numerical calculations are discussed. The model and code are then applied to the analysis of the solder aging experiments, and the results of that analysis are summarized. Finally, some opportunities for further model and code development are discussed, and some conclusions are offered. 


\subsection{EXPERIMENT}

The experimental work focused primarily on aging the solder joint to provide data for variations in intermetallic layer thickness as a function of time and temperature. Experiments with copper substrates and $63 \mathrm{Sn}-37 \mathrm{~Pb}$ solder were performed with aging times of 1 to 400 days and temperatures of $70,100,135$, and $170^{\circ} \mathrm{C}$. Experiments with copper substrates and $100 \mathrm{Sn}$ solder were also performed with aging times of 1 to 400 days and temperatures of $70,100,135,170$, and $205^{\circ} \mathrm{C}$. The procedures for these experiments and the results obtained are summarized below.

Additional work was done to develop techniques for depositing "marker layers" that could be used in Kirkendall-type experiments (Jost, 1960) to observe interface displacement, rather than intermetallic layer growth, which was measured in the solder-aging experiments. Development of the technique for depositing marker layers is summarized in Appendix A, and although a suitable technique was found, the effort required to develop the technique was substantial and precluded further pursuit of the Kirkendall-type experiments.

\subsection{Procedure}

The procedures for experiments with $100 \mathrm{Sn}$ and $63 \mathrm{Sn}-37 \mathrm{~Pb}$ solders were analogous except that with $100 \mathrm{Sn}$ solder, aging temperatures were extended to $205^{\circ} \mathrm{C}$. The procedure with $63 \mathrm{Sn}$ $37 \mathrm{~Pb}$ solder is described below.

The substrates used in the study were oxygen-free, high-conductivity (OFHC) copper tabs measuring $0.635 \times 0.635 \times 0.159 \mathrm{~cm}$. The composition of the copper was verified by atomic emission spectroscopy, induced couple plasma (AES-ICP) analysis to be less than: $40 \mathrm{ppm} \mathrm{Ag}, 50$ ppm Al, $10 \mathrm{ppm} \mathrm{Mg}, 30 \mathrm{ppm} \mathrm{Mn}$, and $10 \mathrm{ppm} \mathrm{Si} \mathrm{(with} \mathrm{a} \mathrm{relative} \mathrm{error} \mathrm{of} \pm 100 \%$ ). The tabs were punched from sheet stock and a small hole drilled into one of the corners. The surface from which the thickness values were measured was optically polished. Next, a steel wire was secured to the hole which allowed for handling of the specimen.

The intermetallic layer thickness data were obtained by hot dipping the copper specimen into a bath of $63 \mathrm{Sn}-37 \mathrm{~Pb}$ solder. The eutectic temperature of the solder is $183^{\circ} \mathrm{C}$; however, the working temperature was slightly higher, $215^{\circ} \mathrm{C}$. The tabs were solvent degreased, and then coated with a water soluble, organic acid flux. Next, each specimen was completely immersed into the solder bath for $5 \mathrm{~s}$ with the optically polished face down and parallel to the surface of the solder so that, upon removal, a large accumulation of solder formed on the surface. This procedure provided for an effectively infinite source of both the solder and the copper for intermetallic growth. Finally, the specimens were cleaned of flux residues.

Thermal aging of the solder-coated copper test samples was performed in air furnaces with temperature stabilities of $\pm 0.5^{\circ} \mathrm{C}$. The $\mathrm{Cu}-63 \mathrm{Sn}-37 \mathrm{~Pb}$ couples were annealed at $70,100,135$, and $170^{\circ} \mathrm{C}$ for time periods of between 1 and 400 days ( \pm 30 minutes). Upon completion of the annealing treatment, each specimen was cut in half; one half was mounted and polished for metallographic examination and analysis. The other half of the sample was retained for archival purposes. 


\subsection{Results}

The composition of the intermetallic layers, as a function of position, was determined by electron microprobe analysis (EMPA). At higher temperatures, two $\mathrm{Cu}-\mathrm{Sn}$ intermetallic layers, $\mathrm{Cu}_{3} \mathrm{Sn}$ and $\mathrm{Cu}_{6} \mathrm{Sn}_{5}$, formed in both $\mathrm{Cu}-100 \mathrm{Sn}$ and $\mathrm{Cu}-63 \mathrm{Sn}-37 \mathrm{~Pb}$ samples. A micrograph illustrating the two $\mathrm{Cu}-\mathrm{Sn}$ intermetallic layers that formed in a $\mathrm{Cu}-100 \mathrm{Sn}$ sample aged for 40 days at $205^{\circ} \mathrm{C}$ is shown in Fig. 2. The corresponding electron microprobe results are shown in Fig. 3. The $\mathrm{Cu}_{3} \mathrm{Sn}$ layer forms adjacent to the $\mathrm{Cu}$ (bottom layer), and the $\mathrm{Cu}_{6} \mathrm{Sn}_{5}$ adjacent to the Sn (top layer). Similarly, a micrograph illustrating the two Cu-Sn intermetallic layers that formed in a $\mathrm{Cu}-63 \mathrm{Sn}-37 \mathrm{~Pb}$ sample aged for 400 days at $170^{\circ} \mathrm{C}$ is shown in Fig. 4. In addition to the two $\mathrm{Cu}-\mathrm{Sn}$ layers, a Pbrich $\mathrm{Sn}$ layer also formed as illustrated in the corresponding electron microprobe data shown in Fig. 5. Again, the $\mathrm{Cu}_{3} \mathrm{Sn}$ layer formed adjacent to the $\mathrm{Cu}$ (bottom layer). $\mathrm{The} \mathrm{Cu}_{6} \mathrm{Sn}_{5}$ formed between the $\mathrm{Cu}_{3} \mathrm{Sn}$ and the $\mathrm{Pb}-\mathrm{Sn}$ layer that formed adjacent to the bulk solder containing a $\mathrm{Pb}$ rich dispersed intermetallic precipitate. At lower temperatures, only one $\mathrm{Cu}-\mathrm{Sn}$ intermetallic layer, $\mathrm{Cu}_{6} \mathrm{Sn}_{5}$, formed in both $\mathrm{Cu}-100 \mathrm{Sn}$ and $\mathrm{Cu}-63 \mathrm{Sn}-37 \mathrm{~Pb}$ samples.

The microprobe traces were made perpendicular to the layer (using 0.5 micron steps for the case of one layer composition). However, the spatial resolution of the concentration profile was a circle of 3-micron diameter about the target point caused by the interaction volume of the electron beam and the subsequent $\mathrm{x}$-ray emissions. The elemental concentrations were listed as a function of distance along the trace. Through the change in the elemental concentrations, the boundaries of the individual intermetallic layers were designated; the sample point midway between the boundary values was used to designate the layer composition for that particular trace. Ten such traces were made per test sample in order to establish the composition of the layers(s). The traces were extended into the solder field, which together with point analysis, were used to determine the extent of $\mathrm{Cu}$ dissolved into the $\mathrm{Pb}$ - and $\mathrm{Pb}$-rich phases as well as any response by the composition of those phases to the aging conditions. 


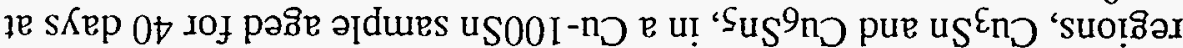

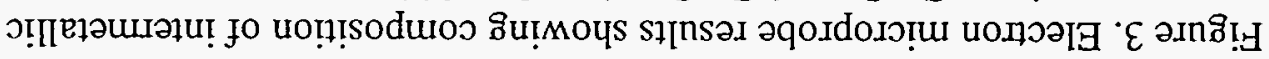
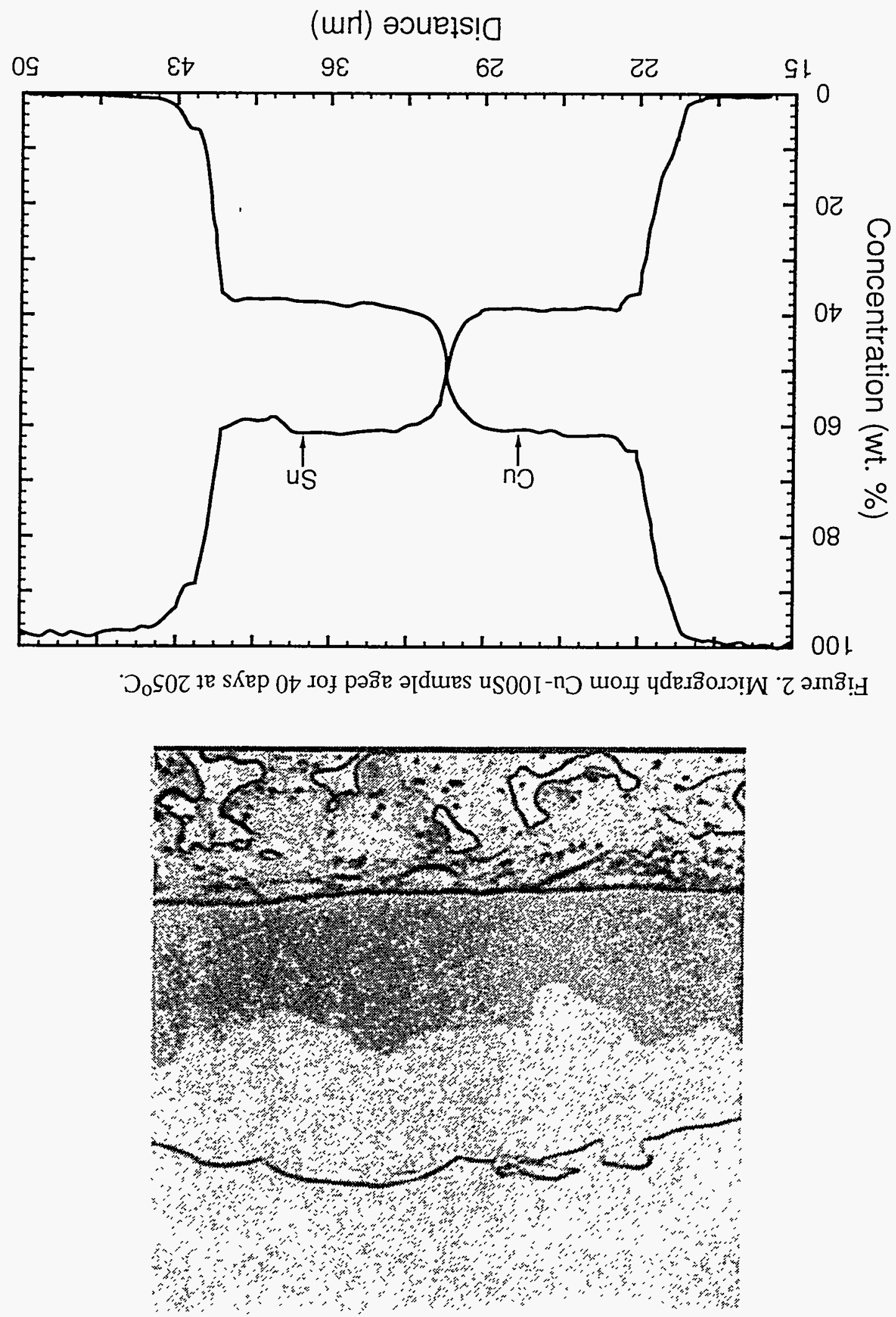


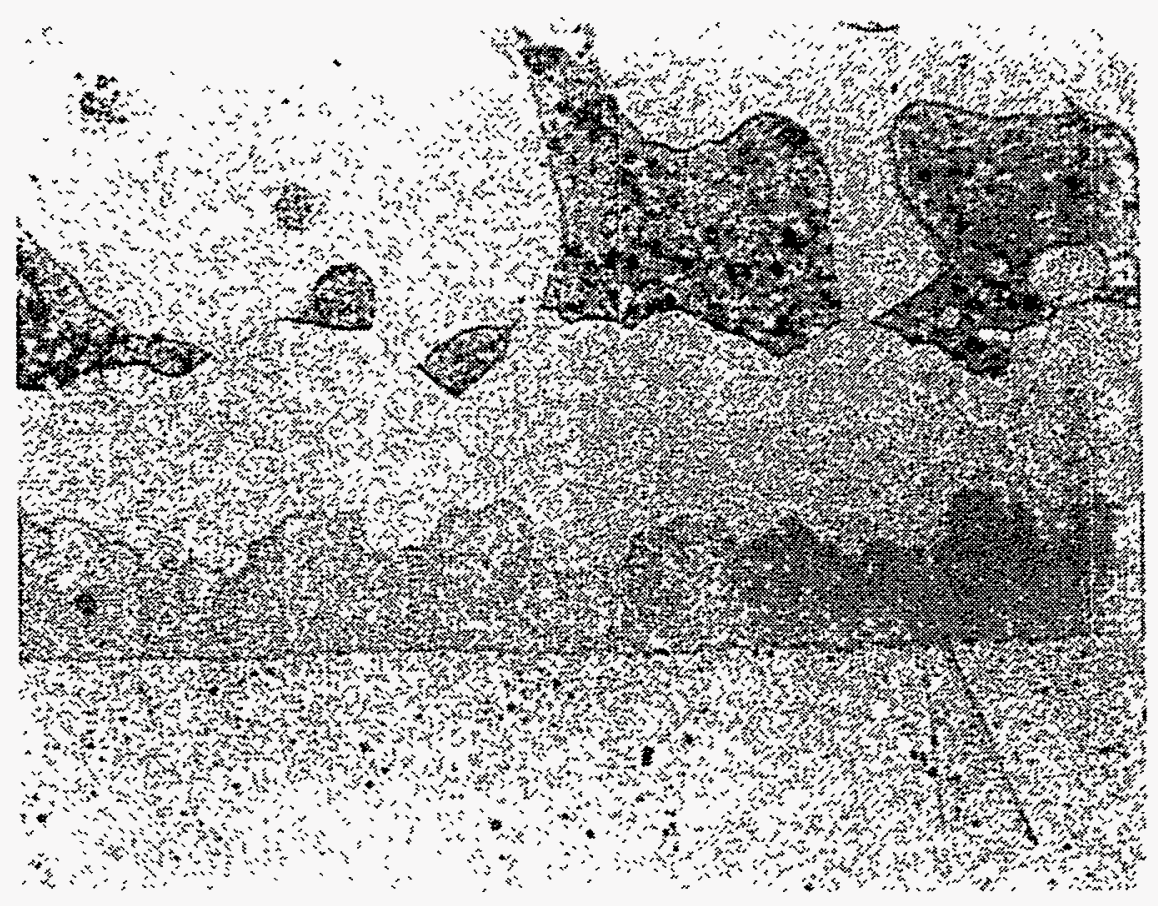

Figure 4. Micrograph from Cu-63Sn-37Pb sample aged for 400 days at $170^{\circ} \mathrm{C}$.

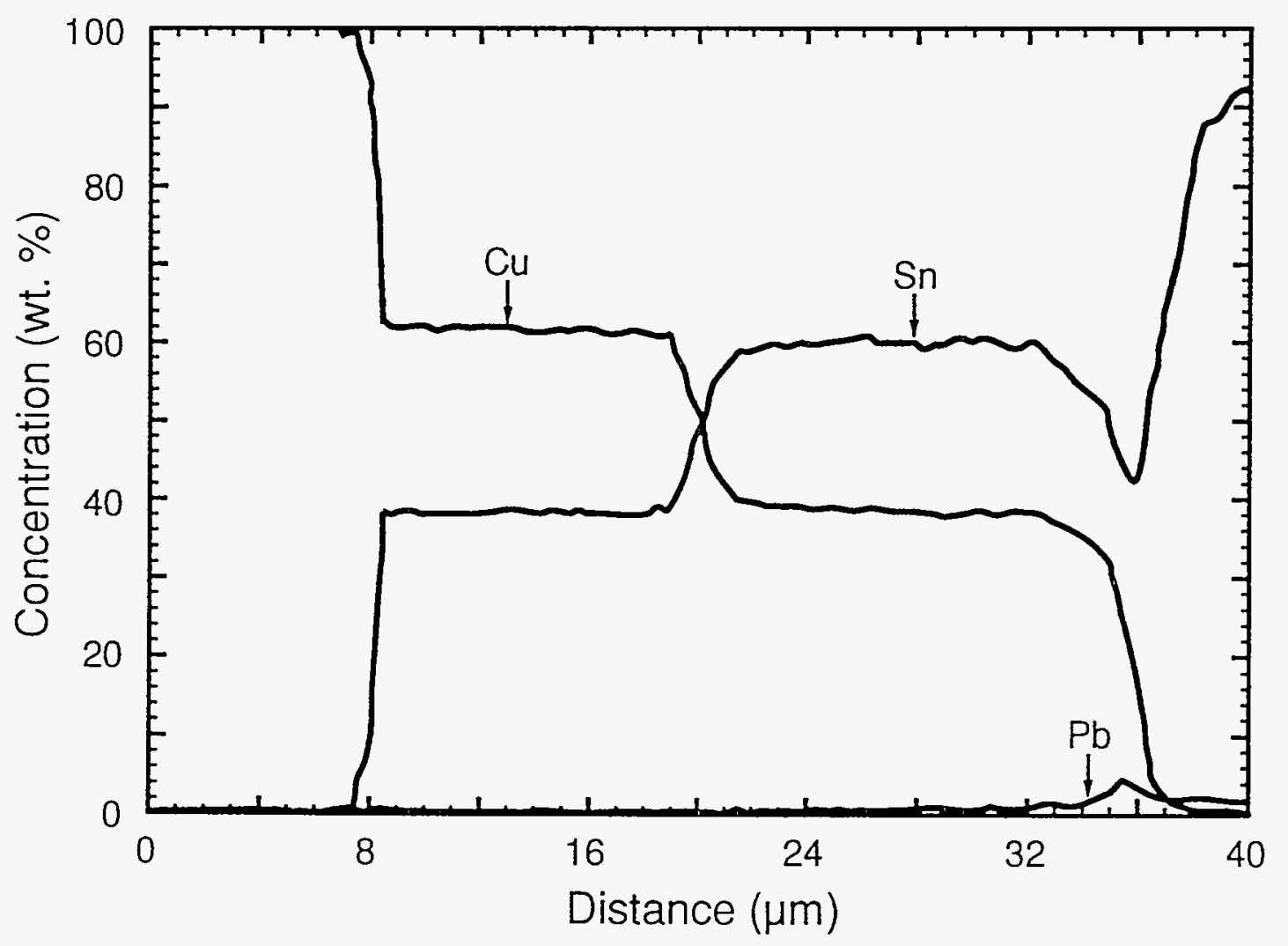

Figure 5. Electron microprobe results showing composition of intermetallic layers, $\mathrm{Cu}_{3} \mathrm{Sn}, \mathrm{Cu}_{6} \mathrm{Sn}_{5}$, and $\mathrm{Pb}$-rich $\mathrm{Pb}-\mathrm{Sn}$, in a $\mathrm{Cu}-63 \mathrm{Sn}-37 \mathrm{~Pb}$ sample aged for 400 days at $170^{\circ} \mathrm{C}$. 
Assessment of the intermetallic layer growth was determined by quantitative image analysis. A study was performed to determine an optimum number of thickness measurements that would satisfy data accuracy, while also limiting the effort required on the part of the analyst. It was determined that a minimum of 40 data points would be adequate for the study. Therefore, a procedure was developed whereby four regions along the solder-copper interface were imaged at a magnification of $1000 \mathrm{X}$. Ten measurements were made per image. In those cases for which two compositions comprised the total intermetallic layer, the thickness measurements were performed on the inner layer $\left(\mathrm{Cu}_{3} \mathrm{Sn}\right)$ as well as on the total layer. The thickness of the outer layer $\left(\mathrm{Cu}_{6} \mathrm{Sn}_{5}\right)$ was determined by subtraction of the inner layer thickness from the total value. The absolute error of the thickness measurement technique was 0.5 microns. The thickness data for each annealing time and temperature condition was represented by the mean of the data and one standard deviation of the mean.

The mean thicknesses of the $\mathrm{Cu}_{3} \mathrm{Sn}$ and $\mathrm{Cu}_{6} \mathrm{Sn}_{5}$ layers determined by image analysis of the $\mathrm{Cu}-100 \mathrm{Sn}$ samples are summarized in Table 1 as a function of aging temperature and time. The numbers in parentheses represent one standard deviation. The thicknesses of the $\mathrm{Cu}-63 \mathrm{Sn}-37 \mathrm{~Pb}$ samples are summarized in Table 2. At a given temperature and time, the total thickness of the intermetallic layers in the $\mathrm{Cu}-100 \mathrm{Sn}$ and $\mathrm{Cu}-63 \mathrm{Sn}-37 \mathrm{~Pb}$ samples are similar. However, the ratio of the thicknesses of the $\mathrm{Cu}_{3} \mathrm{Sn}$ layer to the thickness of the $\mathrm{Cu}_{6} \mathrm{Sn}_{5}$ layer in the $\mathrm{Cu}-100 \mathrm{Sn}$ samples are generally larger than the ratio for the $\mathrm{Cu}-63 \mathrm{Sn}-37 \mathrm{~Pb}$ samples.

Table 1: Intermetallic Layer Thicknesses for $\mathrm{Cu}-100 \mathrm{Sn}$

\begin{tabular}{|c|c|c|c|c|}
\hline \multirow{2}{*}{ Temp. (C) } & Time (days) & $\begin{array}{c}\mathrm{Cu}_{3} \mathrm{Sn} \\
\text { Layer } \\
(\mu \mathrm{m})\end{array}$ & $\begin{array}{c}\mathrm{Cu}_{6} \mathrm{Sn}_{5} \\
\text { Layer } \\
(\mu \mathrm{m})\end{array}$ & $\begin{array}{c}\text { Total } \\
(\mu \mathrm{m})\end{array}$ \\
\hline \hline ambient & 0 & 0 & $0.79(0.28)$ & $0.79(0.28)$ \\
\hline \multirow{2}{*}{70} & 2 & 0 & $0.84(0.51)$ & $0.84(0.51)$ \\
\cline { 2 - 5 } & 10 & 0 & $1.42(0.75)$ & $1.42(0.75)$ \\
\cline { 2 - 5 } & 25 & 0 & $0.87(0.28)$ & $0.87(0.28)$ \\
\cline { 2 - 5 } & 100 & 0 & $0.90(0.32)$ & $0.90(0.32)$ \\
\cline { 2 - 5 } & 200 & 0 & $0.83(0.38)$ & $0.83(0.38)$ \\
\cline { 2 - 5 } & 350 & 0 & $1.02(0.27)$ & $1.02(0.27)$ \\
\hline \multirow{2}{*}{100} & 2 & 0 & $0.82(0.35)$ & $0.82(0.35)$ \\
\cline { 2 - 5 } & 10 & 0 & $0.94(0.43)$ & $0.94(0.43)$ \\
\cline { 2 - 5 } & 25 & 0 & $1.51(0.52)$ & $1.51(0.52)$ \\
\hline
\end{tabular}


Table 1: Intermetallic Layer Thicknesses for Cu-100Sn

\begin{tabular}{|c|c|c|c|c|}
\hline Temp. (C) & Time (days) & $\begin{array}{c}\mathrm{Cu}_{3} \mathrm{Sn} \\
\text { Layer } \\
(\mu \mathrm{m})\end{array}$ & $\begin{array}{c}\mathrm{Cu}_{6} \mathrm{Sn}_{5} \\
\text { Layer } \\
(\mu \mathrm{m})\end{array}$ & $\begin{array}{l}\text { Total } \\
(\mu \mathrm{m})\end{array}$ \\
\hline \multirow[t]{3}{*}{100} & 100 & 0 & $1.98(0.54)$ & $1.98(0.54)$ \\
\hline & 200 & $1.11(0.46)$ & $0.91(0.71)$ & $2.02(0.73)$ \\
\hline & 350 & $2.21(0.70)$ & 2.16 & 4.36 \\
\hline \multirow[t]{6}{*}{135} & 2 & 0 & $1.38(0.31)$ & $1.38(0.31)$ \\
\hline & 10 & $1.4(0.4)$ & $0.86(0.37)$ & $2.3(0.6)$ \\
\hline & 25 & $1.8(0.6)$ & $1.1(0.8)$ & $2.9(1.0)$ \\
\hline & 100 & $3.1(0.9)$ & 5.9 & 9.0 \\
\hline & 200 & $4.1(1.0)$ & $8.6(7.7)$ & $12.7(7.5)$ \\
\hline & 350 & $5.7(1.2)$ & $10.2(6.4)$ & $16.0(7.0)$ \\
\hline \multirow[t]{8}{*}{170} & 1 & $1.6(0.4)$ & $0.9(0.4)$ & $2.5(0.5)$ \\
\hline & 4 & $2.5(0.6)$ & $1.6(0.6)$ & $4.1(0.6)$ \\
\hline & 10 & $3.6(0.8)$ & $2.9(0.9)$ & $6.5(1.1)$ \\
\hline & 40 & $3.5(1.1)$ & $5.3(2.7)$ & $10.8(2.6)$ \\
\hline & 100 & $7.7(1.4)$ & $7.3(2.6)$ & $15.0(2.3)$ \\
\hline & 150 & $9.7(1.8)$ & $7.5(2.3)$ & $17.4(2.1)$ \\
\hline & 200 & $11.1(1.5)$ & $8.8(2.1)$ & $19.9(2.1)$ \\
\hline & 400 & $14.6(2.8)$ & $12.7(6.2)$ & $27.3(5.8)$ \\
\hline \multirow[t]{5}{*}{205} & 1 & $2.7(0.5)$ & $2.3(0.8)$ & $4.9(0.5)$ \\
\hline & 4 & $4.5(0.5)$ & $3.9(1.1)$ & $8.4(0.8)$ \\
\hline & 10 & $7.0(1.2)$ & $5.2(1.7)$ & $12.2(1.2)$ \\
\hline & 40 & $11.6(1.2)$ & $10.1(2.0)$ & $21.7(1.4)$ \\
\hline & 200 & $26.2(2.4)$ & $16.3(2.9)$ & $42.4(1.4)$ \\
\hline
\end{tabular}


Table 2: Intermetallic Layer Thicknesses for $\mathrm{Cu}-63 \mathrm{Sn}-37 \mathrm{~Pb}$

\begin{tabular}{|c|c|c|c|c|}
\hline Temp. (C) & Time (days) & $\begin{array}{c}\mathrm{Cu}_{3} \mathrm{Sn} \\
\text { Layer } \\
(\mu \mathrm{m})\end{array}$ & $\begin{array}{c}\mathrm{Cu}_{6} \mathrm{Sn}_{5} \\
\text { Layer } \\
(\mu \mathrm{m})\end{array}$ & $\begin{array}{l}\text { Total } \\
(\mu \mathrm{m})\end{array}$ \\
\hline ambient & 0 & 0 & & \\
\hline \multirow[t]{11}{*}{70} & 2 & 0 & $1.3(0.3)$ & $1.3(0.3)$ \\
\hline & 6 & 0 & $1.3(0.3)$ & $1.3(0.3)$ \\
\hline & 10 & 0 & $1.4(0.3)$ & $1.4(0.3)$ \\
\hline & 25 & 0 & $1.4(0.3)$ & $1.4(0.3)$ \\
\hline & 51 & 0 & $1.7(0.5)$ & $1.7(0.5)$ \\
\hline & 90 & 0 & $1.7(0.4)$ & $1.7(0.4)$ \\
\hline & 150 & 0 & $1.9(0.4)$ & $1.9(0.4)$ \\
\hline & 200 & 0 & $1.7(0.4)$ & $1.7(0.4)$ \\
\hline & 300 & 0 & $2.1(0.5)$ & $2.1(0.5)$ \\
\hline & 351 & 0 & $1.9(0.5)$ & $1.9(0.5)$ \\
\hline & 400 & 0 & $2.0(0.5)$ & $2.0(0.5)$ \\
\hline \multirow[t]{11}{*}{100} & 2 & 0 & $1.5(0.4)$ & $1.5(0.4)$ \\
\hline & 6 & 0 & $1.5(0.2)$ & $1.5(0.2)$ \\
\hline & 10 & 0 & $1.7(0.3)$ & $1.7(0.3)$ \\
\hline & 25 & 0 & $2.0(0.3)$ & $2.0(0.3)$ \\
\hline & 51 & 0 & $2.3(0.4)$ & $2.3(0.4)$ \\
\hline & 90 & 0 & $3.0(0.5)$ & $3.0(0.5)$ \\
\hline & 150 & 0 & $3.7(0.5)$ & $3.7(0.5)$ \\
\hline & 200 & 0 & $4.0(0.9)$ & $4.0(0.9)$ \\
\hline & 300 & 0 & $4.4(0.9)$ & $4.4(0.9)$ \\
\hline & 351 & 0 & $4.2(0.5)$ & $4.2(0.5)$ \\
\hline & 400 & 0 & $4.8(0.9)$ & $4.8(0.9)$ \\
\hline
\end{tabular}


Table 2: Intermetallic Layer Thicknesses for $\mathrm{Cu}-63 \mathrm{Sn}-37 \mathrm{~Pb}$

\begin{tabular}{|c|c|c|c|c|}
\hline Temp. (C) & Time (days) & $\begin{array}{c}\mathrm{Cu}_{3} \mathrm{Sn} \\
\text { Layer } \\
(\mu \mathrm{m})\end{array}$ & $\begin{array}{c}\mathrm{Cu}_{6} \mathrm{Sn}_{5} \\
\text { Layer } \\
(\mu \mathrm{m})\end{array}$ & $\begin{array}{l}\text { Total } \\
(\mu \mathrm{m})\end{array}$ \\
\hline \multirow[t]{10}{*}{135} & 2.96 & 0 & $2.2(0.6)$ & $2.2(0.6)$ \\
\hline & 5.2 & 0 & $2.4(0.3)$ & $2.4(0.3)$ \\
\hline & 10.3 & 0 & $2.9(0.5)$ & $2.9(0.5)$ \\
\hline & 25 & 0 & $3.7(0.5)$ & $3.7(0.5)$ \\
\hline & 50.4 & 0 & $5.0(0.8)$ & $5.0(0.8)$ \\
\hline & 135 & $1.1(0.4)$ & $6.5(0.8)$ & $7.6(1.2)$ \\
\hline & 150 & $1.4(0.4)$ & $7.7(0.9)$ & $9.1(1.3)$ \\
\hline & 205 & $3.1(0.7)$ & $7.3(1.0)$ & $10.4(1.7)$ \\
\hline & 300.3 & $2.9(0.5)$ & $8.8(1.3)$ & $11.7(1.3)$ \\
\hline & 400 & $4.8(0.7)$ & $9.0(2.0)$ & $13.3(1.6)$ \\
\hline \multirow[t]{12}{*}{170} & 1 & 0 & $2.8(0.3)$ & $2.8(0.3)$ \\
\hline & 4.08 & 0 & $3.5(0.5)$ & $3.5(0.5)$ \\
\hline & 10 & $1.4(0.4)$ & $4.3(1.1)$ & $5.7(1.5)$ \\
\hline & 10 & $1.7(0.3)$ & $4.0(1.0)$ & $5.7(0.8)$ \\
\hline & 40 & $3.5(0.7)$ & $6.9(2.1)$ & $10.4(2.8)$ \\
\hline & 60 & $4.2(0.9)$ & $7.7(2.5)$ & $11.9(3.4)$ \\
\hline & 98 & $5.3(1.0)$ & $8.5(3.0)$ & $18.8(4.0)$ \\
\hline & 149 & $6.5(1.5)$ & $11.7(2.6)$ & $18.2(4.1)$ \\
\hline & 200 & $8.1(1.7)$ & $12.9(2.8)$ & $21.0(4.5)$ \\
\hline & 262 & $8.6(1.6)$ & $15.1(2.7)$ & $23.7(4.3)$ \\
\hline & 311 & $9.7(1.4)$ & $17.2(4.7)$ & $26.9(6.1)$ \\
\hline & 402.7 & $11.1(1.8)$ & $16.2(4.5)$ & $27.3(3.6)$ \\
\hline
\end{tabular}




\subsection{THEORY}

The growth of intermetallic layers occurs by displacement of the interfaces between layers that results from diffusion and interfacial reaction of the constituents of the layers. Analytical solutions to the diffusion and interface displacement equations are available for analyzing simple systems in which: (1) diffusion of the constituents can be represented by Fick's law with a constant diffusion coefficient; (2) interfacial reactions are sufficiently fast so that local chemical equilibrium essentially exists at both sides of each interface, and constituent concentrations at both sides can be considered constant, although generally they are not equal; (3) all layers grow simultaneously and have negligible initial thicknesses; (4) constituent diffusion and interface displacement are not hindered by finite material boundaries; and (5) diffusion and layer growth can be considered one-dimensional. The objective of the present modeling and code development effort was to provide numerical tools necessary for the analysis of more complex systems and for predicting intermetallic growth during service in which: (1) diffusion of constituents occurs by multiple mechanisms having variable diffusion coefficients; (2) interfacial chemical reactions are slow enough to be rate-limiting; (3) all layers do not grow simultaneously, due to different nucleation rates; (4) initial film thicknesses are not negligible; (5) constituent diffusion and interface displacement are hindered by finite material boundaries; (6) the temperature and, therefore, the diffusion coefficients vary substantially during layer growth; and (7) constituent diffusion and layer growth occur in more than one dimension.

A summary of the modeling and corresponding code development work is given below. The equations governing the basic phenomena controlling intermetallic growth are described first. Analytical and numerical solutions of the equations are then discussed, and the use of the numerical model is illustrated by application to experimental data for the $\mathrm{Cu}-100 \mathrm{Sn}$ and the $\mathrm{Cu}-63 \mathrm{Sn}$ $37 \mathrm{~Pb}$ systems. This work primarily addresses the long-term growth of intermetallic layers that were previously formed by short-term contact between a metal substrate and molten solder.

This work is based on a one-dimensional, multi-layer system involving a binary set of interacting constituents, such as $\mathrm{Cu}$ and $\mathrm{Sn}$, and in each layer, the diffusion of either constituent can be rate-controlling. The model consists of a basic set of material balance equations for each layer and displacement equations for the interfaces on each side of the layer. The material balance equations describe bulk diffusion of the rate-controlling constituent in each layer. In addition to bulk diffusion, the material balance equations can accommodate terms for additional diffusion mechanisms, such as grain boundary diffusion, and terms for rate-limiting interfacial reactions. Material balance equations can also be included to describe diffusion of trace constituents as appropriate.

A substrate-solder system in which $I-1$ intermetallic layers form and grow between the substrate and bulk solder is shown schematically in Fig. 6. Let the substrate form the left boundary of the system, and solder the right boundary. Let $i=1,2,3, \ldots, I-1$ denote the sequence of intermetallic layers growing from left to right. That is, $i=1$ denotes the layer adjacent to the right edge of the substrate $(i=0)$, and $i=I-1$ denotes the layer adjacent to the left edge of the solder $(i=I)$. 


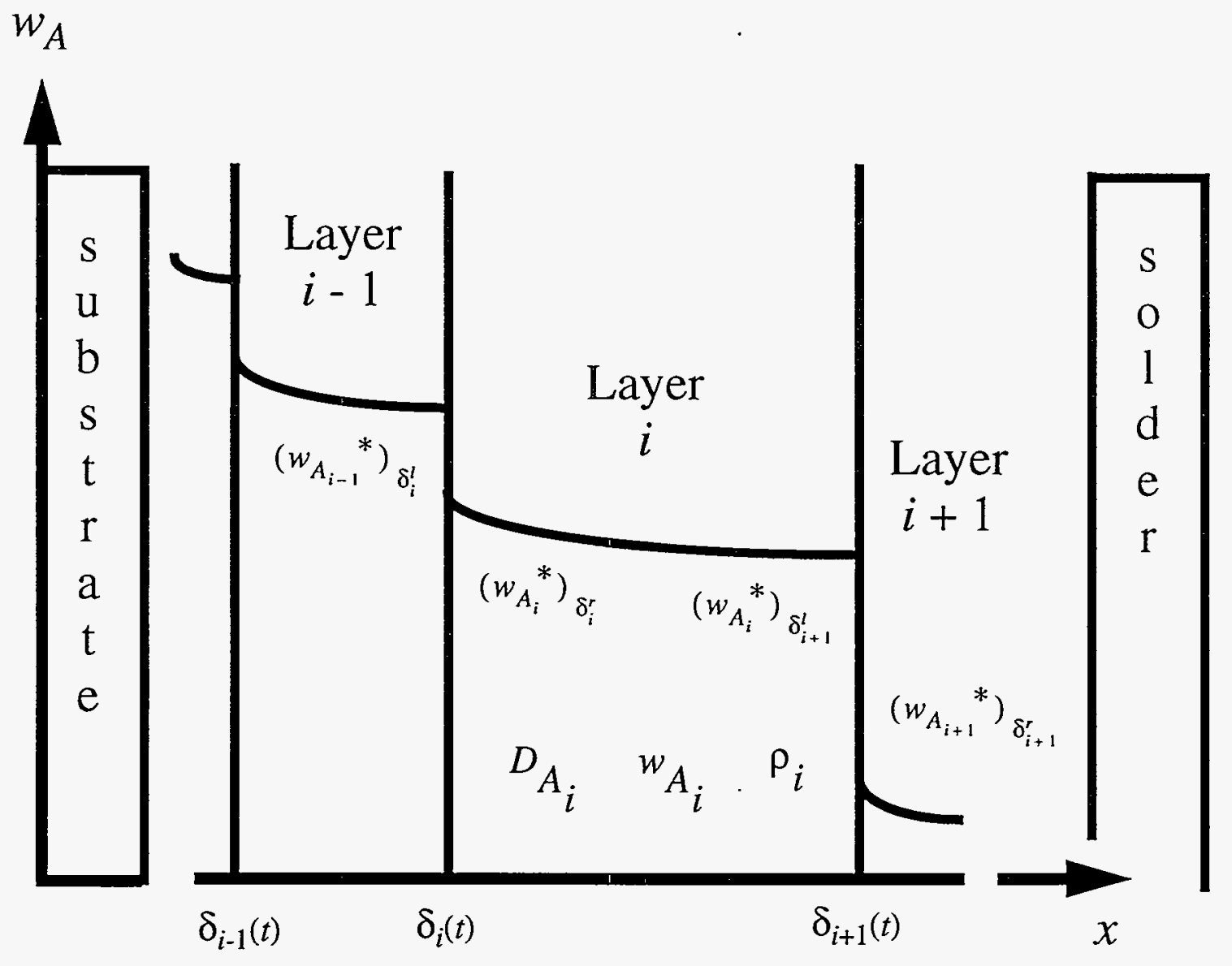

Figure 6. Schematic diagram of intermetallic layer growth between substrate and solder.

Furthermore, let $T$ denote the temperature, $t$ denote time, $x$ denote position with respect to an origin fixed in space, $\delta_{i}(t)$ the position of the interface between layer $i-1$ and layer $i$, and $\Delta_{i}(t)$ the thickness of layer $i$

$$
\Delta_{i}(t)=\delta_{i+1}(t)-\delta_{i}(t)
$$

Then, for $\delta_{i}(t)<x<\delta_{i+1}(t)$, the material balance for the rate controlling constituent in each layer is given by 


$$
\bar{\partial}_{A_{i}}=\frac{\partial}{\partial x}\left(D_{A_{i}} \frac{\partial w_{A_{i}}}{}\right)
$$

where $w_{A_{j}}$ denotes the mass fraction of the rate-controlling constituent in layer $\mathrm{i}$, and $D_{A_{i}}$ denotes the diffusion coefficient, which can be a function of $x, t, w_{A_{i}}$, and $T$, and can be specified accordingly. In general, the temperature $T$ can be a function of $x$ and $t$, which also can be specified.

When constituent diffusion and interface displacement are not affected by finite material boundaries, and the rate of interfacial chemical reaction, $R_{i}$, is sufficiently fast, local chemical equilibrium exists at the interface, and the concentrations of the diffusing constituents in layer $i$ are essentially constant at $\delta_{i}(t)$. Therefore, at $\delta_{i}(t)$, the boundary condition for Eq. 2 is

$$
\left(w_{A_{i}}\right)_{\delta_{i}^{r}}=\text { constant }=\left(w_{A_{i}}^{*}\right)_{\delta_{i}^{r}}
$$

and if local equilibrium exists at $\delta_{i+1}(t)$, the boundary condition is

$$
\left(w_{A_{i}}\right)_{\delta_{i+1}^{l}}=\text { constant }=\left(w_{A_{i}}^{*}\right)_{\delta_{i+1}^{l}}
$$

where $\left(w_{A_{i}}^{*}\right)_{\delta_{i}^{r}} \neq\left(w_{A_{i}}^{*}\right)_{\delta_{i+1}^{l}}$, and superscripts $l$ and $r$ denote values at the left and right sides of the interface, respectively. The initial condition for Eq. 2 is

$$
w_{A_{i}}(x, 0)=f_{i}(x)
$$

where $f_{i}(x)$ is known or assumed.

When the rate of interfacial reaction, $R_{i}$, is slow enough to preclude local equilibrium at the interface, the constant concentration boundary conditions given by Eqs. 3 and 4 must be replaced by flux-type boundary conditions given by

$$
\begin{aligned}
& -\rho_{i} D_{A_{i}}\left(\frac{\partial w_{A_{i}}}{\partial x}\right)_{\delta_{i}^{r}}=R_{i}^{r} \\
& -\rho_{i} D_{A_{i}}\left(\frac{\partial w_{A_{i}}}{\partial x}\right)_{\delta_{i+1}^{l}}=R_{i+1}^{l}
\end{aligned}
$$

where $\rho_{i}$ denotes the mass density of layer $i$. Furthermore, when constituent diffusion encounters a finite material boundary, the boundary condition for Eq. 2 becomes the zero flux condition at that boundary. 
The displacement of each interface is given by

$$
\left[\rho_{i-1}\left(w_{A_{i-1}}\right)_{\delta_{i}^{l}}-\rho_{i}\left(w_{A_{i}}\right)_{\delta_{i}^{r}}\right] \frac{d \delta_{i}}{d t}=-\rho_{i-1} D_{A_{i-1}}\left(\frac{\partial w_{A_{i-1}}}{\partial x}\right)_{\delta_{i}^{l}}+\rho_{i} D_{A_{i}}\left(\frac{\partial w_{A_{i}}}{\partial x}\right)_{\delta_{i}^{r}}
$$

The initial condition for Eq. 8 is

$$
\delta_{i}(t=0)=\delta_{i}^{0}=\text { constant }
$$

In the numerical analyses discussed below, the interfacial reaction rates were expressed by generic linear-driving-force expressions of the form

$$
R_{i}^{r}=k_{i}^{r} \rho_{i}\left[\left(w_{A_{i}}^{*}\right)_{\delta_{i}^{r}}-\left(w_{A_{i}}\right)_{\delta_{i}^{r}}\right]
$$

and

$$
R_{i+1}^{l}=k_{i}^{l} \rho_{i}\left[\left(w_{A_{i}}^{*}\right)_{\delta_{i+1}^{\prime}}-\left(\dot{w}_{A_{i}}\right)_{\delta_{i+1}^{l}}\right]
$$

where $k_{i}^{r}$ and $k_{i}^{l}$ are usually empirical rate constants. Equations 10 and 11 are useful for examining order of magnitude effects.

Depending on the magnitude of the right side of Eq. 8, the left side can cause numerical problems when the term in brackets approaches zero, since $d \delta / d t$ can become large and physically unreasonable. These problems can be circumvented with an alternate form of Eq. 8 derived using the interface $\delta_{i}(t)$ as the frame of reference for diffusion in the region $\delta_{i}(t)<x<\delta_{i+1}(t)$. This alternate approach is summarized in Appendix B, where equations analogous to Eqs. 1-9 are given. The disadvantages in using $\delta_{i}(t)$ as the frame of reference are that the physical interpretation of the diffusion coefficient is difficult, and the approach would be very difficult to extend to two dimensions. 


\subsection{NUMERICAL APPROACH}

\subsection{Equation Transformation}

Section 1.0 discusses different approaches to solving Stefan problems, particularly in the heat transfer arena. One advantage of the enthalpy method is that the need to explicitly track interface boundaries is circumvented. Unfortunately, there is no enthalpy analogy in problems of mass transfer. A difficulty with moving boundary solutions is remeshing the growing or shrinking layers. Remeshing increases computational time and can introduce error as the solution from one mesh is interpolated onto an updated mesh. In the method described in this report, a transformation of the spatial coordinate, $x$, given by

$$
\bar{x}_{i}=\frac{x-\delta_{i}(t)}{\Delta_{i}(t)}
$$

is used to circumvent the need to remesh the growing or shrinking layers. Then, for $\delta_{i}<x<\delta_{i+1}$, or $0<\bar{x}_{i}<1$,

$$
\bar{\partial}_{A_{i}}=\frac{1}{\Delta_{i}^{2}} \frac{\partial}{\partial \bar{x}_{i}}\left(D_{A_{i}} \frac{\partial w_{A_{i}}}{\partial \bar{x}_{i}}\right)+F\left(\bar{x}_{i}, \delta_{i}, \Delta_{i}\right) \frac{\partial w_{A_{i}}}{\partial \bar{x}_{i}}
$$

where

$$
F\left(\bar{x}_{i}, \delta_{i}, \Delta_{i}\right)=\left(\frac{1}{\Delta_{i}} \bar{d}_{i}+\frac{\bar{x}_{i}}{\Delta_{i}} \frac{d \Delta_{i}}{d t}\right)
$$

At $x=\delta_{i}^{r}(t)$, or $\bar{x}_{i}=0$,

$$
\left[\rho_{i-1}\left(w_{A_{i-1}}\right)_{\bar{x}_{i-1}=1}-\rho_{i}\left(w_{A_{i}}\right)_{\bar{x}_{i}=0}\right] \frac{d \delta_{i}}{d t}=-\frac{\rho_{i-1} D_{A_{i-1}}}{\Delta_{i-1}}\left(\frac{\partial w_{A_{i-1}}}{\partial \bar{x}_{i-1}}\right)_{x_{i-1}=1}+\frac{\rho_{i} D_{A_{i}}}{\Delta_{i}}\left(\frac{\partial w_{A_{i}}}{\partial \bar{x}_{i}}\right)_{\bar{x}_{i}=0}
$$

and at $x=\delta_{i+1}^{l}(t)$, or $\bar{x}_{i}=1$,

$$
\left[\rho_{i}\left(w_{A_{i}}\right)_{\bar{x}_{i}=1}-\rho_{i+1}\left(w_{A_{i+1}}\right)_{\left.\bar{x}_{i+1}=0\right] \overline{d t}}=-\frac{\rho_{i} D_{A_{i}}}{\Delta_{i}}\left(\frac{\partial w_{A_{i}}}{\partial \bar{x}_{i}}\right)_{\bar{x}_{1}=1}+\frac{\rho_{i+1} D_{A_{i+1}}}{\Delta_{i+1}}\left(\frac{\partial w_{A_{i+1}}}{\partial \bar{x}_{i+1}}\right)_{\bar{x}_{i+1}=0}\right. \text { (16) }
$$

During intermetallic growth, the initial rates of diffusion often appear to be higher than the rates at later times. To empirically account for those effects, the following variable diffusion coefficient $\overline{D_{A_{i}}}$ was used

$$
\overline{D_{A_{i}}}=D_{A_{i}}\left(1+\frac{D_{A_{i}^{\prime}}}{D_{A_{i}}} \exp \left(-\lambda_{i} \Delta_{i}\right)\right)
$$


where $D_{A_{i}}$ is an early-time diffusion coefficient that decays with the layer thickness $\Delta_{i}(t)$, and $\lambda_{i}$ is the decay constant.

\subsection{Implementation}

The computer code ILaG (Intermetallic Layer Growth) solves the equations of Section 4.1 that describe intermetallic layer growth and mass fraction distribution in a multicomponent system. The numerical approach adopted to solve these equations, known as the method of lines (MOL) (Hyman, 1979), uncouples the spatial and temporal discretization of the partial differential equations. In this application, the spatial discretization is represented using a finite difference approximation, which results in a set of coupled, first-order, ordinary differential equations (ODE) in time. These are solved in turn by an efficient library ODE solver that determines internally the time step required to maintain stability. The implicit solution procedure of the ODE solver, DEBDF, uses a variable order (one through five) backward difference formulation (Shampine and Watts, 1980; Hindmarsh, 1981). This method has been successfully used in a number of applications (e.g. Baer, et al., 1986; Gross, et al., 1993). Baer's implementation for solving the reactive diffusion equations associated with thermal ignition of energetic materials was used as the basis for the current application. This implementation includes an adaptive meshing scheme (Baer, et al. , 1986) that automatically resolves steep mass fraction gradients and will return to a coarser grid as the gradient relaxes. ILaG reads an ASCII input file that defines the case-specific mesh, material, and solution parameters. The code produces an output file that repeats the problem setup and reports the resulting mass fraction distribution and interface locations at the user-defined times. Two other ASCI output files are produced for use in plotting mass fraction profiles and layer thickness. A flow chart of the major functions within $\mathrm{LaG}$ is given in Appendix $\mathrm{C}$. The format of the required ASCII input file is described in Appendix D. A general discussion of the code's functions and the adaptation of the equations to the solution procedure follows.

After the user input file has been read (USERIN) and the solution parameters initialized, the initial mesh is generated (GRIDIN) for use with adaptive meshing. Mesh adjustments include positioning a node close to the zone boundaries and ensuring a smooth transition in the mesh from zone to zone. The distance between two nodes cannot vary by more than a factor of two than the distance to their neighboring nodes, a further restriction for mesh smoothness. The adaptive meshing routine, RFE1P1D, examines the initial conditions and default mesh adding nodes where needed based on the tolerances and maximum levels of refinement defined in line 4 of the user input file (see Appendix D). The meshing algorithm first performs a posteriori error analysis to produce a cumulative relative solution error. If this error is greater than RTOLREF, refinement is sought; if the error is less than RTOLREC, combining two adjacent cells is considered. Default values for RTOLREF and RTOLREC are $1.0 \times 10^{-4}$ and $0.5^{*}$ RTOLREF, respectively. The default values may be invoked by setting RTOLREF and/or RTOLREC to zero in the input file. The default maximum level of refinement is six and again may be invoked by a zero value in the input file. Initial conditions, along with grid information, are written to the output file. Solution procedure parameters are then initialized, including the initial time step size which is some fraction of the maximum time step supplied in the input file.

Next, the transient solution procedure begins. The time step size is increased by ten percent until it reaches the specified maximum time step size. The current solution and mesh are passed to 
RFEIPID for possible adaptation. Coordinate transformations are then applied to the modified mesh. After defining the time at which a new solution is needed, the ODE solver is called.

DEBDF makes use of a subroutine (FUNC) external to the library package to evaluate the system of differential equations. DEBDF takes intermediate time steps to maintain stability, passing a value of time and the solution vector at that time to FUNC which returns the time derivatives. The time derivatives use a finite difference approximation to compute the required gradients. Two time derivatives, $d \delta_{i} / d t$ and $d \Delta_{i} / d t$, are used in computing the mass fraction time derivative. These derivatives, denoted by $C_{i, 1}$ and $C_{i, 2}$, respectively, in Eq. 18, are computed using a finite difference approximation at the end of a time step and then held constant during the subsequent time step. This approach is used because DEBDF is much more efficient if the Jacobian matrix is banded. For convenience, the subscript $A$ denoting a particular constituent has been assumed in the equations below. Also, let $\mathrm{i}=0,1,2, \ldots$ I denote the layers of the system, and $n=1,2, \ldots \mathrm{N}$ denote the nodal points within a layer so that $w_{i, n}$ is the mass fraction in layer $i$ of the $n^{\text {th }}$ node. The mass fraction time derivatives defined by Eq. 13 are calculated according to the following approximation

$$
\dot{w}_{i, n}=\frac{1}{\Delta_{i}} \frac{\left[q_{n+1 / 2}-q_{n-1 / 2}\right]}{\Delta \bar{x}_{n}}+\frac{1}{\Delta_{i}}\left[C_{i, 1}+\bar{x}_{i, n} C_{i, 2}\right]\left[\frac{w_{i, n+1}-w_{i, n}}{\bar{x}_{i, n+1}-\bar{x}_{i, n}}\right]
$$

where

$$
\begin{aligned}
q_{n+1 / 2} & =\frac{\bar{D}_{i}}{\Delta_{i}}\left[\frac{w_{i, n+1}-w_{i, n}}{\bar{x}_{i, n+1}-\bar{x}_{i, n}}\right] \\
q_{n-1 / 2} & =\frac{\bar{D}_{i}}{\Delta_{i}}\left[\frac{w_{i, n}-w_{i, n-1}}{\bar{x}_{i, n}-\bar{x}_{i, n-1}}\right] \\
\Delta \bar{x}_{n} & =\frac{1}{2}\left[\bar{x}_{i, n+1}-\bar{x}_{i, n-1}\right]
\end{aligned}
$$

Flux conditions are applied at the boundaries of each layer. The flux is defined to be zero at the outside boundaries, that is, at the left edge of the substrate and the right edge of the solder (Fig. 1). The flux at internal boundaries (or interfaces) is defined by the rate of reaction described in Eqs. 10 and 11 . Note that the flux at the right side of interface $i$ is the flux at the left edge of layer $i$ and likewise, the flux at the left side of interface $i+l$ is the flux at the right edge of layer $i$. The finite difference implementation of this boundary flux yields the following time derivative for the mass fraction at the left end of a layer

$$
\dot{w}_{i, 1}=\frac{1}{\Delta_{i}} \frac{q_{3 / 2}+R_{i}^{r} / \rho_{i}}{\Delta \bar{x}_{0}}+\frac{1}{\Delta_{i}}\left[C_{i, 1}+\bar{x}_{i, 1} C_{i, 2}\right]\left[\frac{w_{i, 2}-w_{i, 1}}{\bar{x}_{i, 2}-\bar{x}_{i, 1}}\right]
$$


and for the right end

$$
\dot{w}_{i, N}=\frac{1}{\Delta_{i}} \frac{q_{i, N-1 / 2}+R_{i+1}^{l} / \rho_{i}}{\Delta \bar{x}_{N}}+\frac{1}{\Delta_{i}}\left[C_{i, 1}+\bar{x}_{i, N} C_{i, 2}\right]\left[\frac{w_{i, N}-w_{i, N-1}}{\bar{x}_{i, N}-\bar{x}_{i, N-1}}\right]
$$

where

$$
\begin{gathered}
\Delta \bar{x}_{0}=\bar{x}_{i, 1}+\frac{1}{2}\left[\bar{x}_{i, 2}-\bar{x}_{i, 1}\right] \\
\Delta \bar{x}_{N}=1.0-\bar{x}_{i, N}+\frac{1}{2}\left[\bar{x}_{i, N}-\bar{x}_{i, N-1}\right]
\end{gathered}
$$

Presently, only the internal interface locations are allowed to move, that is, the outside edges of the solder and substrate are considered fixed. The time derivatives for the interface locations defined by Eq. 15 are approximated as

$$
\dot{\delta}_{i}=\frac{-\frac{\rho_{i-1} \bar{D}_{i-1}}{\Delta_{i-1}}\left[\frac{w_{i-1, N}-w_{i-1, N-1}}{\bar{x}_{i-1, N}-\bar{x}_{i-1, N-1}}\right]+\frac{\rho_{i} \bar{D}_{i}}{\Delta_{i}}\left[\frac{w_{i, 2}-w_{i, 1}}{\bar{x}_{i, 2}-\bar{x}_{i, 1}}\right]}{\rho_{i-1} w_{i-1, N}-\rho_{i} w_{i, 1}}
$$

Control is returned to the main program from DEBDF with the solution vectors at the specified time. Results are printed and/or written according to criteria defined by the user in the input file. The values of $C_{i, 1}$ and $C_{i, 2}$ are updated, time is incremented, and the procedure repeated until the user-specified maximum time or number of time steps is exceeded.

\subsection{Verification}

If $D_{A_{i}}$ and $\rho_{i}$ have constant values in each layer, if the boundary conditions given by Eqs. 3 and 4 apply, and if $\delta_{i}^{0}$ in Eq. 9 is negligible, then Eqs. 2 and 8 can be solved analytically for each layer as discussed by Jost (1960). In each layer, $w_{A_{t}}$ is given by

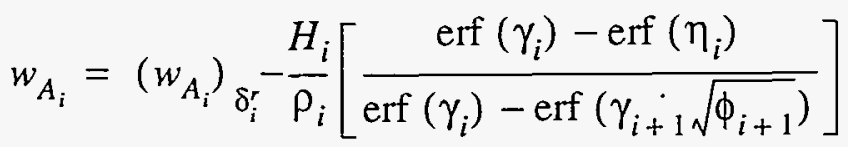

where

$$
\eta_{i}=\frac{x}{2 \sqrt{D_{A_{i}}{ }^{2}}}
$$


and

$$
\phi_{i}=\frac{D_{A_{i}}}{D_{A_{i-1}}}
$$

$$
H_{i}=\rho_{i}\left[\left(w_{A_{i}}\right)_{\delta_{i}^{r}}-\left(w_{A_{i}}\right)_{\delta_{i+1}^{l}}\right]
$$

The displacement of each interface is given by

$$
\delta_{i}(t)=2 \gamma_{i} \sqrt{D_{A_{i}}} t
$$

where

$$
\gamma_{i}=\frac{1}{\sqrt{\pi \phi_{i}}} \frac{1}{h_{i}}\left[\frac{\sqrt{\phi_{i}} H_{i} \exp \left(-\gamma_{i}^{2}\right)}{\operatorname{erf}\left(\gamma_{i}\right)-\operatorname{erf}\left(\gamma_{i+1} \sqrt{\phi_{i+1}}\right)}-\frac{H_{i-1} \exp \left(-\phi_{i} \gamma_{i}^{2}\right)}{\operatorname{erf}\left(\gamma_{i-1}\right)-\operatorname{erf}\left(\gamma_{i} \sqrt{\phi_{i}}\right)}\right]
$$

and

$$
h_{i}=\rho_{i-1}\left(w_{A_{i-1}}\right)_{\delta_{i}^{l}}^{l}-\rho_{i}\left(w_{A_{i}}\right)_{\delta_{i}^{r}}
$$

Equations 27 through 33 are useful for data analysis and for verifying numerical techniques. It should be noted that terms involving $\gamma_{i}, \gamma_{i-1}$, and $\gamma_{i+1}$ appear in Eq. 32. Therefore, the equations for $\gamma_{i}$ must be solved simultaneously, and since the equations are nonlinear, a numerical solution is necessary. For a system involving growth of $I$ - 1 intermetallic layers, the $\gamma_{i}$ in Eq. 32 satisfy the following inequalities

$$
\begin{gathered}
\gamma_{i}<0 \\
\gamma_{i}<\gamma_{i+1} \sqrt{\phi_{i+1}}
\end{gathered}
$$

when $i=1,2,3 \ldots I$, and

$$
\gamma_{I+1}>0
$$

In this work, the equations for $\gamma_{i}$ were solved using the symbol manipulation code Mathematica (Wolfram, 1991). For each $\gamma_{\mathrm{i}}$, Eq. 32 was used as the source term for an ordinary differential equation of the form

$$
\frac{d \gamma_{i}}{d t}=A_{i}+B_{i} \gamma_{i}
$$


so that the long-time solutions of the differential equations approach the roots of the original equations for $\gamma_{i}$.

The numerical solution of Eqs. 2 and 8 was compared with the analytical solution for systems involving 2, 3, and 5 layers. The analytical solution is based on zero initial thickness of the intermetallic layers and local chemical equilibrium between constituents at the interfaces between layers. The numerical solutions for the same conditions were in good agreement with the analytical results, as indicated in Fig. 7, which compares the analytical and numerical results for a five-layer system. The parameter values used in the calculations shown in Fig. 7 are given in Table 3. The material density was assumed constant and equal in all layers.

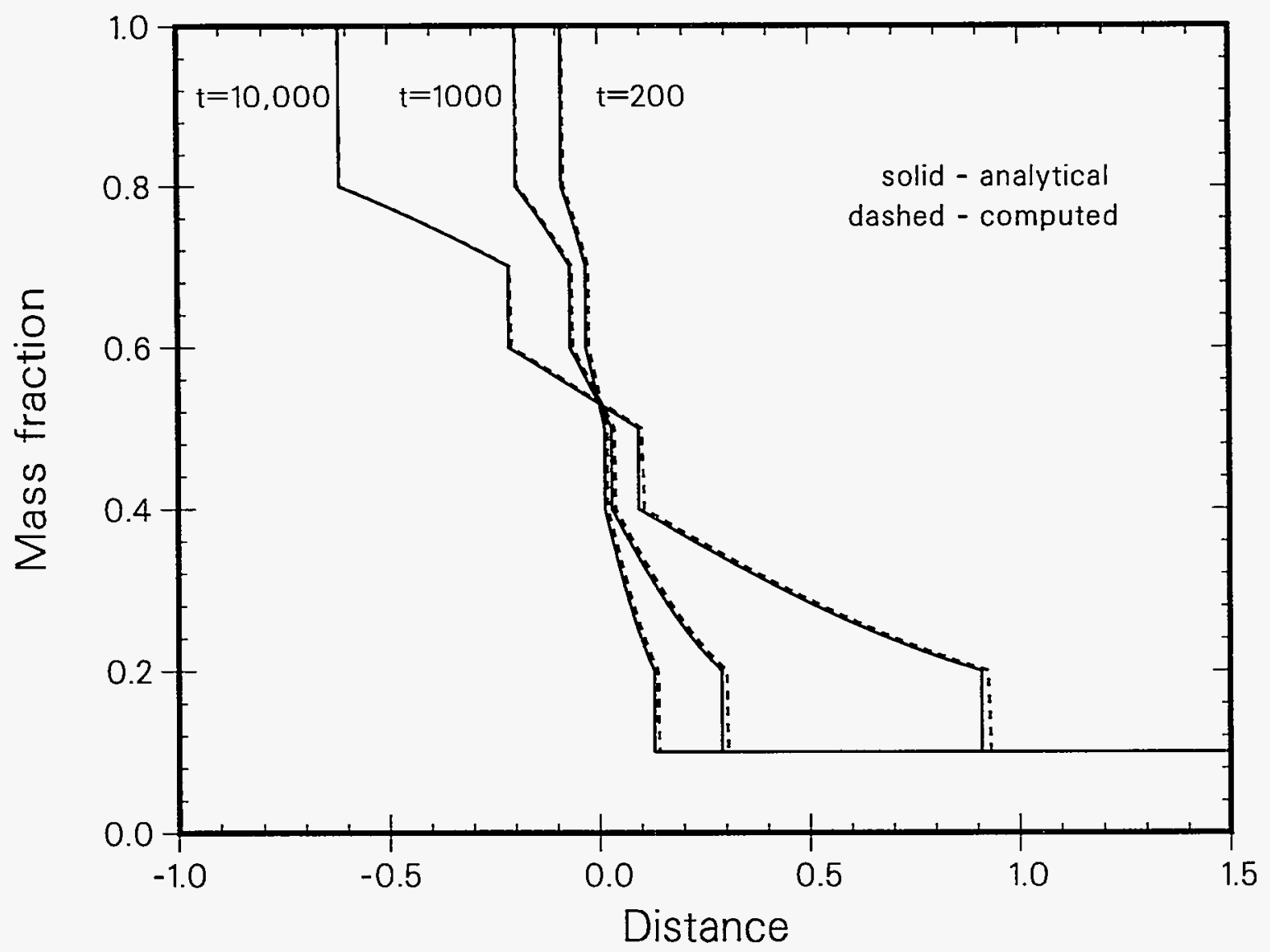

Figure 7. Comparison of analytical and numerical solutions for a five-zone system. 
Table 3: Parameter Values for Comparison of Analytical and Numerical Solutions

\begin{tabular}{|c|c|c|c|c|}
\hline Layer & $\left(w_{A_{i}}\right) \delta_{i}^{r}$ & $\left(w_{A_{i}}\right) \delta_{i+1}^{l}$ & $\begin{array}{c}D_{i} \times 10^{5} \\
\left(\mathrm{~cm}^{2} / \text { day }\right)\end{array}$ & $\gamma_{i}$ \\
\hline \hline 1 & 1.0 & 1.0 & 0.0 & -- \\
\hline 2 & 0.8 & 0.7 & 3.0 & -0.56894 \\
\hline 3 & 0.6 & 0.5 & 3.0 & -0.197728 \\
\hline 4 & 0.4 & 0.2 & 3.0 & 0.0861818 \\
\hline 5 & 0.1 & 0.1 & 0.0 & 0.838057 \\
\hline
\end{tabular}




\subsection{APPLICATIONS}

In this work, the principal application of numerical modeling was in the analysis of the experimental data discussed previously for the $\mathrm{Cu}-100 \mathrm{Sn}$ and $\mathrm{Cu}-63 \mathrm{Sn}-37 \mathrm{~Pb}$ systems. Detailed analyses using numerical modeling were performed to compare the experimental data for intermetallic growth with results calculated assuming growth was controlled by bulk diffusion of $\mathrm{Cu}$ or $\mathrm{Sn}$. The analysis for $\mathrm{Cu}-100 \mathrm{Sn}$ is discussed first, followed by that for $\mathrm{Cu}-63 \mathrm{Sn}-37 \mathrm{~Pb}$.

The analyses for the $\mathrm{Cu}-100 \mathrm{Sn}$ system were performed using a four-layer model that consisted of $\mathrm{Cu}, \mathrm{Cu}_{3} \mathrm{Sn}, \mathrm{Cu}_{6} \mathrm{Sn}_{5}$, and $\mathrm{Sn}$ layers, denoted by subscripts $1,2,3$, and 4 , respectively. Since the experimental data indicated that diffusion of $\mathrm{Sn}$ into the $\mathrm{Cu}$ substrate and diffusion of $\mathrm{Cu}$ into the bulk $\mathrm{Sn}$ were negligible, two diffusion equations (Eq. 2) were required, one for each of the $\mathrm{Cu}_{3} \mathrm{Sn}$ and $\mathrm{Cu}_{6} \mathrm{Sn}_{5}$ layers, and three interface displacement equations, one each for the interface $\delta_{1}(t)$ between $\mathrm{Cu}$ and $\mathrm{Cu}_{3} \mathrm{Sn}, \delta_{2}(t)$ between $\mathrm{Cu}_{3} \mathrm{Sn}$ and $\mathrm{Cu}_{6} \mathrm{Sn}_{5}$, and $\delta_{3}(t)$ between $\mathrm{Cu}_{6} \mathrm{Sn}_{5}$ and $\mathrm{Sn}$. However, the experimental data did not indicate which constituent controlled bulk diffusion in the intermetallic layers. Since the choice of constituent does not alter the overall effect of bulk diffusion, the analyses were based on $\mathrm{Cu}$ being the diffusion-controlling constituent. Local equilibrium was assumed at each side of $\delta_{1}(t), \delta_{2}(t)$, and $\delta_{3}(t)$. The constant concentration boundary conditions given by Eqs. 3 and 4 were then evaluated from the $\mathrm{Cu}-\mathrm{Sn}$ phase diagram and are shown in Table 4, which also includes the mass density of each layer. The initial thicknesses of the intermetallic layers were taken from the experimental data for one day of heat treatment (1.6 and 0.9 microns for $\mathrm{Cu}_{3} \mathrm{Sn}$ and $\mathrm{Cu}_{6} \mathrm{Sn}_{5}$, respectively).

Table 4: Interfacial Concentrations and Mass Densities

\begin{tabular}{|c|c|c|c|}
\hline Layer & $\left(w_{A_{i}}{ } \delta_{i}^{r}\right.$ & $\left(w_{A_{i}}\right)_{\delta_{i+1}^{l}}$ & $\begin{array}{c}\rho_{i} \\
\left(\mathrm{~g} / \mathrm{cm}^{3}\right)\end{array}$ \\
\hline \hline $\mathrm{Cu}(1)$ & 1.000 & 1.000 & 8.9 \\
\hline $\mathrm{Cu}_{3} \mathrm{Sn}(2)$ & 0.623 & 0.605 & 9.0 \\
\hline $\mathrm{Cu}_{6} \mathrm{Sn}_{5}(3)$ & 0.410 & 0.400 & 8.4 \\
\hline $\mathrm{Sn}(4)$ & 0.000 & 0.000 & 7.3 \\
\hline
\end{tabular}

The diffusion coefficients $D_{A}$ in both intermetallic layers were initially assumed constant. The experimental data for layer growth at times from 1 to 40 days were then used to determine values for $D_{A_{i}}$ that reasonably reproduced the experimental data. Using those values, growth of the $\mathrm{Cu}_{3} \mathrm{Sn}$ and $\mathrm{Cu}_{6} \mathrm{Sn}_{5}$ layers was predicted for times to 400 days and compared with the corresponding experimental data. Analogous calculations were then repeated using the experimental data from 1 to 100,1 to 150,1 to 200 , and 1 to 400 days to determine the values for $D_{A i}$. These results are summarized in Figs. 8 and 9 for the $\mathrm{Cu}_{3} \mathrm{Sn}$ and $\mathrm{Cu}_{6} \mathrm{Sn}_{5}$ layers, respectively, at $170^{\circ} \mathrm{C}$. The solid portion of each curve indicates the time interval in which the experimental data were used to evaluate the diffusion coefficients, and the dashed portion indicates the time interval in which the thickness was predicted. The diffusion coefficients corresponding to each curve for $\mathrm{Cu}_{3} \mathrm{Sn}$ and $\mathrm{Cu}_{6} \mathrm{Sn}_{5}$ are shown in Table 5. The results generally indicate that the experimental data are consistent with a bulk diffusion mechanism, but the diffusion coefficient is probably not con- 


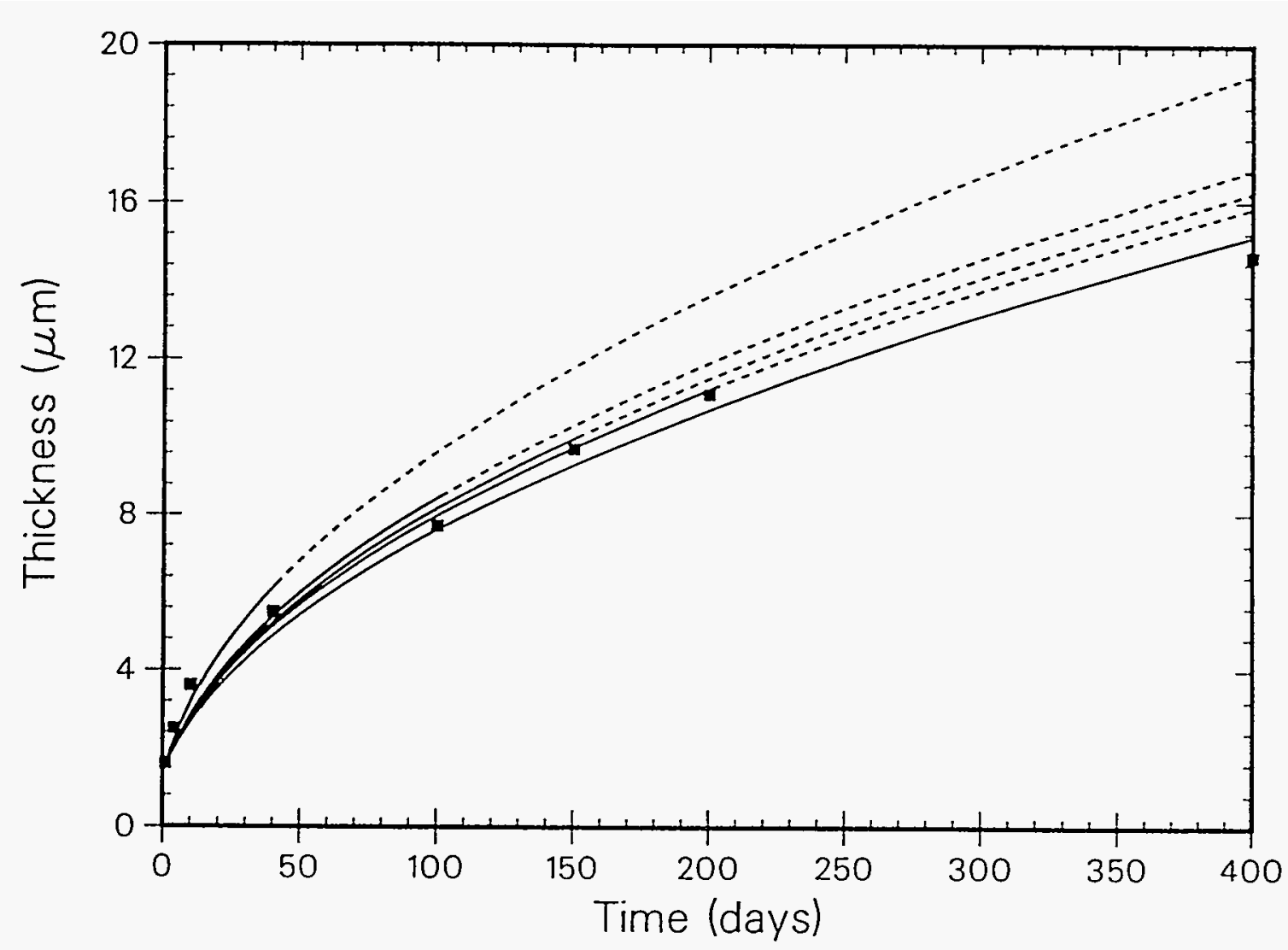

Figure 8. Intermetallic layer thicknesses calculated using a constant diffusion coefficient for $\mathrm{Cu}_{3} \mathrm{Sn}$ at $170^{\circ} \mathrm{C}$.

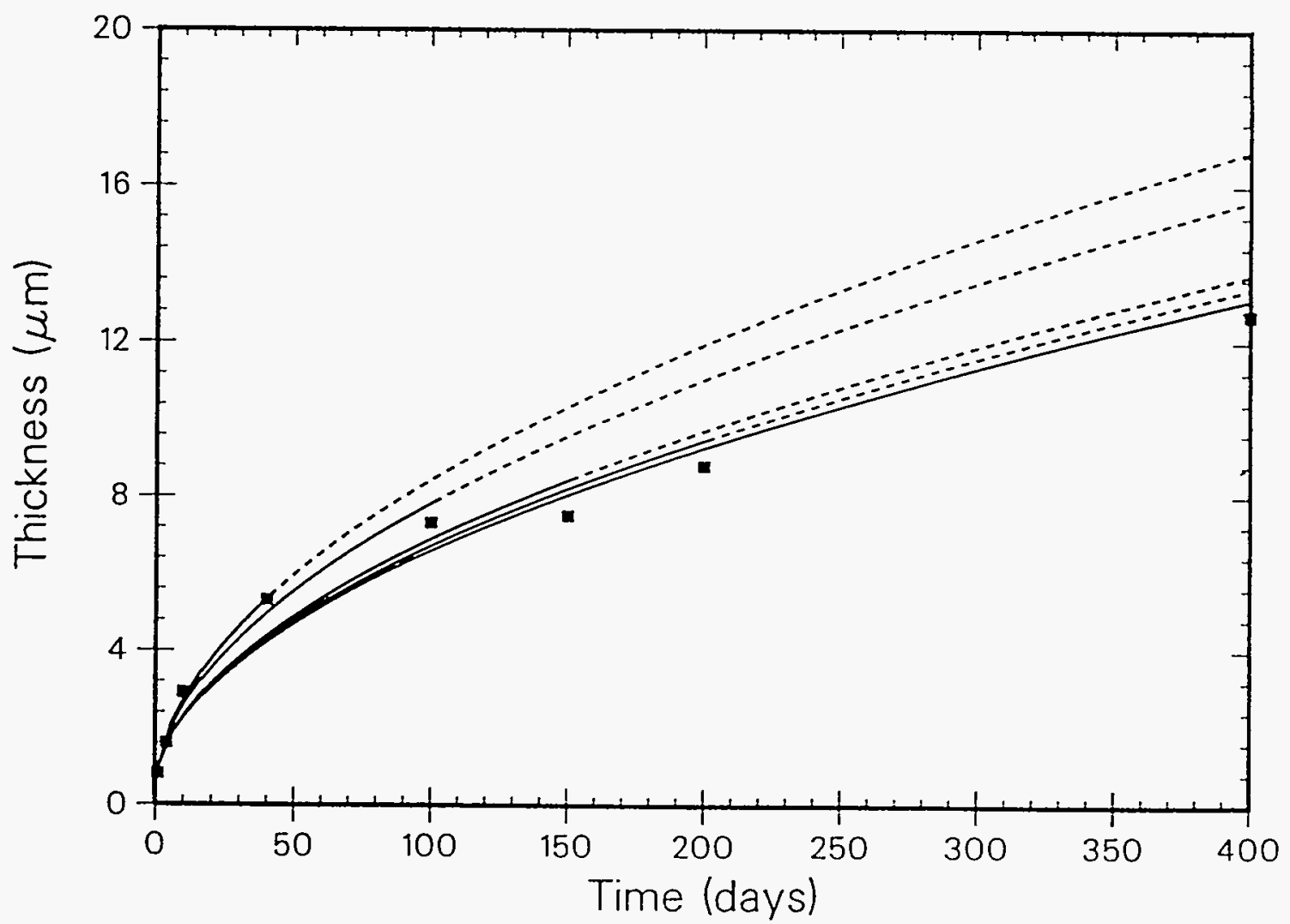

Figure 9. Intermetallic layer thicknesses calculated using a constant diffusion coefficient for $\mathrm{Cu}_{6} \mathrm{Sn}_{5}$ at $170^{\circ} \mathrm{C}$. 
stant. During early times, diffusion appears to be faster relative to later times. Similar effects have been reported previously. Kofstad (1966) used the term "enhanced diffusion" to indicate effects which could be attributed to grain boundary diffusion, residual strain, and poor crystallization during early layer growth.

Table 5: Constant $\mathrm{Cu}$ Diffusion Coefficients for the $\mathrm{Cu}-100 \mathrm{Sn}$ Layers at $170^{\circ} \mathrm{C}$

\begin{tabular}{|c|c|c|}
\hline $\begin{array}{c}\text { Time Interval from } \\
\text { Day 1 to Day }\end{array}$ & $\begin{array}{c}D_{A}\left(\mathrm{Cu}_{3} \mathrm{Sn}\right) \times 10^{8} \\
\left(\mathrm{~cm}^{2} / \text { day }\right)\end{array}$ & $\begin{array}{c}D_{A}\left(\mathrm{Cu}_{6} \mathrm{Sn}_{5}\right) \times 10^{7} \\
\left(\mathrm{~cm}^{2} / \text { day }\right)\end{array}$ \\
\hline \hline 40 & 9.0 & 1.5 \\
\hline 100 & 7.5 & 1.2 \\
\hline 150 & 6.8 & 1.0 \\
\hline 200 & 6.5 & 0.9 \\
\hline 400 & 6.0 & \\
\hline
\end{tabular}

To empirically account for the effects of enhanced diffusion, an analogous series of calculations was performed using a variable diffusion coefficient $\overline{D_{A} i}$ defined by Eq. 17 . The numerical results are compared with the experimental data in Figs. 10 and 11. The corresponding values for $D_{A_{i}}, D_{A_{i}}$, and $\lambda_{i}$ are given in Table 6 . The agreement between experimental and calculated values is considerably improved. This improvement is further illustrated in Figs. 12 and 13 which compare the numerical results obtained using a constant diffusion coefficient and the variable coefficient given by Eq. 17.

Table 6: Variable Cu Diffusion Coefficients for the $\mathrm{Cu}-100 \mathrm{Sn}$ Layers at $170^{\circ} \mathrm{C}$

\begin{tabular}{|c|c|c|c|c|}
\hline \multirow{2}{*}{ Layer } & $\begin{array}{c}\text { Time Interval from } \\
\text { Day 1 to Day }\end{array}$ & $\begin{array}{c}D_{A} \times 10^{8} \\
\left(\mathrm{~cm}^{2} / \text { day }\right)\end{array}$ & $\begin{array}{c}D_{A}^{\prime} \times 10^{7} \\
\left(\mathrm{~cm}^{2} / \mathrm{day}\right)\end{array}$ & $\begin{array}{c}\lambda_{i} \times 10^{3} \\
\left(\mathrm{~cm}^{-1}\right)\end{array}$ \\
\hline \hline \multirow{2}{*}{$\mathrm{Cu}_{3} \mathrm{Sn}$} & 100 & 3.5 & 1.6 & 3.5 \\
\cline { 2 - 5 } & 200 & 4.5 & 1.4 & 3.8 \\
\cline { 2 - 5 } & 400 & 4.3 & 1.4 & 3.8 \\
\hline \multirow{2}{*}{$\mathrm{Cu}_{6} \mathrm{Sn}_{5}$} & 100 & 4.0 & 1.8 & 1.9 \\
\cline { 2 - 5 } & 200 & 4.0 & 1.8 & 2.1 \\
\cline { 2 - 5 } & 400 & 5.0 & 1.7 & 2.1 \\
\hline
\end{tabular}




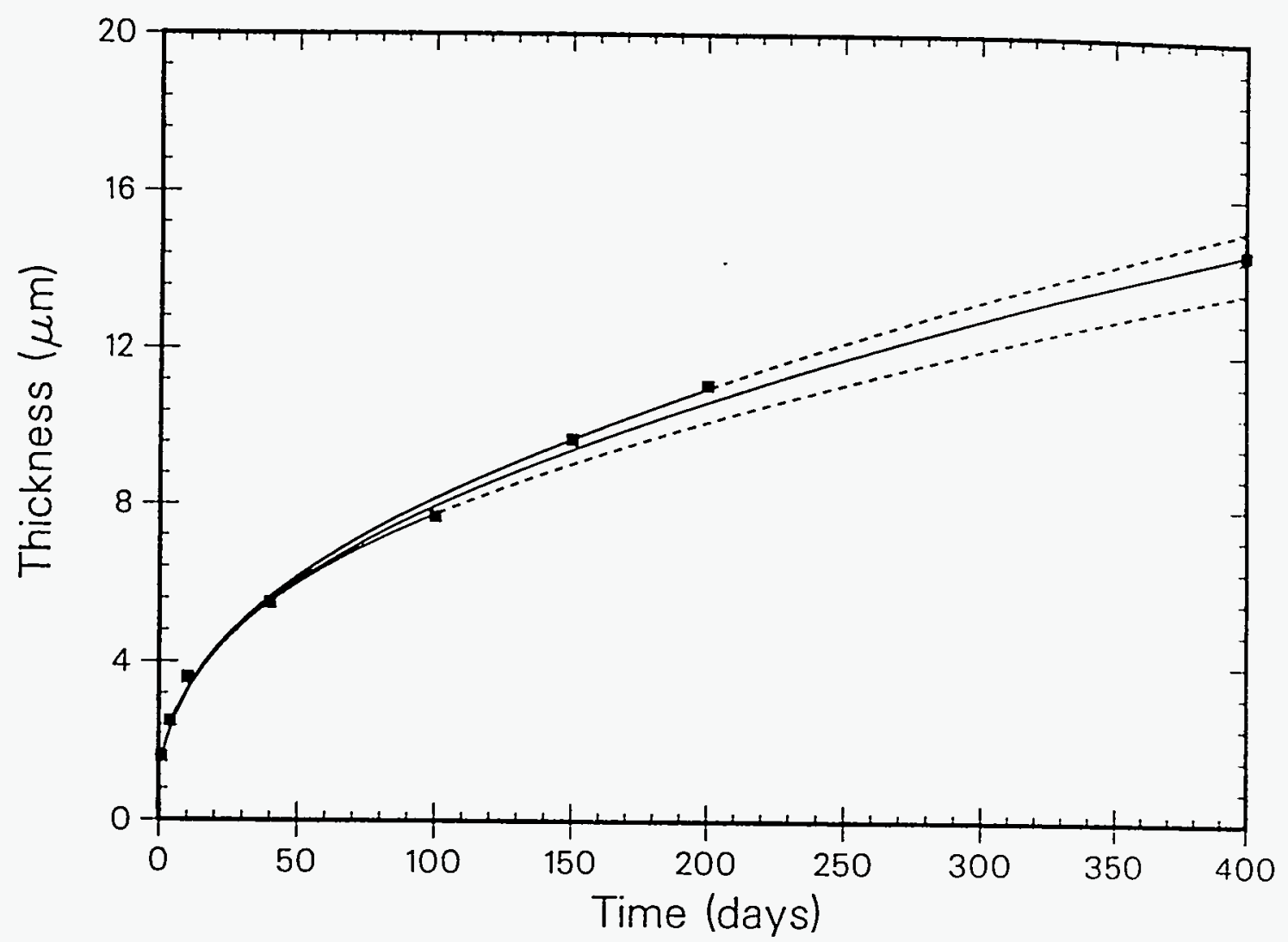

Figure 10. Intermetallic layer thicknesses (100Sn solder) calculated using a variable diffusion coefficient (Eq. 17) for $\mathrm{Cu}_{3} \mathrm{Sn}$ at $170^{\circ} \mathrm{C}$.

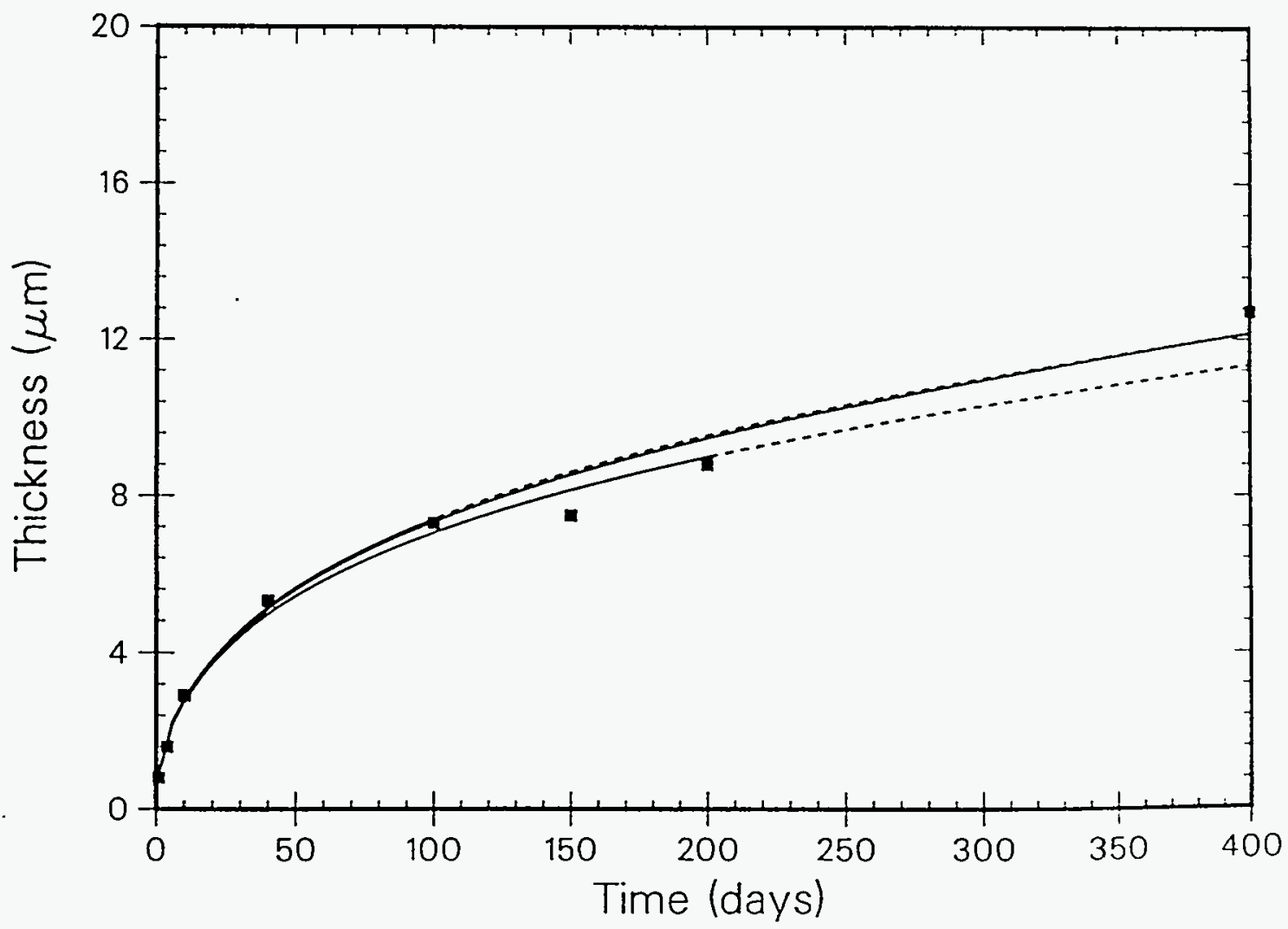

Figure 11. Intermetallic layer thicknesses (100Sn solder) calculated using a variable diffusion coefficient (Eq. 17) for $\mathrm{Cu}_{6} \mathrm{Sn}_{5}$ at $170^{\circ} \mathrm{C}$. 


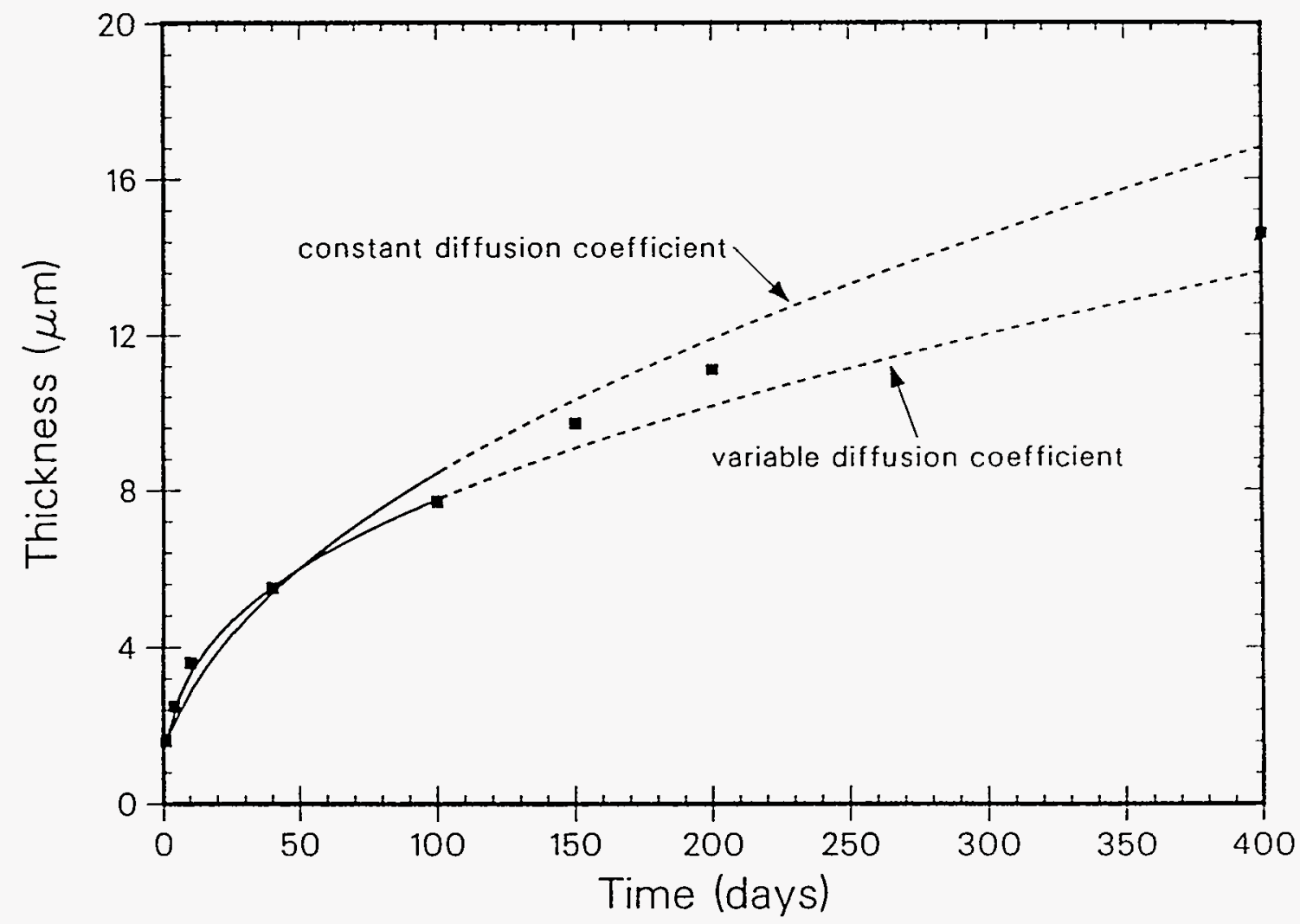

Figure 12. Comparison of $\mathrm{Cu}_{3} \mathrm{Sn}$ layer thicknesses calculated using constant and variable (Eq. 17) diffusion coefficients at $170^{\circ} \mathrm{C}$

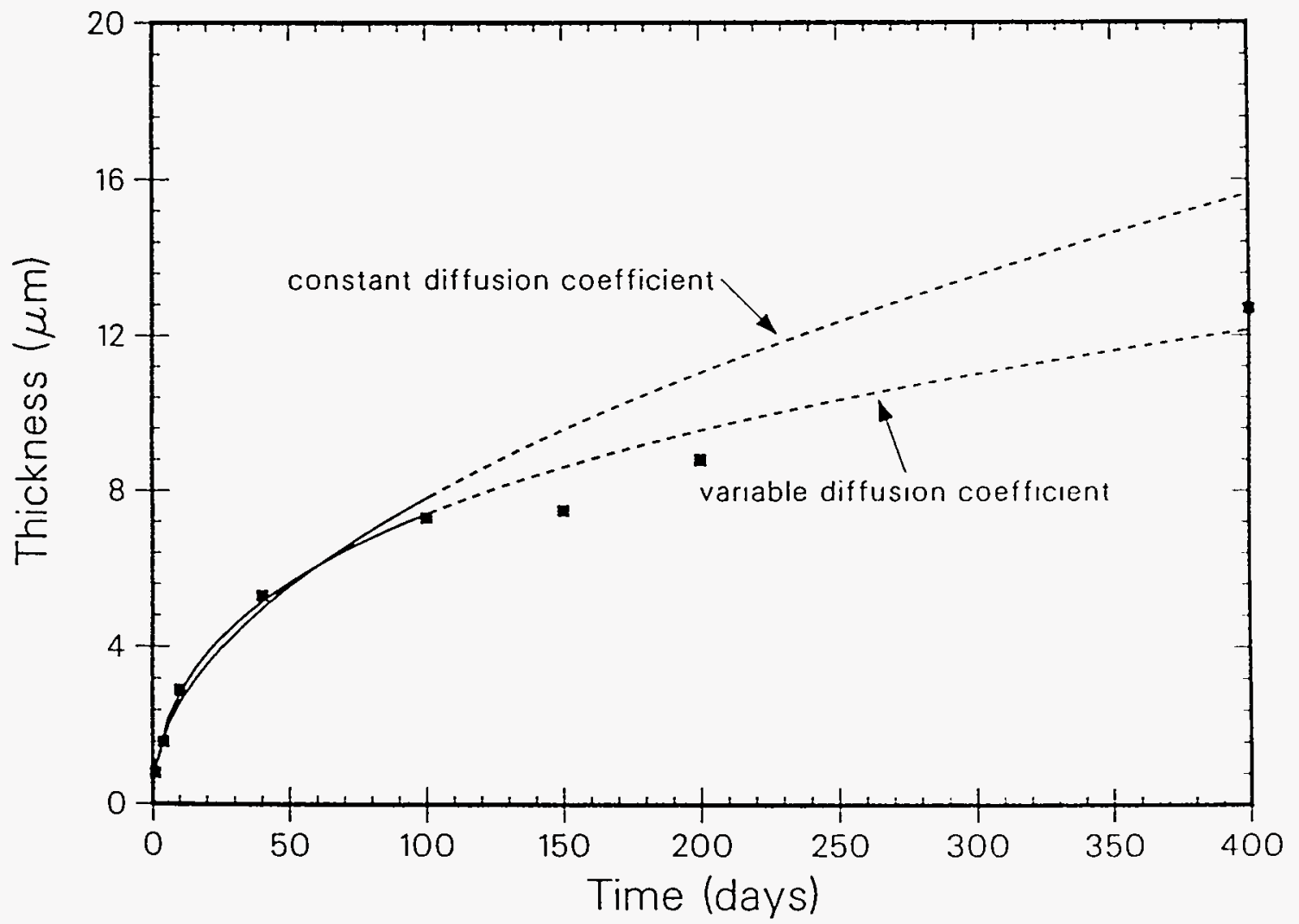

Figure 13. Comparison of $\mathrm{Cu}_{6} \mathrm{Sn}_{5}$ layer thicknesses calculated using constant and variable (Eq. 17) diffusion coefficients at $170^{\circ} \mathrm{C}$. 
Similar analyses were performed with the data from the experiments at 135 and $205^{\circ} \mathrm{C}$, and the results also indicated that layer growth is consistent with a bulk diffusion mechanism involving a variable diffusion coefficient that reflects some enhanced diffusion during early layer growth. A comparison between the computational and experimental data for $135^{\circ} \mathrm{C}$ is shown in Figs. 14 and 15 for the $\mathrm{Cu}_{3} \mathrm{Sn}$ and $\mathrm{Cu}_{6} \mathrm{Sn}_{5}$ layers, respectively, and for $205^{\circ} \mathrm{C}$ in Figs. 16 and 17. The values for $D_{A_{i}}, D_{A}^{\prime}$, and $\lambda_{i}$ corresponding to the computational results shown in Figs. 14 through 17 are given in Table 7 . The computational results at $135^{\circ} \mathrm{C}$ require some additional explanation. Initially ( $t=1$ day), only the $\mathrm{Cu}_{6} \mathrm{Sn}_{5}$ layer was present. But, during the period between 2 and 10 days the $\mathrm{Cu}_{3} \mathrm{Sn}$ layer nucleated, coalesced, and began to grow. The net effect of which was a "sudden" decrease in the thickness of the $\mathrm{Cu}_{6} \mathrm{Sn}_{5}$ layer and the "sudden" appearance of $\mathrm{a} \mathrm{Cu}_{3} \mathrm{Sn}$ layer. This effect was accounted for numerically by choosing an initial nucleation time ( $t=6$ days), a negligibly small initial $\mathrm{Cu}_{3} \mathrm{Sn}$ layer thickness ( 0.2 microns), and large values for $D_{A_{i}}$, and $\lambda_{i}$ so that growth of the $\mathrm{Cu}_{3}$ Sn layer was extremely fast during the first 10 days and then decayed rapidly to the long time rates observed experimentally. To obtain better agreement with the experimental data at early times, non-equilibrium was assumed at the $\mathrm{Cu}_{3} \mathrm{Sn}$ - $\mathrm{Cu}_{6} \mathrm{Sn}_{5}$ interface during nucleation and coalescence. The flux-type boundary condition given by Eqs. 6 and 10 was used for the $\mathrm{Cu}_{6} \mathrm{Sn}_{5}$ layer at $\delta_{2}^{r}\left(k_{2}^{r}=2.8 \times 10^{-4} \mathrm{~cm} / \mathrm{s}\right)$.

Table 7: Comparison of Variable $\mathrm{Cu}$ Diffusion Coefficients for the $\mathrm{Cu}$-100Sn Layers

\begin{tabular}{|c|c|c|c|c|c|}
\hline \multirow{2}{*}{ Layer } & $\begin{array}{c}\text { Temperature } \\
\left({ }^{\circ} \mathrm{C}\right)\end{array}$ & $\begin{array}{c}D_{A} \times 10^{8} \\
\left(\mathrm{~cm}^{2} / \mathrm{day}\right)\end{array}$ & $\begin{array}{c}D_{A^{\prime} \times 10^{7}} \\
\left(\mathrm{~cm}^{2} / \mathrm{day}\right)\end{array}$ & $\begin{array}{c}\lambda_{i} \times 10^{3} \\
\left(\mathrm{~cm}^{-1}\right)\end{array}$ & $D_{A}{ }^{\prime} / D_{A}$ \\
\hline \hline \multirow{2}{*}{$\mathrm{Cu}_{3} \mathrm{Sn}$} & 135 & 1.0 & 8.0 & 20.0 & 80.0 \\
\cline { 2 - 6 } & 170 & 4.3 & 1.4 & 3.8 & 3.3 \\
\cline { 2 - 6 } & 205 & 29 & 12.0 & 5.0 & 4.1 \\
\hline \multirow{2}{*}{$\mathrm{Cu}_{6} \mathrm{Sn}_{5}$} & 135 & 2.0 & 8.0 & 3.8 & 4.0 \\
\cline { 2 - 6 } & 170 & 5.0 & 1.7 & 2.1 & 3.4 \\
\cline { 2 - 6 } & 205 & 30.0 & 14.0 & 2.6 & 4.7 \\
\hline
\end{tabular}

Analysis of the data from the $\mathrm{Cu}-63 \mathrm{Sn}-37 \mathrm{~Pb}$ experiments was analogous to analysis of the data from the $\mathrm{Cu}-100 \mathrm{Sn}$ samples discussed above, except that the data were from experiments performed at 170,135 , and $100^{\circ} \mathrm{C}$. The $\mathrm{Pb}$-rich $\mathrm{Pb}$-Sn layer was neglected because $\mathrm{Cu}$ was not detected in the layer. Again, the results indicated that layer growth was consistent with a bulk diffusion mechanism involving a variable diffusion coefficient that reflects some enhanced diffusion during early layer growth. However, the numerical values for the diffusion coefficients were significantly different from the values obtained for the $\mathrm{Cu}-100 \mathrm{Sn}$ samples at the same temperature. This is somewhat unexpected, since the bulk composition of $\mathrm{Cu}_{3} \mathrm{Sn}$ and $\mathrm{Cu}_{6} \mathrm{Sn}_{5}$ layers appear similar in both the $\mathrm{Cu}-100 \mathrm{Sn}$ and $\mathrm{Cu}-63 \mathrm{Sn}-37 \mathrm{~Pb}$ samples. A comparison between the 


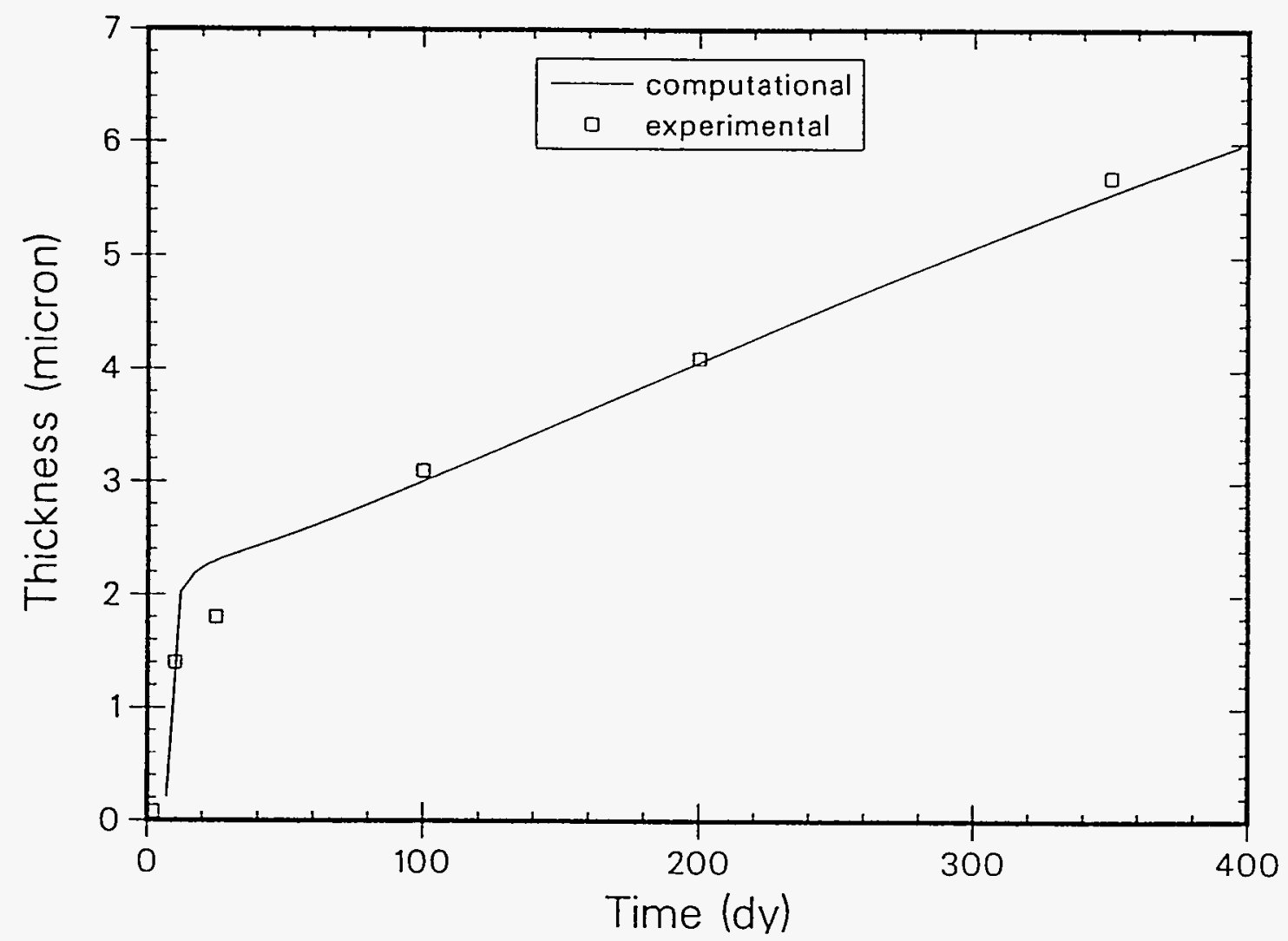

Figure 14. Intermetallic layer thicknesses (100Sn solder) calculated using a variable diffusion coefficient (Eq. 17) for $\mathrm{Cu}_{3} \mathrm{Sn}$ at $135^{\circ} \mathrm{C}$.

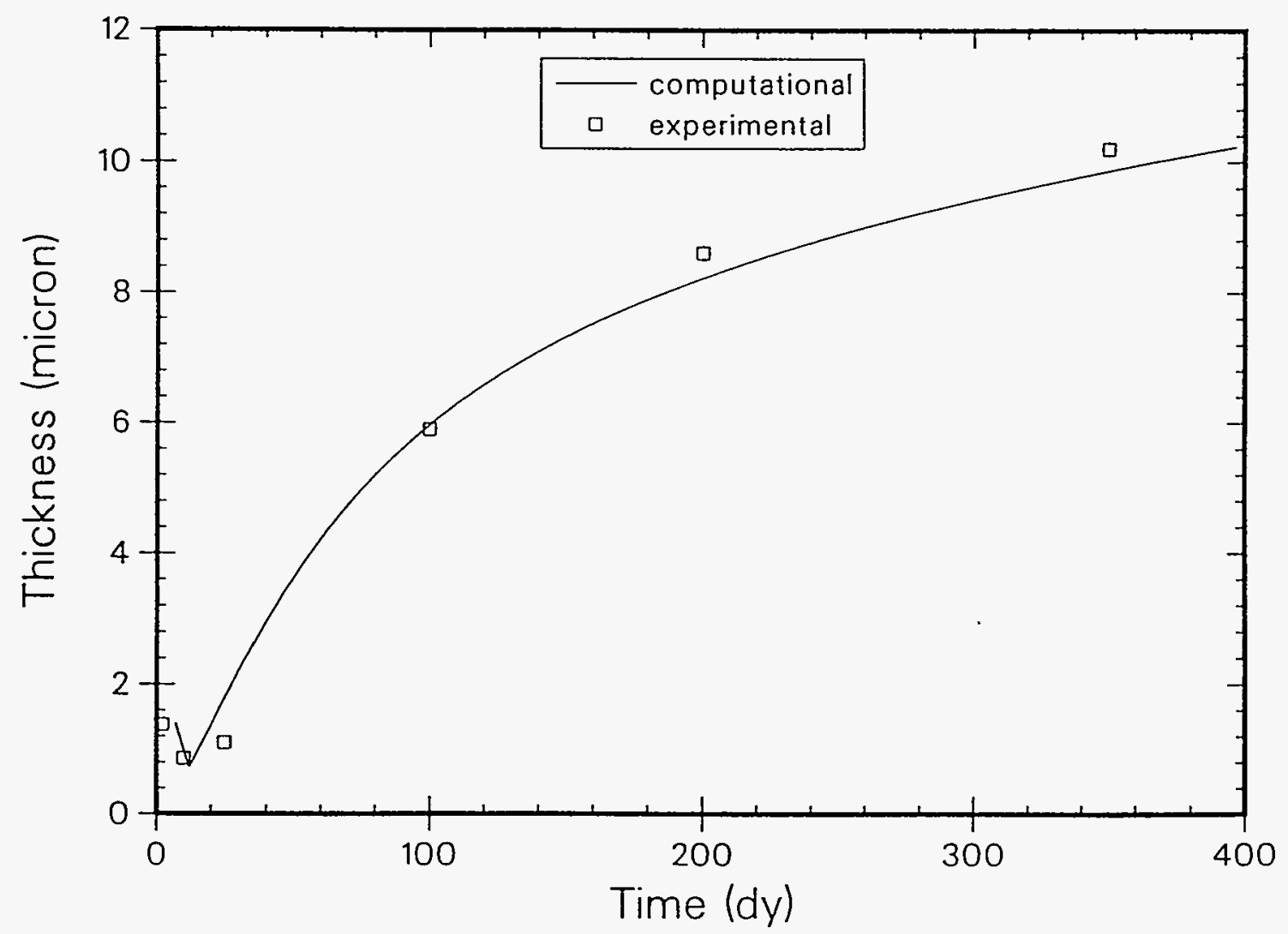

Figure 15. Intermetallic layer thicknesses (100Sn solder) calculated using a variable diffusion coefficient (Eq. 17) for $\mathrm{Cu}_{6} \mathrm{Sn}_{5}$ at $135^{\circ} \mathrm{C}$. 


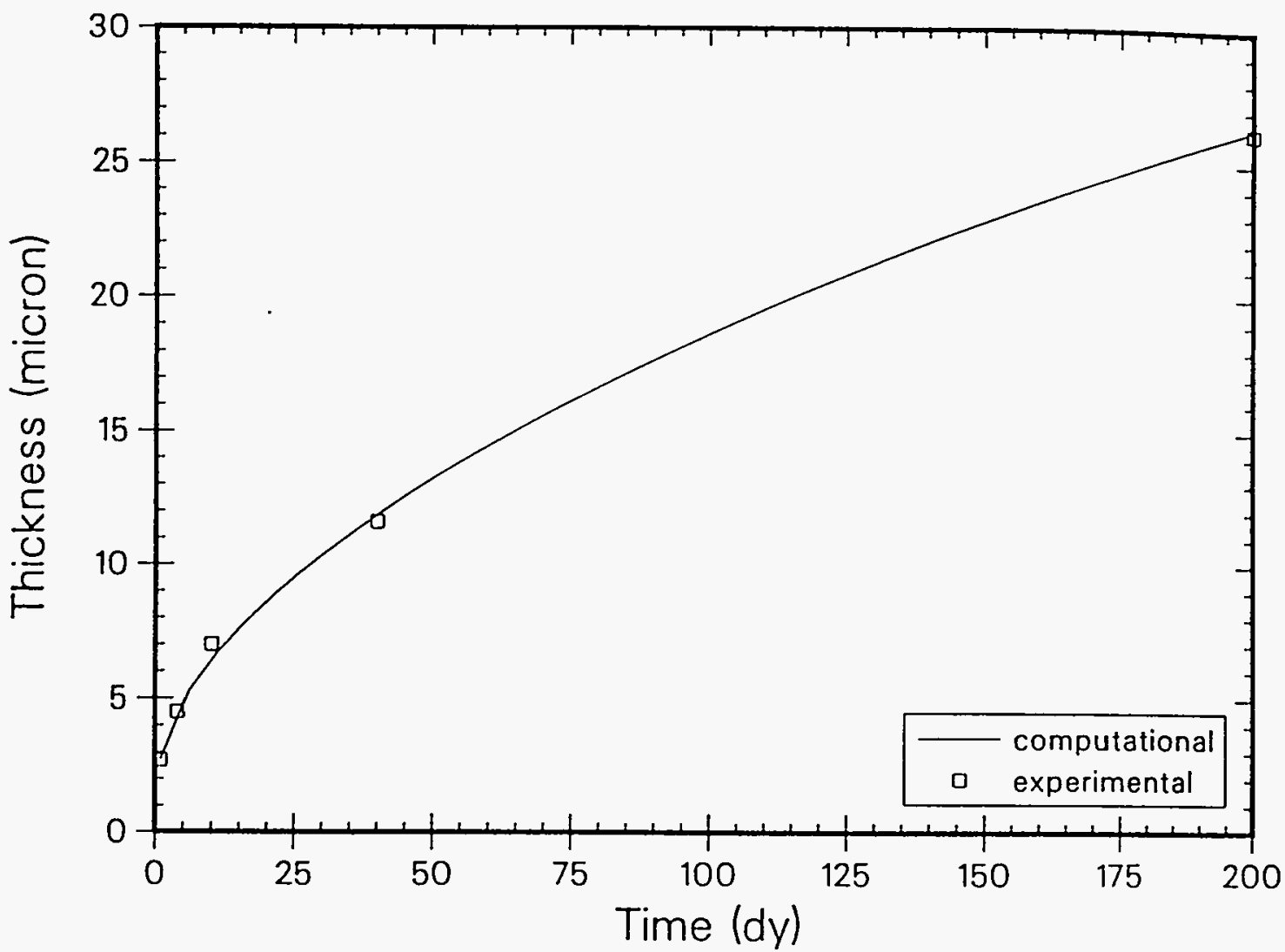

Figure 16. Intermetallic layer thicknesses (100Sn solder) calculated using a variable diffusion coefficient (Eq. 17) for $\mathrm{Cu}_{3} \mathrm{Sn}$ at $205^{\circ} \mathrm{C}$.

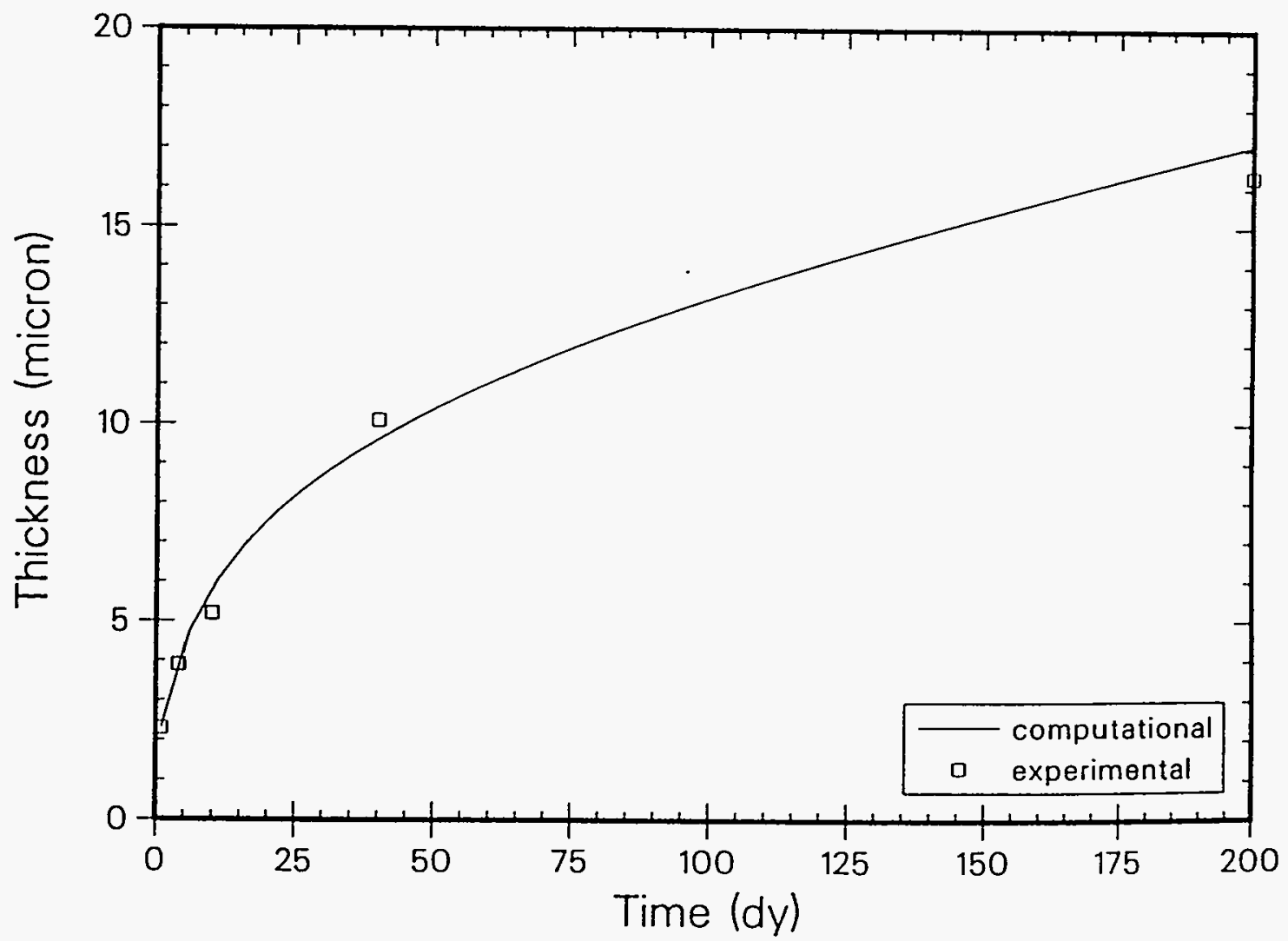

Figure 17. Intermetallic layer thicknesses (100Sn solder) calculated using a variable diffusion coefficient (Eq. 17) for $\mathrm{Cu}_{6} \mathrm{Sn}_{5}$ at $205^{\circ} \mathrm{C}$. 
computational and experimental results for $170^{\circ} \mathrm{C}$ is shown in Figs. 18 and 19 for $\mathrm{Cu}_{3} \mathrm{Sn}$ and $\mathrm{Cu}_{6} \mathrm{Sn}_{5}$, respectively, for $135^{\circ} \mathrm{C}$ in Figs. 20 and 21, and for $100^{\circ} \mathrm{C}$ in Fig. 22 for $\mathrm{Cu}_{6} \mathrm{Sn}_{5}\left(\mathrm{Cu}_{3} \mathrm{Sn}\right.$ did not form at $100^{\circ} \mathrm{C}$ ). The values for $D_{A_{i}}, D_{A_{i}}^{\prime}$, and $\lambda_{i}$ corresponding to the computational results shown in Figs. 18 through 22 are given in Table 8.

Table 8: Comparison of Variable Cu Diffusion Coefficients for Cu-63Sn-37Pb Layers

\begin{tabular}{|c|c|c|c|c|c|}
\hline \multirow{2}{*}{ Layer } & $\begin{array}{c}\text { Temperature } \\
\left({ }^{\circ} \mathrm{C}\right)\end{array}$ & $\begin{array}{c}D_{A} \times 10^{8} \\
\left(\mathrm{~cm}^{2} / \text { day }\right)\end{array}$ & $\begin{array}{c}D_{{ }_{A}^{\prime} \times 10^{7}} \\
\left(\mathrm{~cm}^{2} / \text { day }\right)\end{array}$ & $\begin{array}{c}\lambda_{i} \times 10^{3} \\
\left(\mathrm{~cm}^{-1}\right)\end{array}$ & $D_{A}^{\prime} / D_{A}$ \\
\hline \hline \multirow{2}{*}{$\mathrm{Cu}_{3} \mathrm{Sn}$} & 100 & --- & --- & --- & $\cdots$ \\
\cline { 2 - 6 } & 135 & 0.7 & 0.4 & 20.0 & 5.7 \\
\cline { 2 - 6 } & 170 & 3.7 & 8.0 & 20.0 & 21.6 \\
\hline & & & & & \\
\hline $\mathrm{Cu}_{6} \mathrm{Sn}_{5}$ & 100 & 0.1 & 0.22 & 3.9 & 22.0 \\
\cline { 2 - 6 } & 135 & 2.0 & 1.6 & 3.7 & 8.0 \\
\cline { 2 - 6 } & 170 & 13.0 & 3.6 & 3.8 & 2.8 \\
\hline
\end{tabular}

The values of $D_{A}$ obtained for the $\mathrm{Cu}-100 \mathrm{Sn}$ and $\mathrm{Cu}-63 \mathrm{Sn}-37 \mathrm{~Pb}$ samples at 135 and $170^{\circ} \mathrm{C}$ are compared in Table 9. In the $\mathrm{Cu}_{3} \mathrm{Sn}$ layer, the value of $D_{A}$ for the $\mathrm{Cu}-63 \mathrm{Sn}-37 \mathrm{~Pb}$ samples at both temperatures is about 70 to 80 percent that of the value for the $\mathrm{Cu}-100 \mathrm{Sn}$ samples. In the $\mathrm{Cu}_{6} \mathrm{Sn}_{5}$ layer, the value of $D_{A}$ for the $\mathrm{Cu}-63 \mathrm{Sn}-37 \mathrm{~Pb}$ sample at $135^{\circ} \mathrm{C}$ is the same as the value for the $\mathrm{Cu}-100 \mathrm{Sn}$ sample. However, the value for the $\mathrm{Cu}-63 \mathrm{Sn}-37 \mathrm{~Pb}$ sample at $170^{\circ} \mathrm{C}$ is much larger than the value for the $\mathrm{Cu}-100 \mathrm{Sn}$ sample.

The differences in the values of $D_{A}$ obtained with $\mathrm{Cu}-100 \mathrm{Sn}$ and $\mathrm{Cu}-63 \mathrm{Sn}-37 \mathrm{~Pb}$ samples result from the differences in layer growth shown in Tables $i$ and 2, and primarily from the differences in the ratios of the thickness of the $\mathrm{Cu}_{3} \mathrm{Sn}$ layer to the thickness of the $\mathrm{Cu}_{6} \mathrm{Sn}_{5}$ layer, which are shown in Table 10.

Table 9: Comparison of $D_{A}$ Obtained from Cu-100Sn and $\mathrm{Cu}-63 \mathrm{Sn}-37 \mathrm{~Pb}$ Samples

\begin{tabular}{|c|c|c|c|}
\hline \multirow{2}{*}{$T\left({ }^{\circ} \mathrm{C}\right)$} & $\begin{array}{c}\text { Intermetallic Layer Thickness } \\
\text { (microns) }\end{array}$ & Solder & $D_{A}\left(\mathrm{~cm}^{2} /\right.$ day $) \times 10^{8}$ \\
\hline \hline \multirow{3}{*}{135} & $\mathrm{Cu}_{3} \mathrm{Sn}$ & $100-\mathrm{Sn}$ & 1.0 \\
\cline { 2 - 4 } & & $63 \mathrm{Sn}-37 \mathrm{~Pb}$ & 0.7 \\
\cline { 2 - 4 } & & & \\
\cline { 2 - 4 } & $\mathrm{Cu}_{6} \mathrm{Sn}_{5}$ & $100 \mathrm{Sn}$ & 2.0 \\
\hline
\end{tabular}


Table 9: Comparison of $D_{A}$ Obtained from $\mathrm{Cu}-100 \mathrm{Sn}$ and $\mathrm{Cu}-63 \mathrm{Sn}-37 \mathrm{~Pb}$ Samples

\begin{tabular}{|c|c|c|c|}
\hline$T\left({ }^{\circ} \mathrm{C}\right)$ & $\begin{array}{c}\text { Intermetallic Layer Thickness } \\
\text { (microns) }\end{array}$ & Solder & $D_{A}\left(\mathrm{~cm}^{2} /\right.$ day $) \times 10^{8}$ \\
\hline \hline 135 & $\mathrm{Cu}_{6} \mathrm{Sn}_{5}$ & $63 \mathrm{Sn}-37 \mathrm{~Pb}$ & 2.0 \\
\hline \multirow{2}{*}{170} & & & \\
\cline { 2 - 4 } & $\mathrm{Cu}_{3} \mathrm{Sn}$ & $100-\mathrm{Sn}$ & 4.3 \\
\cline { 2 - 4 } & & $63 \mathrm{Sn}-37 \mathrm{~Pb}$ & 3.7 \\
\cline { 2 - 4 } & & & \\
\hline & $\mathrm{Cu}_{6} \mathrm{Sn}_{5}$ & $100-\mathrm{Sn}$ & 5.0 \\
\hline & & $63 \mathrm{Sn}-37 \mathrm{~Pb}$ & 13.0 \\
\hline
\end{tabular}

Table 10: Ratio of $\mathrm{Cu}_{3} \mathrm{Sn}$ to $\mathrm{Cu}_{6} \mathrm{Sn}_{5}$ Layer Thickness

\begin{tabular}{|c|c|c|c|}
\hline $\mathrm{T}\left({ }^{\circ} \mathrm{C}\right)$ & Time (days) & $\begin{array}{c}\text { Cu-100Sn } \\
\text { Samples }\end{array}$ & $\begin{array}{c}\text { Cu-63Sn-37Pb } \\
\text { Samples }\end{array}$ \\
\hline \hline 70 & --- & --- & -- \\
\hline 100 & 350 & 1.02 & 0.00 \\
\hline 135 & 350 & 0.56 & \\
\cline { 2 - 4 } & 400 & & 0.53 \\
\hline 170 & 400 & 1.15 & 0.69 \\
\hline 205 & 200 & 1.6 & $\cdots$ \\
\hline
\end{tabular}




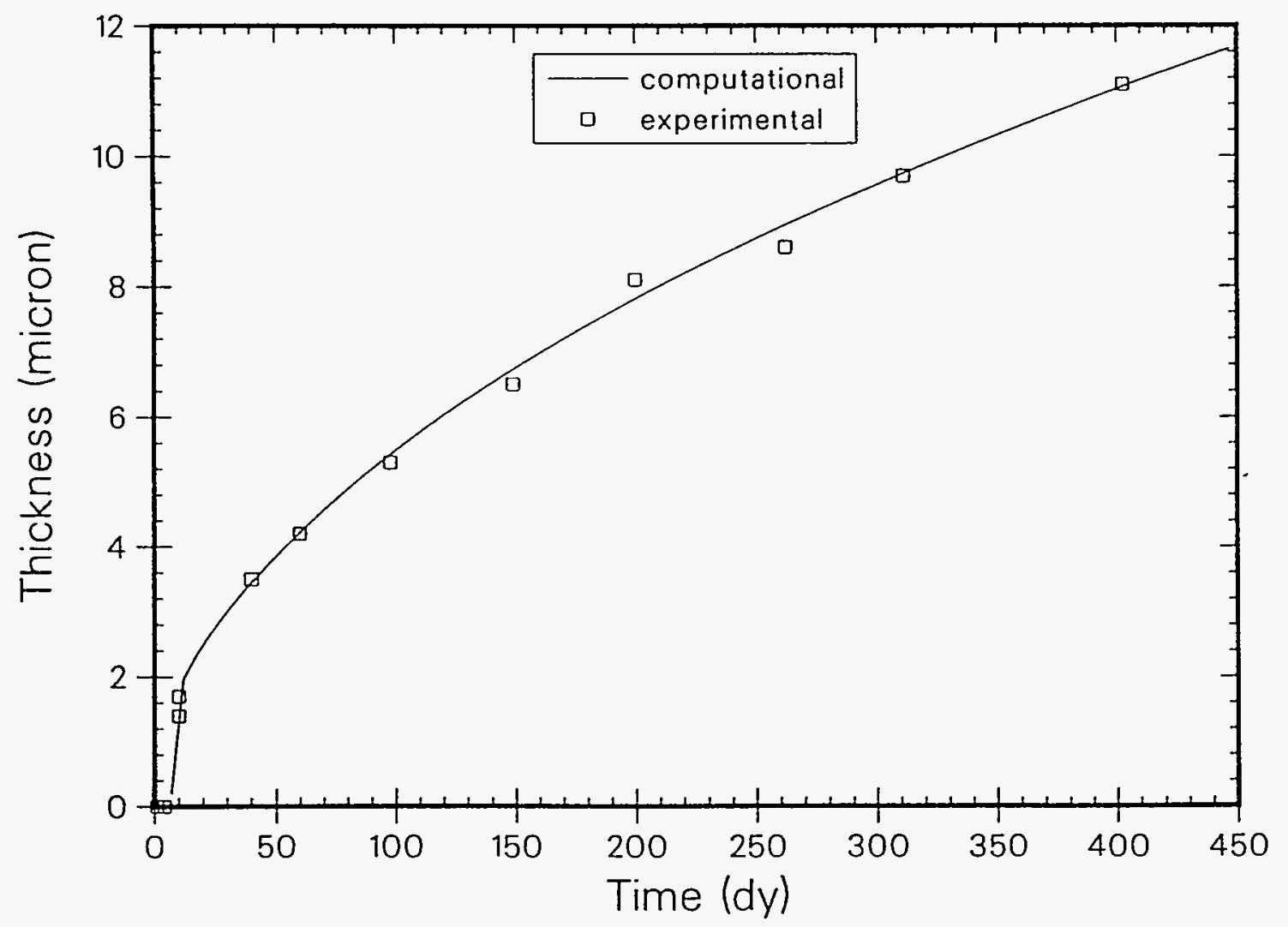

Figure 18. Intermetallic layer thicknesses $(63 \mathrm{Sn}-37 \mathrm{~Pb}$ solder) calculated using a variable diffusion coefficient (Eq. 17) for $\mathrm{Cu}_{3} \mathrm{Sn}$ at $170^{\circ} \mathrm{C}$.

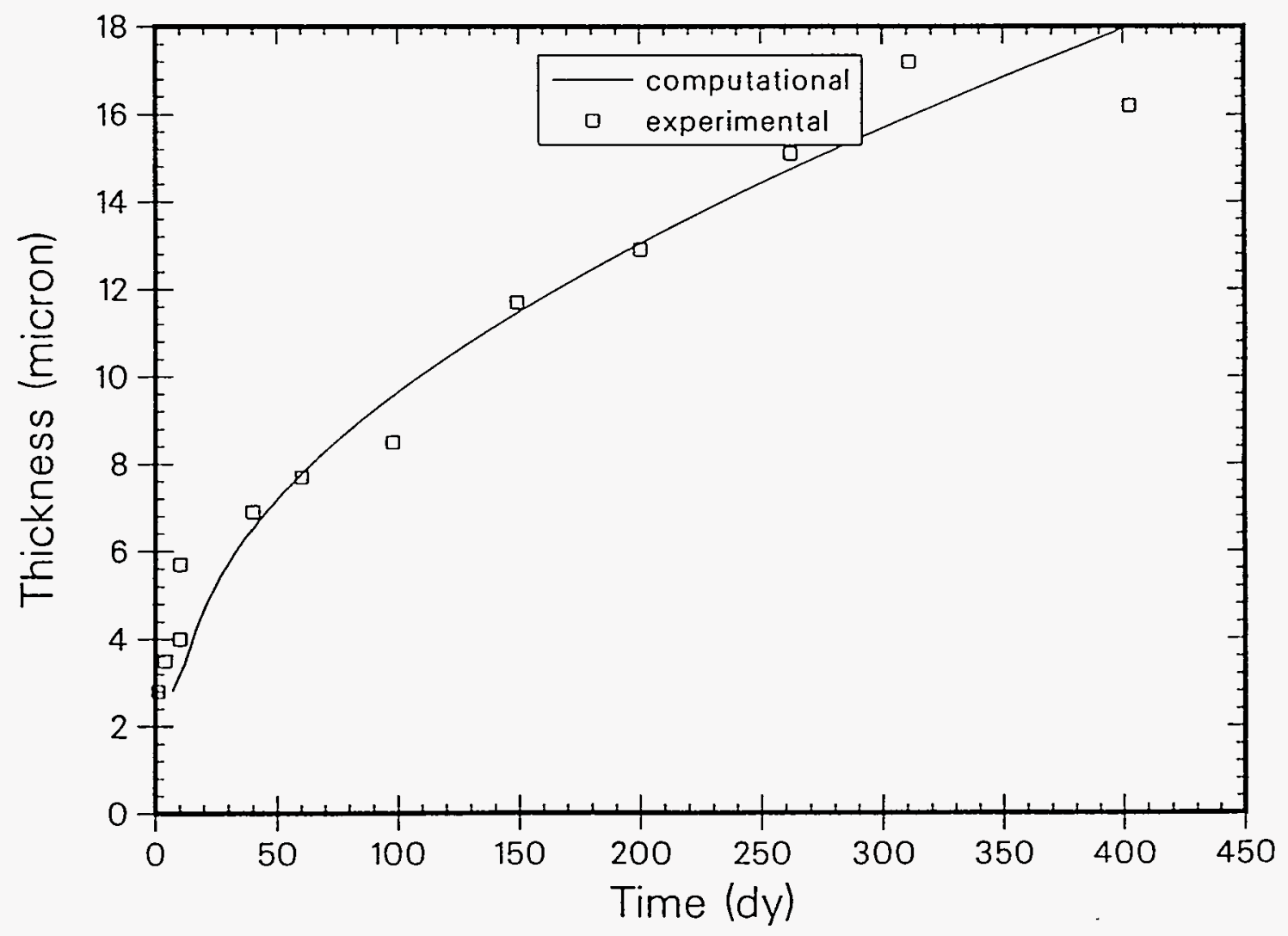

Figure 19. Intermetallic layer thicknesses (63Sn-37Pb solder) calculated using a variable diffusion coefficient (Eq. 17) for $\mathrm{Cu}_{6} \mathrm{Sn}_{5}$ at $170^{\circ} \mathrm{C}$. 


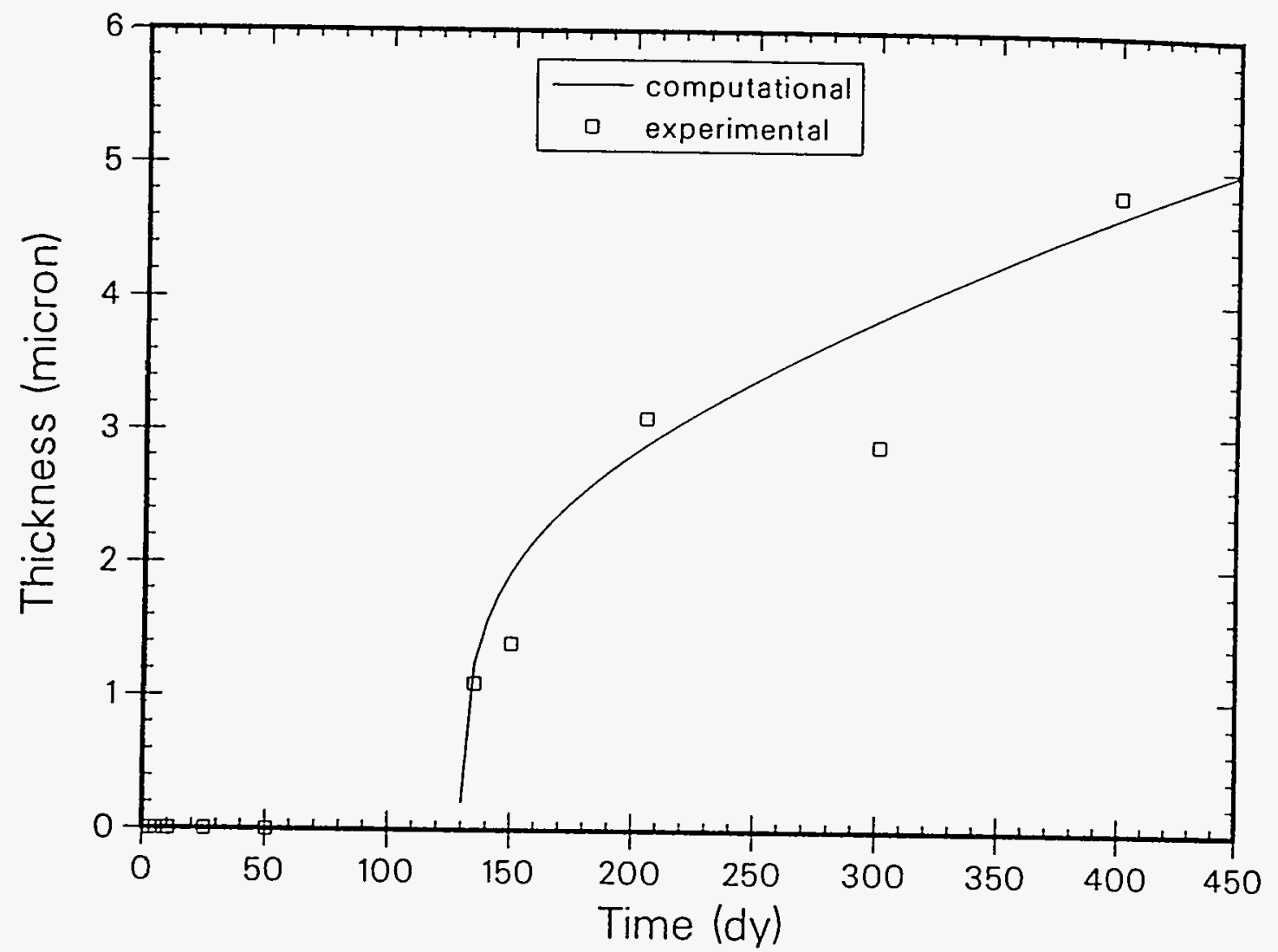

Figure 20. Intermetallic layer thicknesses $(63 \mathrm{Sn}-37 \mathrm{~Pb}$ solder) calculated using a variable diffusion coefficient (Eq. 17) for $\mathrm{Cu}_{3} \mathrm{Sn}$ at $135^{\circ} \mathrm{C}$.

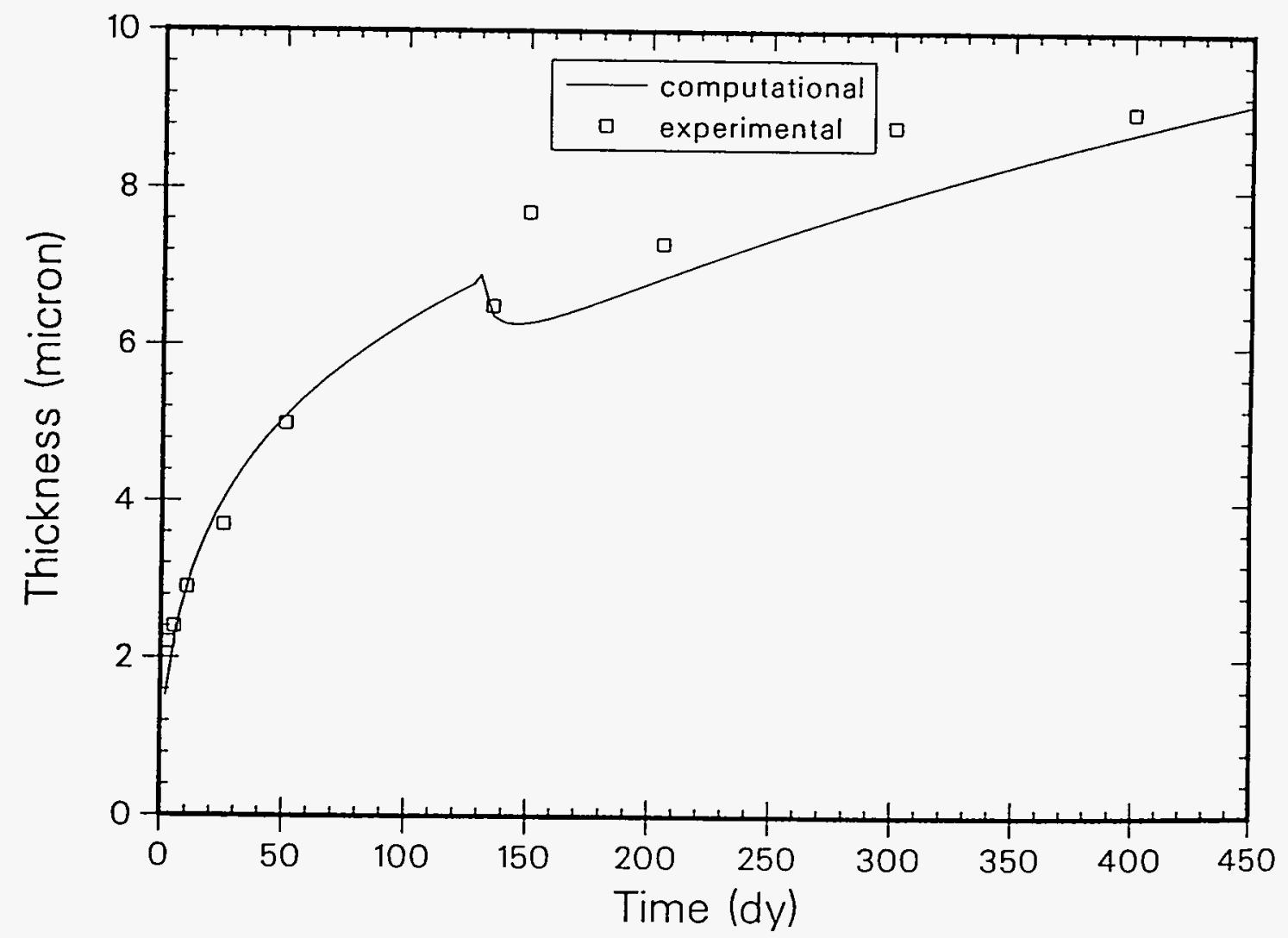

Figure 21. Intermetallic layer thicknesses (63Sn-37Pb solder) calculated using a variable diffusion coefficient (Eq. 17) for $\mathrm{Cu}_{6} \mathrm{Sn}_{5}$ at $135^{\circ} \mathrm{C}$. 


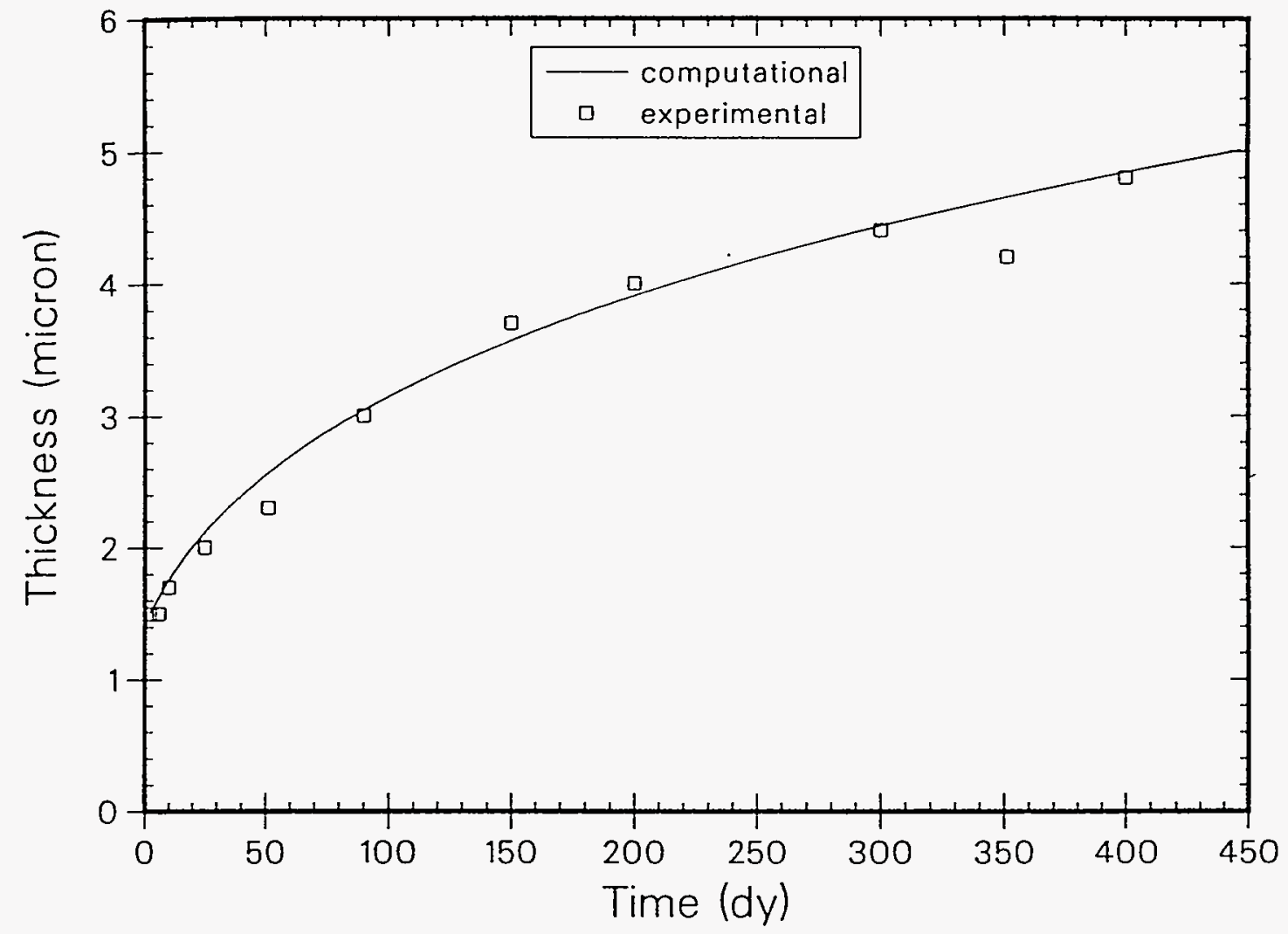

Figure 22. Intermetallic layer thicknesses ( $63 \mathrm{Sn}-37 \mathrm{~Pb}$ solder) calculated using a variable diffusion coefficient (Eq. 17) for $\mathrm{Cu}_{6} \mathrm{Sn}_{5}$ at $100^{\circ} \mathrm{C}$.

Arrhenius plots of the values for $D_{A}$ in the $\mathrm{Cu}_{3} \mathrm{Sn}$ and $\mathrm{Cu}_{6} \mathrm{Sn}_{5}$ layers formed with the $\mathrm{Cu}$ $100 \mathrm{Sn}$ samples are shown in Figs. 23 and 24, respectively, and with the $\mathrm{Cu}-63 \mathrm{Sn}-37 \mathrm{~Pb}$ samples in Figs. 25 and 26. The values for $D_{o}$ and $Q$ in the expression

$$
D_{A}=D_{o} \exp \left(-\frac{Q}{R T}\right)
$$

are given in Table 11 and were calculated using the data at the two highest temperatures (lowest values of $1 / T$ ), because nucleation of $\mathrm{Cu}_{3} \mathrm{Sn}$ occurred very early during layer growth.

Table 11: Arrhenius Parameters

\begin{tabular}{|c|c|c|c|}
\hline Solder & Intermetallic Layer & $\begin{array}{c}D_{o} \\
\left(\mathrm{~cm}^{2} / \text { day }\right)\end{array}$ & $\begin{array}{c}Q \\
(\mathrm{kcal} / \mathrm{mol})\end{array}$ \\
\hline \hline \multirow{2}{*}{$\mathrm{Cu}-100 \mathrm{Sn}$} & $\mathrm{Cu}_{3} \mathrm{Sn}$ & $1.0 \times 10^{4}$ & 23.2 \\
\cline { 2 - 4 } & $\mathrm{Cu}_{6} \mathrm{Sn}_{5}$ & $1.9 \times 10^{3}$ & 21.6 \\
\hline \multirow{2}{*}{$\mathrm{Cu}-63 \mathrm{Sn}-37 \mathrm{~Pb}$} & & & \\
\cline { 2 - 4 } & $\mathrm{Cu}_{3} \mathrm{Sn}$ & 10 & 17.2 \\
\hline
\end{tabular}


An apparent reason for the differences in layer growth and, therefore, diffusion coefficients obtained with $\mathrm{Cu}-100 \mathrm{Sn}$ and $\mathrm{Cu}-63 \mathrm{Sn}-37 \mathrm{~Pb}$ samples is that diffusion in the $\mathrm{Cu}_{6} \mathrm{Sn}_{5}$ layer is more rapid in the $\mathrm{Cu}-63 \mathrm{Sn}-37 \mathrm{~Pb}$ samples than in the $\mathrm{Cu}-100 \mathrm{Sn}$ samples. The results at $170^{\circ} \mathrm{C}$ (Table 9) certainly indicate rapid diffusion in the $\mathrm{Cu}-63 \mathrm{Sn}-37 \mathrm{~Pb}$ sample, although the results at $135^{\circ} \mathrm{C}$ appear to contradict rapid diffusion. However, nucleation of $\mathrm{Cu}_{3} \mathrm{Sn}$ in the $\mathrm{Cu}-63 \mathrm{~Pb}-37 \mathrm{Sn}$ sample occurred relatively late at $135^{\circ} \mathrm{C}$ and could have perturbed layer growth enough to preclude accurate analyses with the current numerical model, since nucleation processes were not specifically included in the model development. Furthermore, some additional considerations also indicate that diffusion in the $\mathrm{Cu}_{6} \mathrm{Sn}_{5}$ layer is faster in the $\mathrm{Cu}-63 \mathrm{Sn}-37 \mathrm{~Pb}$ samples: (l) at $100^{\circ} \mathrm{C}, \mathrm{Cu}_{3} \mathrm{Sn}$ nucleated at long times in the $\mathrm{Cu}-100 \mathrm{Sn}$ samples but did not nucleate in the $\mathrm{Cu}-63 \mathrm{Sn}-37 \mathrm{~Pb} \mathrm{sam}$ ples; (2) also at $100^{\circ} \mathrm{C}$, prior to nucleation of $\mathrm{Cu}_{3} \mathrm{Sn}$, the $\mathrm{Cu}_{6} \mathrm{Sn}_{5}$ layer in the $\mathrm{Cu}-63 \mathrm{Sn}-37 \mathrm{~Pb}$ samples grew faster than the layer in the $\mathrm{Cu}-100 \mathrm{Sn}$ samples; and (3) at $135^{\circ} \mathrm{C}$, the $\mathrm{Cu}_{3} \mathrm{Sn}$ layer nucleates much earlier in the $\mathrm{Cu}-100 \mathrm{Sn}$ samples than in the $\mathrm{Cu}-63 \mathrm{Sn}-37 \mathrm{~Pb}$ samples.

The mechanism for rapid diffusion in the $\mathrm{Cu}_{6} \mathrm{Sn}_{5}$ layer of the $\mathrm{Cu}-63 \mathrm{Sn}-37 \mathrm{~Pb}$ samples was not determined. An obvious possibility is a perturbation caused by trace amounts of $\mathrm{Pb}$ in the $\mathrm{Cu}_{6} \mathrm{Sn}_{5}$ layer; however, Auger depth profiling did not detect $\mathrm{Pb}$ in the $\mathrm{Cu}_{6} \mathrm{Sn}_{5}$ layers. 


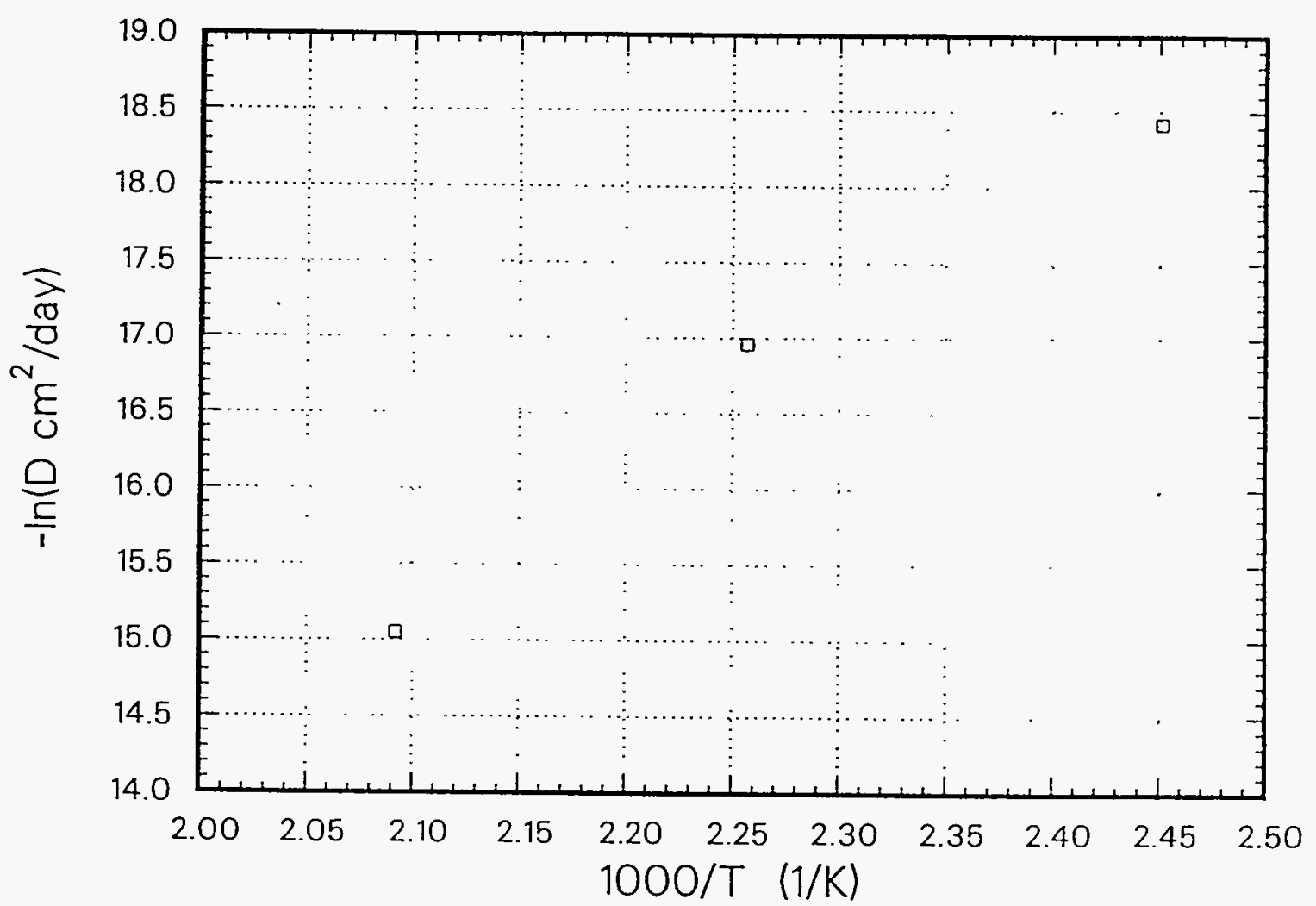

Figure 23. Arrhenius plot for $D_{A}$ in $\mathrm{Cu}_{3} \mathrm{Sn}$ layer (Cu-100Sn).

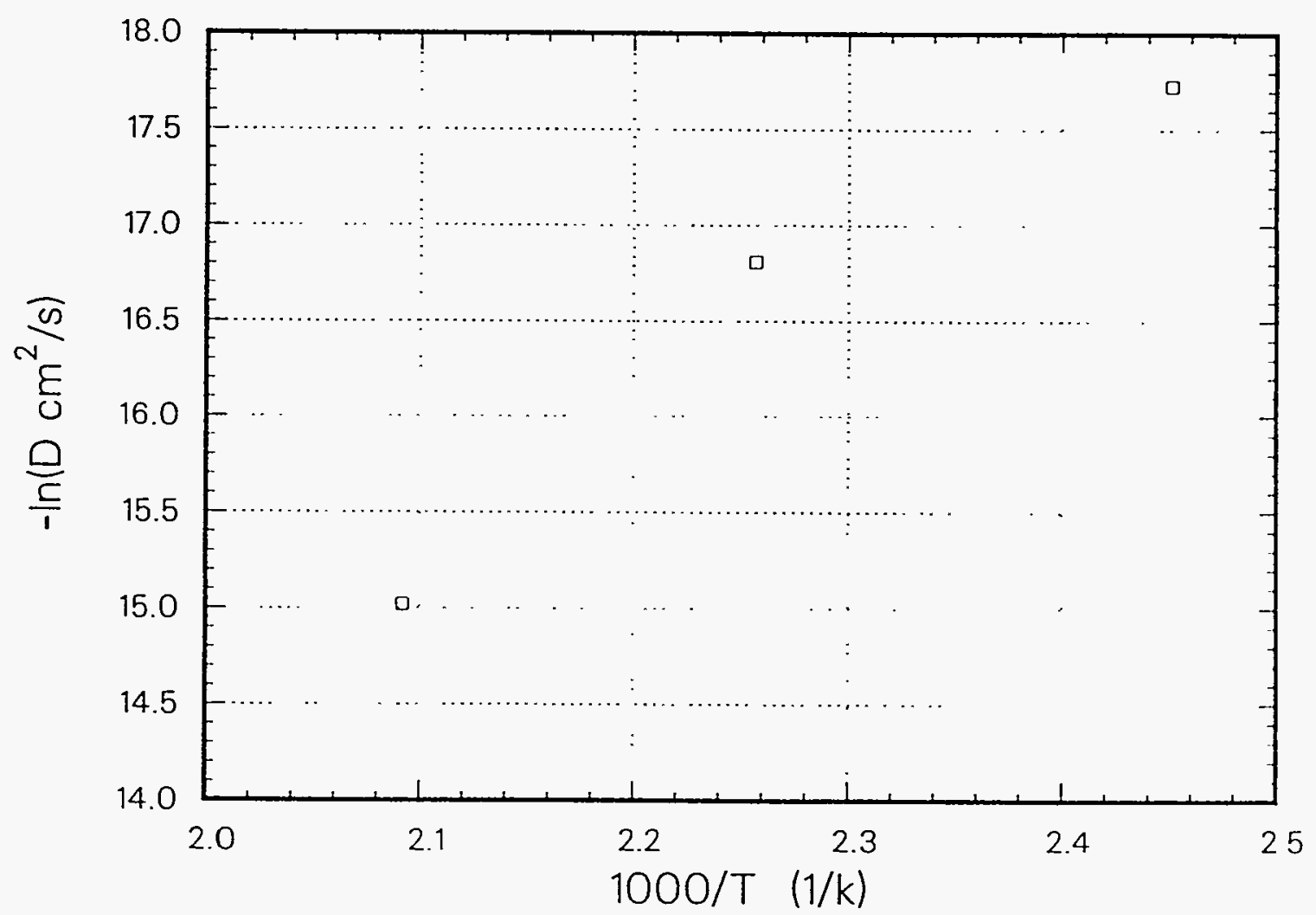

Figure 24. Arrhenius plot for $D_{A}$ in $\mathrm{Cu}_{6} \mathrm{Sn}_{5}$ layer (Cu-10()Sn). 


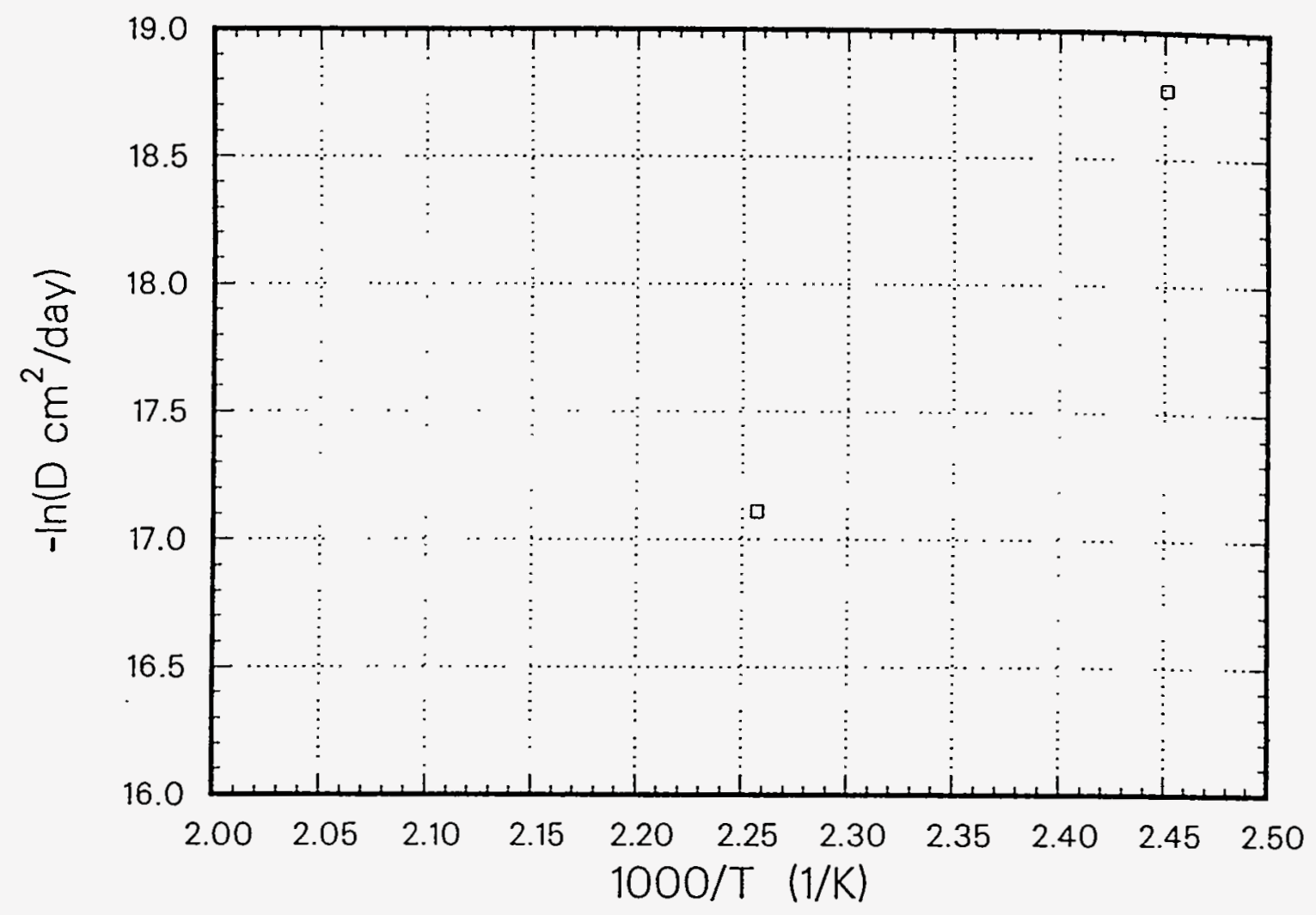

Figure 25. Arrhenius plot for $D_{A}$ in $\mathrm{Cu}_{3} \mathrm{Sn}$ layer $(\mathrm{Cu}-63 \mathrm{Sn}-37 \mathrm{~Pb})$.

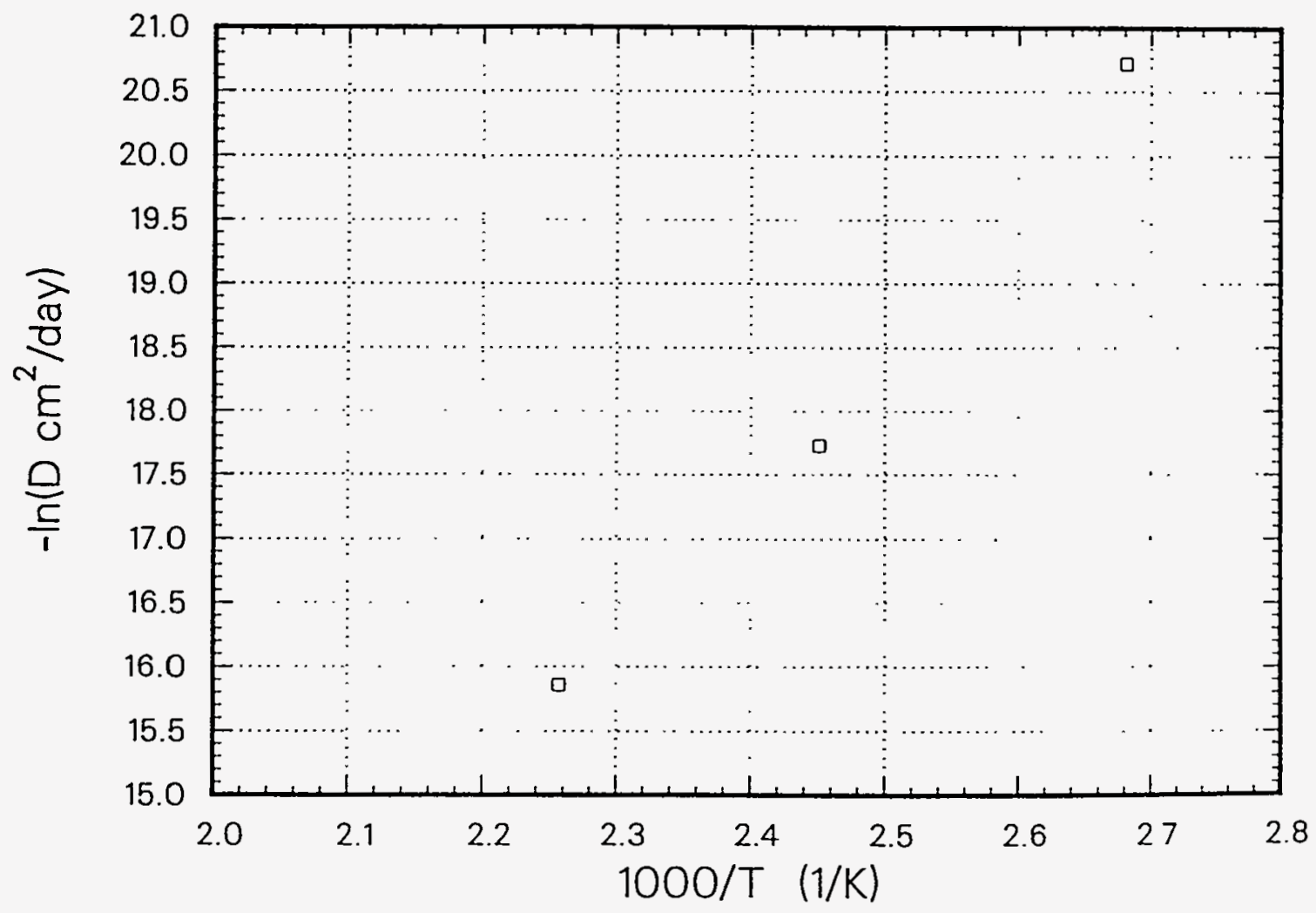

Figure 26.Arrhenius plot for $D_{A}$ in $\mathrm{Cu}_{6} \mathrm{Sn}_{5}$ layer $(\mathrm{Cu}-63 \mathrm{Sn}-37 \mathrm{~Pb})$. 


\subsection{RECOMMENDATIONS FOR FURTHER WORK}

The model and code developed in this work provide tools for analyzing growth of multiple intermetallic layers in one-dimensional systems in which layer growth is primarily controlled by bulk chemical diffusion and (or) interfacial reactions involving two layer-forming constituents. In both commercial and research applications, these conditions often will be satisfied. However, more complex systems are becoming increasingly of interest, and several avenues for further work exist, as illustrated in Fig. 27. These principally consist of extending the current model to include expressions for additional mass transfer mechanisms, equations for multicomponent systems of diffusing, layer forming species, and multidimensional mass transfer and layer growth. These extensions are discussed in more detail below.

Expressions for several mass transfer mechanisms could be added to the current model. The most immediately useful addition would be Arrhenius expressions for the diffusion coefficients $D=D_{o} \exp (-Q / \mathrm{RT})$ and interfacial reaction rate constants $k=k_{o} \exp (-Q / \mathrm{RT})$, which would permit analysis of nonisothermal aging experiments and the prediction of intermetallic growth under nonisothermal service conditions for product reliability analyses. Other mass transfer mechanisms which can be added to the current model and could be important in reliability analyses and basic materials science and engineering studies include: (1) multiple chemical diffusion mechanisms (such as substitutional, interstitial, etc.), (2) concentration and stress dependent diffusion coefficients, (3) grain boundary diffusion, (4) stress-induced diffusion, and (5) thermally-induced diffusion. These mechanisms, particularly (2-5), can be especially important in analyzing or predicting intermetallic layer growth in situations involving thermal and (or) mechanical cycling during which large temperature or stress gradients exist and may be timedependent.

While the current model is limited to diffusion of two layer forming species, the governing equations can be expanded to include diffusion of additional trace constituents (say one to three species). This extension would be useful in examining the possible effects of contaminants on intermetallic layer growth and the formation of interfacial defects due to contaminant accumulation, which can have substantial impact on joint integrity and reliability.

Although the emphasis in this work has been on aging studies and intermetallic growth during service, the model can also be applied to intermetallic growth during several processing applications, which will often involve a melt layer. For analyses involving a melt layer, the model should incorporate temperature-dependent interfacial concentrations (to account for a temperature dependent solubility of the diffusing species in a melt layer). Heat conduction equations with latent heat and energy of reaction terms also should be added to account for solidification and energy generation due to intermetallic formation. These additions would also be valuable for modeling the combustion of gasless pyrotechnics such as thermites.

Also, further work can be done to develop approximate expressions for incorporating the effects of phase nucleation and coalescence; enhanced diffusion during early layer growth could be addressed in more detail, and for ionic systems, the interaction between the electric field and the diffusing ionic species could be included. Since the mechanisms for enhanced diffusion are somewhat obscure, a more detailed treatment of this phenomena must be approached with complementary experimental work. The effects of nucleation, particularly when examining criteria for when nucleation will occur, will require a similar approach. 


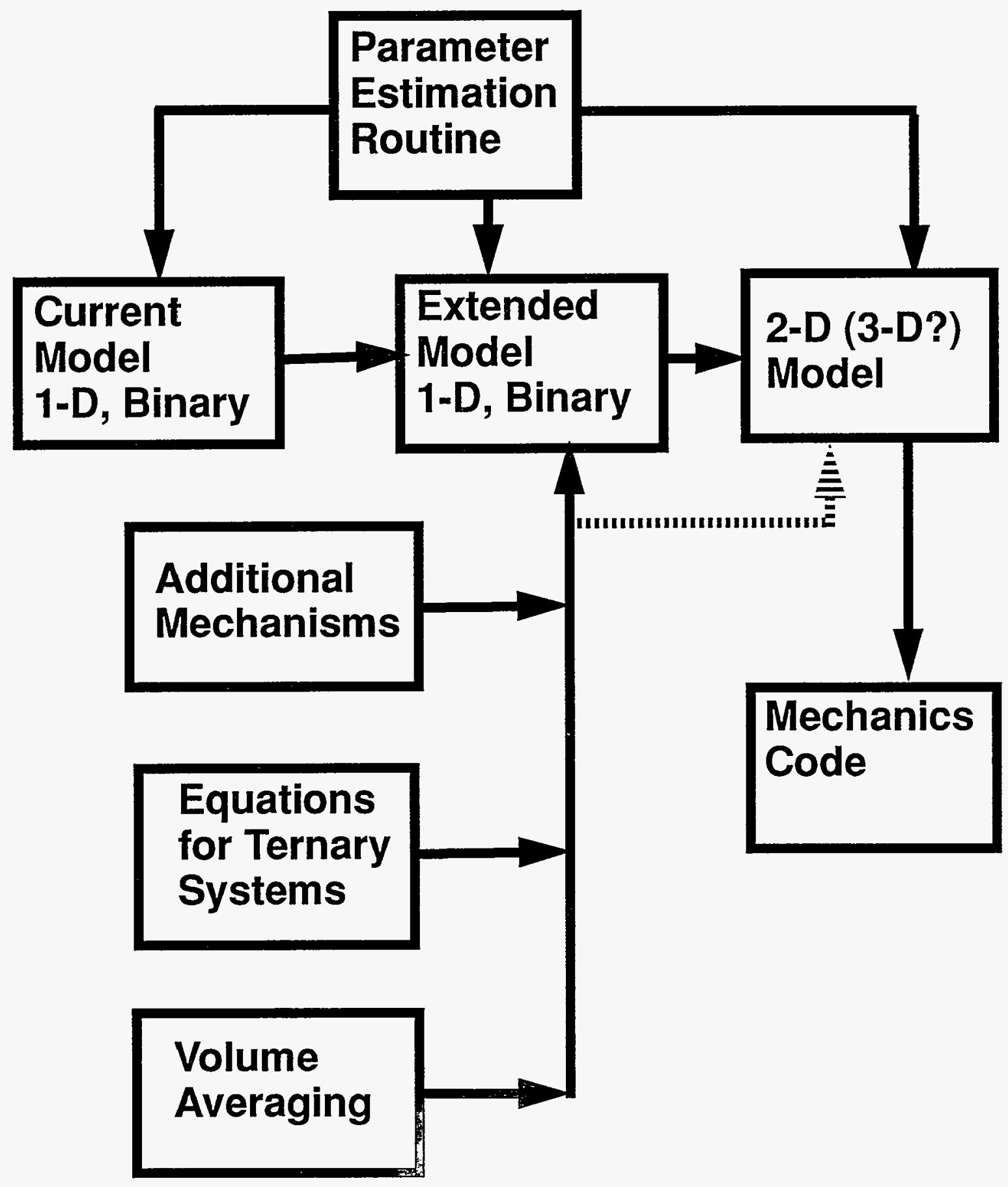

Figure 27. Schematic diagram showing recommendations for future work. 
Extension of the governing equations to ternary systems of the layer forming species could have broad applications in the joining of advanced materials, such as braze joints involving metals and ceramics. However, since the chemistry and geometry of intermetallic formation in ternary systems is often complex, care would be needed in formulating equations and defining criteria for their application. Also, volume averaging techniques should be investigated for application to complex geometries involving dispersed and (or) very irregularly shaped intermetallic phases. One probable situation is a very irregularly shaped intermetallic layer between two otherwise relatively uniform bulk materials. Here, volume averaging could be applied to an interfacial region, which is then coupled to the bulk regions using appropriately derived boundary conditions. A second probable situation involves a dispersed phase having a relatively simple geometry. Here, the interface is treated as in the current model, and volume averaging would be applied to the bulk material.

Development of a 2-D code based on the method of lines appears feasible. The extension to complex 2-D, and 3-D, geometries would probably require finite element techniques. The extension to at least 2-D would have considerable value with respect to the geometries that could be modeled as well as addressing phenomena, such as nucleation and density change accompanying intermetallic formation, that cannot adequately be addressed in 1-D. Nucleation and coalescence is inherently at least a 2-D process, although simplifying assumptions can always be attempted. Likewise, density changes that occur as a result of intermetallic formation usually require at least a 2-D description. Density changes will also cause stress and strain effects and are inherently coupled with the mechanical properties of the intermetallic layers and bulk materials. The effects of density changes can severely impact joint integrity and reliability. Density changes can result in severe stress, such as expansion of a growing layer at an internal corner, and can also result in void formation, which seriously affects the fracture toughness of brittle materials such as ceramics.

To adequately model the effects of density changes, a 2-D intermetallic growth code would have to be loosely coupled to a solid mechanics code. In addition to analyzing the effects of density change due to reaction, the coupling would provide the means for analyzing the combined effects of intermetallic growth, thermal stress, and work failure (fatigue), which could be particularly important to the reliability of joints in systems involving thermal and mechanical cycling, especially if large temperature and stress gradients occur.

Finally in terms of analyzing experimental data, an extremely valuable addition to the current code and to any codes developed in future work would be a parameter estimation routine to determine the parameters giving the "best" fit to experimental data. In fact the most immediate progress would be made by extending the current code to include Arrhenius expressions for the diffusion coefficients and interfacial rate constants and then coupling the resulting code with a parameter estimation routine. 


\subsection{CONCLUSIONS}

A model describing the diffusion-controlled growth of multiple intermetallic layers and the displacement of the interfaces between layers was developed and implemented in a one-dimensional computer code based on the method-of-lines. The model can accommodate problems, which cannot be modeled analytically, involving: (1) finite initial layer thicknesses, (2) rate-limiting interfacial reactions, (3) multiple and variable diffusion coefficients, and (4) finite material boundaries. Additionally, the effects of nucleation can be modeled empirically. A transformation of the spatial coordinate circumvented the need to remesh the growing and (or) shrinking layers. Results from the one-dimensional code were verified by comparing the numerical results with analytical solutions for simple systems involving two, three, and five layers. The computer code was applied to analysis of the intermetallic layer growth that occurred in solder aging experiments that were done with $100 \mathrm{Sn}$ and $63 \mathrm{Sn}-37 \mathrm{~Pb}$ solders. The $\mathrm{Cu}-63 \mathrm{Sn}-37 \mathrm{~Pb}$ couples were aged for 1 to 400 days at temperatures of $70,100,135$, and $170^{\circ} \mathrm{C}$. The $\mathrm{Cu}-100 \mathrm{Sn}$ samples were aged similarly, except that annealing treatments were also done at $205^{\circ} \mathrm{C}$. Two intermetallic layers, $\mathrm{Cu}_{3} \mathrm{Sn}$ and $\mathrm{Cu}_{6} \mathrm{Sn}_{5}$, were observed. Some differences between the thickness of the intermetallic layers formed with $100 \mathrm{Sn}$ and $63 \mathrm{Sn}-37 \mathrm{~Pb}$ solders were observed. At higher temperatures, the total thickness of the layers were similar, but the ratio of the thicknesses of the $\mathrm{Cu}_{3} \mathrm{Sn}$ to the $\mathrm{Cu}_{6} \mathrm{Sn}_{5}$ layer differed significantly.

The analysis of the experimental data demonstrated that numerical modeling can be a valuable tool in the investigation of intermetallic layer growth. The results indicated that intermetallic layer growth was consistent with a bulk diffusion mechanism involving $\mathrm{Cu}$ and (or) $\mathrm{Sn}$ and variable diffusion coefficients that reflected enhanced diffusion during early layer growth. The enhanced diffusion can be accounted for empirically using a variable diffusion coefficient that is a function of layer thickness. Such effects are important when using data from short term isothermal experiments to evaluate diffusion coefficients to be used for predicting long-term layer growth under nonisothermal service conditions. The effects of enhanced diffusion are also important when trying to predict the nucleation of additional phases during growth of the original layers. A satisfactory explanation for the difference between intermetallic layer growth that was observed with $100 \mathrm{Sn}$ and $63 \mathrm{Sn}-37 \mathrm{~Pb}$ solder was not established. Diffusion in the $\mathrm{Cu}_{6} \mathrm{Sn}_{5}$ layer appeared to be faster with $63 \mathrm{Sn}-37 \mathrm{~Pb}$ samples than with $100 \mathrm{Sn}$ samples. The faster diffusion may have been due to trace amounts of $\mathrm{Pb}$ perturbing the layer, although the presence of $\mathrm{Pb}$ could not be confirmed by Auger depth profiling and electron microprobe analysis.

Several commercially relevant avenues for further work exist. These principally consist of extending the current model to include expressions for additional mass transfer mechanisms, equations for multicomponent systems of diffusing, layer forming species, and multidimensional mass transfer and layer growth. Expressions for several mass transfer mechanisms could be added to the current model. The most immediate progress would be made by extending the current code to include Arrhenius expressions for the diffusion coefficients and interfacial rate constants and then coupling the resulting code with a parameter estimation routine. 


\subsection{ACKNOWLEDGMENTS}

The authors gratefully acknowledge the technical assistance provided by M. R. Baer and J. R. Torczynski of Sandia National Laboratories. We also want to thank J. A. Regent for preparing the diffusion couple samples; A. Kilgo for metallographic sample preparation and intermetallic compound thickness measurements, and R. Grant with P. Hlava for performing the computational analysis of the IMC layers. The review of this document by R. E. Hogan and M. A. Dvorack is also greatly appreciated. 


\subsection{REFERENCES}

Baer, M. R., Benner, R. E., Gross, R. J., and Nunziato, J. W., "Modeling and Computation of Deflagration-to-Detonation Transition (DDT) in Reactive Granular Materials", Lectures in Applied Mechanics, V. 24, 1986.

Cannon, J. R., Douglas, J. Jr., and Hill, C. D., “A Multi-Boundary Stefan Problem and the Disappearance of Phases," Journal of Mathematics and Mechanics (1967) 17, 1, 21-33.

Carslaw, H. S. and Jaeger, J. C., Heat Conduction in Solids, 2nd ed., Clarendon Press, Oxford 1959.

Chadam, J. M. and Rasmussen, H., eds., Emerging Applications in Free Boundary Problems, John Wiley \& Sons, Inc., New York, 1993a.

Chadam, J. M. and Rasmussen, H., eds., Free Boundary Problems Involving Solids, John Wiley \& Sons, Inc., New York, 1993b.

Crank, J., The Mathematics of Diffusion, Clarendon Press, Oxford, 1975.

Crank, J., Free and Moving Boundary Problems, Clarendon Press, Oxford, 1988.

Duda, J. L., Malone, M. F., and Notter, R. H., "Analysis of Two-Dimensional Diffusion-Controlled Moving Boundary Problems," Int. J. Heat Mass Transfer (1978) 18, 901-912.

Friedman, A., "Free Boundary Problems for Parabolic Equations I. Melting of Solids," Journal of Mathematics and Mechanics (1959) 8, 4, 499-517.

Friedman, A., "Free Boundary Problems for Parabolic Equations II. Evaporation or Condensation of a Liquid Drop," Journal of Mathematics and Mechanics (1960) 9, 1, 19-66.

Friedman, A., Partial Differential Equations of Parabolic Type, Prentice-Hall, Inc., Englewood Cliffs, N. J., 1964.

Gross, R. J., Baer, M. R., and Hobbs, M. L., XCHEM-1D A Heat Transfer/Chemical Kinetics Computer Program for Multilayered Reactive Materials, SAND93-1603, Sandia National Laboratories, Albuquerque, N. M., 1993.

Hindmarsh, A. C., ODE Solvers for Use with the Method-of-Lines, UCRL-85293 (Rev. 1), Lawrence Livermore National Laboratory, Livermore, California, 1981.

Hyman, J. M., Method of Lines Approach to the Numerical Solution of Conservation Laws, LAUR-79-837, (Los Alamos Scientific Laboratory, Los Alamos, N. M.: 1979).

Jost, W., Diffusion in Solids, Liquids, Gases, Academic Press, New York, 1960, pp. 69-75.

Kofstad, P., High Temperature Oxidation of Metals, John Wiley \& Sons, Inc., New York, 1966, pp. $140-144$. 
Meyer, G., "Multidimensional Stefan Problems," SIAM J. Numer. Anal., (June 1973) 10, 2, 522538 .

Meyer, G. H. "An Application of the Method of Lines to Multidimensional Free Boundary Problems." J. Inst. Maths. Applics. (1977) 20, 317-329.

Meyer, G. H., "The Numerical Solution of Stefan Problems with Front-Tracking and Smoothing Methods," Applied Mathematics and Computation, (1978) 4, 283-306.

Miranker, W. L. and Keller, J. B., "The Stefan Problem for a Nonlinear Equation," Journal of Mathematics and Mechanics, (1960) 9, 1, 67-70.

Ockendon, J. and Hodgkins, W. eds., Moving Boundary Problems in Heat Flow and Diffusion, Clarendon, Oxford, 1974.

Rubenstein, L. I., The Stefan Problem, American Mathematical Society, Providence, Rhode Island, 1971.

Shampine, L. F. and Watts, H. A., DEPAC-Design of a User Oriented Package of ODE Solvers, SAND79-2374, Sandia National Laboratories, Albuquerque, N. M., 1980.

Shamsunder, N. and Sparrow, E. M., "Analysis of Multidimensional Conduction Phase Change via the Enthalpy Model," Journal of Heat Transfer, (August 1975) 333-340.

Tu, K. and Thompson, R., Acta Metall., (1982) 30, 947.

Wheeler, J. ed., Diffusion in Body-Centered Cubic Metals, ASM, Metals Park, Ohio, 1965, pp.5256.

Wolfram, S., Mathematica: a system for doing mathematics by computer, 2nd ed., Addison-Wesley, Redwood City, California, 1991. 


\section{APPENDIX A: Marker Layers}

The use of marker layers at the solder-substrate interface would allow for determining the absolute movement of the various interfaces during growth of the intermetallic compound layer. The marker is typically a thin film layer deposited at the interface and which does not react with either of the members of the diffusion couple (in this case, the solder and the substrate material) so that the position of the original interface can be maintained as a reference point. Marker layers have been used in diffusion studies of vapor deposited multilayer thin films, the marker layers, themselves, being thin films, as well (Tu and Thompson,1982). Diffusion studies between bulk materials have used refractory metal wires to denote movement of the interface(s) (Wheeler,1965). The use of marker layers in solder-substrate diffusion couples would provide a method of determining the diffusion mechanism(s) responsible for the growth of interfacial intermetallic layers.

The selection of the marker layer material was based upon several requirements. First, the material had to be deposited by evaporation techniques to thicknesses of greater than one micron (which is relatively thick by thin-film evaporation standards) in order to be visible for later reference. A non-precious metal material was favored, due to the extent of lost metal by this technique. The metal had to be adherent to the substrate metal (oxygen-free, high-conductivity OFHC copper) and remain so after deposition. Therefore, the residual stresses in the film, at those thicknesses, had to be minimal. Secondly, the layer had to be wetted by the molten solder, yet not be dissolved by the solder. Finally, the marker layer should not react during the solid state diffusion process so that the interface position would remain accessible.

Preliminary trials to find a suitable marker film were performed on OFHC copper tabs $6.35 \mathrm{x}$ $6.35 \times 1.60 \mathrm{~mm}$. One surface of the tab was optically polished. Two tabs were cleaned by: (1) solvent degreasing; (2) 1-minute etch in 1:1 HCL: $\mathrm{H}_{2} \mathrm{O}$ solution: and (3) rinsed with water and alcohol. Next, the substrate was coated with Blackstone ${ }^{\text {TM }} 642$ flux and immersed into a pot of molten $100 \mathrm{Sn}$ at $270^{\circ} \mathrm{C}$ to provide the fused coating. Finally, the samples were cleaned of any flux residues.

The durability of the marker layer to heat treatments used in the solid state aging studies had to be assessed. Therefore, one of the coated tabs was air annealed at $170^{\circ} \mathrm{C}$ for 10 days and the other at $205^{\circ} \mathrm{C}$ for the same period. Upon completion of the annealing process, the tabs were cross sectioned across the marker layer, and one-half was mounted and polished for metallographic examination of the marker film.

Several marker layer systems were initially identified, primarily from barrier layer studies on copper. The first two systems included: (1) $800 \mathrm{~nm} \mathrm{TiN}+2000 \mathrm{~nm} \mathrm{Cu}$ (top), and (2) $200 \mathrm{~nm} \mathrm{TiN} \mathrm{+}$ $1000 \mathrm{~nm} \mathrm{Ni}+2000 \mathrm{~nm} \mathrm{Cu}$. The TiN and TiN + Ni formed the marker layers, respectively, while the copper layer served as the solderable finish in order to promote wetting by the molten tin. The $\mathrm{TiN}$ layer was sputtered deposited; the $\mathrm{Ni}$ and $\mathrm{Cu}$ layers were evaporation deposited. The two layer systems demonstrated excellent adhesion to the copper. The samples were then electroplated with copper $(0.038 \mathrm{~mm})$ to form the second layer to which the tin would wet. In this case, the marker layers would have been buried and themselves, not be contacted by the molten tin. The markers survived the electroplating process. However, the marker film exhibited cracking after hot dipping in the molten bath, prior to aging. 
The next two systems that were examined included: (1) $3 \mathrm{~nm} \mathrm{Al}+1000 \mathrm{~nm} \mathrm{Cu}$, and (2) $3000 \mathrm{~nm} \mathrm{Al}$. The films adhered very well to the copper. However, they did not survive the hot dipping operation.

Film systems were developed using nickel as the marker layer, owing to its reduced propensity for dissolution onto the molten tin. Two systems were attempted: (1) $1500 \mathrm{~nm} \mathrm{Ni}+3000 \mathrm{~nm}$ $\mathrm{Au}$, and (2) $3000 \mathrm{~nm} \mathrm{Ni}+3000 \mathrm{~nm} \mathrm{Au}$. The gold served to protect the nickel layer from excess oxidation, thereby maintaining its solderability. The latter system did not survive the deposition process; the nickel layer spalled from the copper surface due to an excess of residual stresses (which are common in thick, nickel films). The system (1) showed no spalling. When the samples were hot dipped in solder and later cross sectioned (prior to the aging treatment), the markers were clearly visible with excellent wetting by the tin (i.e., no voids were present). This system was developed too late to be used in an aging study. However, the selected marker system is $1500 \mathrm{~nm} \mathrm{Ni}+3000 \mathrm{~nm} \mathrm{Cu}$.

Lastly, fixtures and aperature masks were designed and fabricated which would allow for the deposition of the marker strips on copper plates measuring $38 \times 38 \times 3.2 \mathrm{~mm}$ in order to fabricate a large number of samples at the same time. In addition, a technique was developed to fabricate said samples with a controlled amount of tin coating. The specific tin coating thicknesses were 7.6 microns, 20 microns, 25 microns, and 41 microns. This technique would provide the quantitative growth data of the intermetallic layer as a function of available tin from which to further refine the computer models. 


\section{APPENDIX B: The Interface as the Frame of Reference}

If $\delta_{i}(t)$ is used as the frame of reference for diffusion, then for $\delta_{i}(t)<x<\delta_{i+1}(t)$, the material balance (diffusion) equation corresponding to Eq. 2 is

$$
\frac{\partial w_{A_{i}}}{\partial t}=\frac{\partial}{\partial x}\left(D_{A_{i}} \bar{\partial}_{A_{i}}\right)+\frac{d \delta_{i}}{d t} \frac{\partial w_{A_{i}}}{\partial x}
$$

and at $\delta_{i}(t)$, the interface displacement equation corresponding to Eq. 8 is

$$
\rho_{i-1}\left(w_{A_{i-1}}\right)_{\delta_{i}^{l}}\left(\frac{d \delta_{i}}{d t}\right)=\left(\begin{array}{c}
\left.\left(\rho_{i-1}\right)\left(w_{A_{i-1}}\right)_{\delta_{i}^{l}}\left(\frac{d \delta_{i-1}}{d t}\right)\right) D_{A_{i-1}}\left(\frac{\left.\partial w_{A_{i-1}}\right)_{\delta_{i}^{l}}}{\left(\rho_{i-1}\right.}+\right. \\
\rho_{i} D_{A_{i}}\left(\frac{\partial w_{A_{i}}}{\partial x}\right)_{\delta_{i}^{r}}
\end{array}\right.
$$

Let

and

$$
\bar{x}_{i}=\frac{x-\delta_{i}(t)}{\Delta_{i}(t)}
$$

$$
\Delta_{i}(t)=\delta_{i+1}(t)-\delta_{i}(t)
$$

Then, for $\delta_{i}<x<\delta_{i+1}$, or $0<\bar{x}_{i}<1$,

$$
\bar{\partial}_{A_{i}}=\frac{1}{\Delta_{i}^{2}} \frac{\partial}{\partial x}\left(D_{A_{i}} \bar{\partial}_{A_{i}}\right)+F\left(\bar{x}_{i}, \delta_{i}, \Delta_{i}\right) \frac{\partial w_{A_{i}}}{\partial \bar{x}}
$$

where

$$
F\left(\bar{x}_{i}, \delta_{i}, \Delta_{i}\right)=\frac{\bar{x}_{i} d \Delta_{i}}{\Delta_{i}} \overline{d t}
$$

At $x=\delta_{i}(t)$, 


$$
\begin{aligned}
& \rho_{i-1}\left(w_{A_{i-1}}\right)_{\bar{x}_{i-1}=1}\left({\frac{d \delta_{i-1}}{d t}}^{i-1}-\right. \\
& \rho_{i-1}\left(w_{A_{i-1}}\right)_{\bar{x}_{i-1}=1}\left(\frac{d \delta_{i}}{d t}\right)=\frac{\rho_{i-1} D_{A_{t-1}}}{\Delta_{i}}\left({\frac{\partial w_{A_{i-1}}}{\partial x}}_{\tilde{x}_{i-1}=1}+\right. \\
& \frac{\rho_{i} D_{A_{i}}}{\Delta_{i}}\left(\frac{\partial w_{A_{i}}}{\partial x}\right)_{\bar{x}_{i}=0}
\end{aligned}
$$

When all $\delta_{\mathbf{i}}(0)=0$, Eqs. B-1 and B-2 can be solved analytically, similarly to Eqs. 2 and 8 , using the constant concentration (local equilibrium at the interface) boundary conditions corresponding to Eqs. 3 and 4 . For $\delta_{i}<x<\delta_{1+1}$, or $0<\bar{x}_{i}<1$,

$$
w_{A_{i}}=\left(w_{A_{i}}\right)_{\delta_{i}^{r}}-\left[\left(w_{A_{i}}\right)_{\delta_{i}^{r}}-\left(w_{A_{i}}\right)_{\delta_{i+1}^{\prime}}\right] \frac{\left.\operatorname{erf}\left(\eta_{i}\right)_{\operatorname{erf}\left(\gamma_{i-1}^{\prime}\right.}\right)}{\operatorname{erf}}
$$

where

$$
\begin{aligned}
& \eta_{i}=\frac{x-\delta_{i}(t)}{2 \sqrt{D_{A_{i}}}} \\
& \delta_{i}(t)=\delta_{i-1}(t)+\Delta_{i}(t) \\
& \Delta_{i}(t)=\delta_{i}(t)-\delta_{i-1}(t)=2 \gamma_{i}^{\prime} \cdot \sqrt{D_{A_{i}}{ }^{t}} \\
& \gamma_{i}^{\prime}=\frac{1}{\sqrt{\pi}}\left[\frac{\left(w_{A_{i-1}}\right)_{\delta_{i-1}^{r}}-\left(w_{A_{t-1}}\right)_{\delta_{i}^{\prime}}}{\left(w_{A_{i-1}}\right) \delta_{i}^{l}}\right]\left(\frac{\exp \left(-\gamma_{i}^{\prime 2}\right)}{\operatorname{erf}\left(\gamma_{i}^{\prime}\right)}\right) \\
& -\frac{1}{\sqrt{\pi}}\left[\frac{\left(w_{A_{i}}\right)_{\delta_{i}^{r}}-\left(w_{A_{i}}\right)_{\delta_{i+1}^{l}}}{\left(w_{A_{i-1}}\right)_{\delta_{i}^{l}}}\right]\left(\frac{\sqrt{\phi_{i}}}{\operatorname{erf}\left(\gamma_{i+1}^{\prime}\right)}\right)
\end{aligned}
$$

and

where $\phi_{i}$ is defined by Eq. 29. Since Eq. B-12 involves only $\gamma_{i}$ and $\gamma_{i+1}$, the evaluation of $\gamma_{i}$ is 
much easier than in the case of Eq. 32. The numerical solution of Eqs. B-5 and B-7 was compared with the analytical solution given by Eqs. B-8 through B-12 for systems involving 2, 3, and 5 layers. The numerical results were in good agreement with the analytical results as shown in Fig. B1 , which compares the numerical and analytical results for a five-layer system. The parameter valwes used in the calculations shown in Fig. B-1 are given in Table B-1.

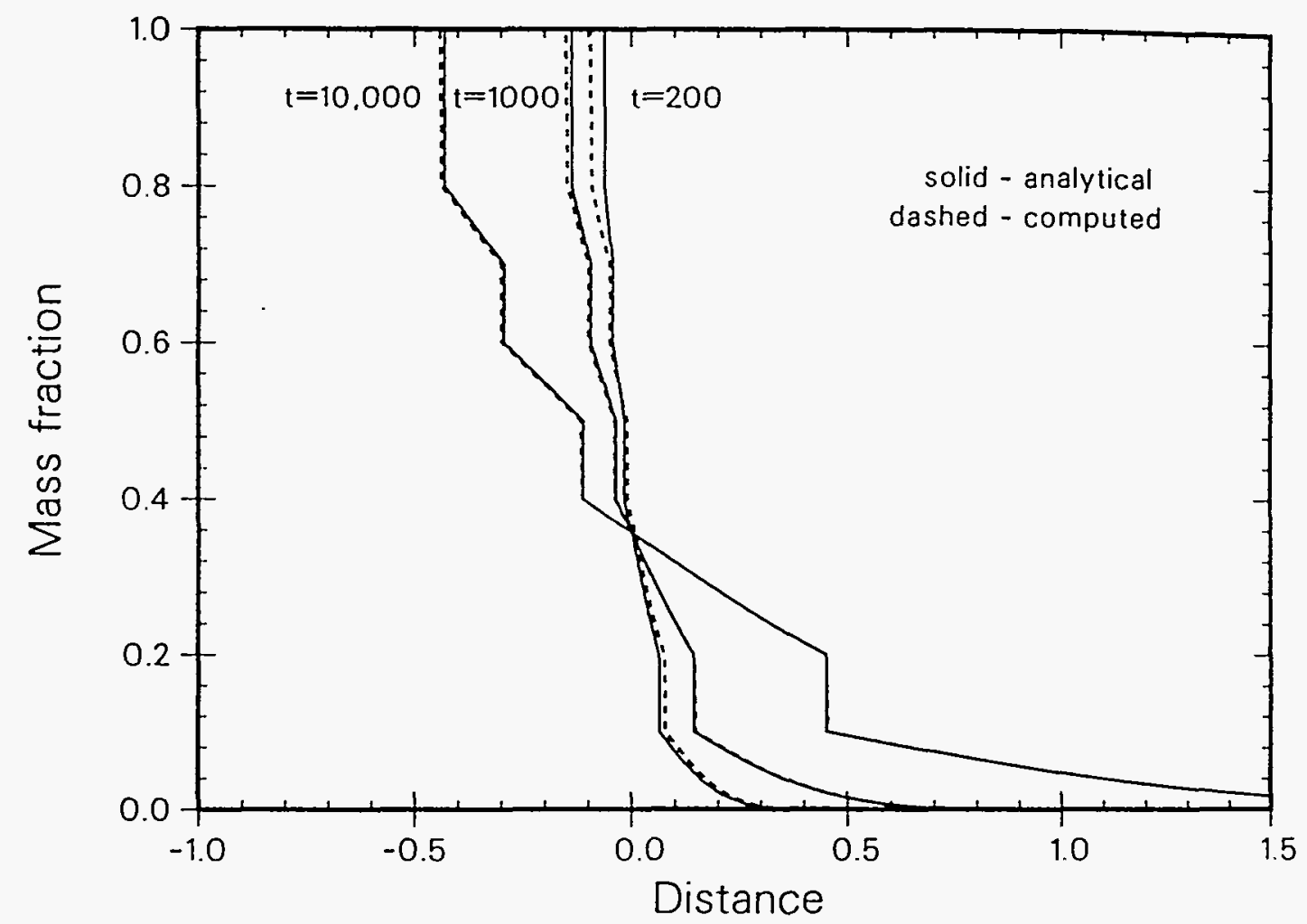

Figure B-1. Comparison of analytical and numerical solutions, using $\delta_{i}(t)$ as the frame of reference.

Table B-1: Parameter Values for Comparison of Analytical and Numerical Solutions, using $\delta_{i}(t)$ as the frame of reference

\begin{tabular}{|c|c|c|c|c|c|}
\hline Layer & $\left(w_{A_{1}}\right)_{i}$ & $\left(w_{A_{1}}\right)_{\delta_{1+1}^{\prime}}$ & $\begin{array}{c}\rho_{i} \\
\left(\mathrm{~g} / \mathrm{cm}^{3}\right)\end{array}$ & $\begin{array}{c}D_{i} \times 10^{5} \\
\left(\mathrm{~cm}^{2} / \text { day }\right)\end{array}$ & $\gamma_{\mathrm{i}}$ \\
\hline \hline 1 & 1.0 & 1.0 & 1.0 & 0.0 & -- \\
\hline 2 & 0.8 & 0.7 & 1.0 & 3.0 & -0.396825 \\
\hline 3 & 0.6 & 0.5 & 1.0 & 3.0 & 0.126671 \\
\hline 4 & 0.4 & 0.2 & 1.0 & 3.0 & 0.167156 \\
\hline 5 & 0.1 & 0.1 & 1.0 & 3.0 & 0.519433 \\
\hline
\end{tabular}




\section{APPENDIX C: Program ILaG Flow Chart}

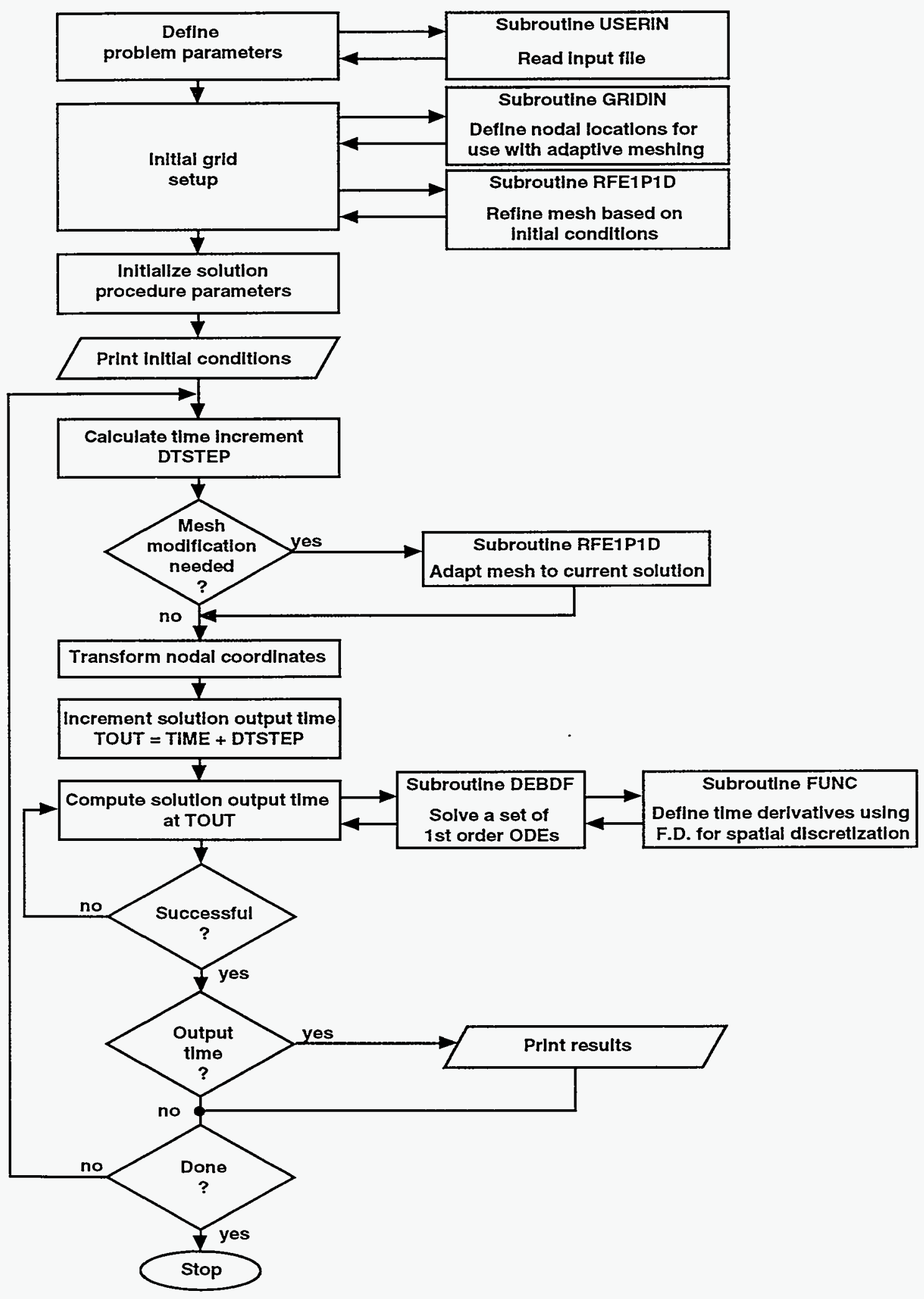




\section{APPENDIX D: ILaG Input File Description}

The contents of the ASCII input file required by the user is defined below. Input is free-field format so that columns are unimportant but the number of fields per line can be important (i.e., Line 1 fields can be put on two lines however Line 2 fields cannot be appended to Line 1). Comments are allowable after the data required for a line has been supplied. A sample input deck is presented in Appendix E.

Lines 1 through 4 - these lines contain general problem definition and mesh information

Line 1 - four integers

field 1: the geometry of the problem, currently must be 0

field 2: the number of zones involved

field 3: the number of components

field 4: the index of the component that controls diffusion

Line 2 - nzone +1 real numbers

field 1: the coordinate of the left-most boundary of the domain

field 2: the coordinate of the left-most internal interface

field nzone: the coordinate of the right-most internal interface

field nzone+1: the coordinate of the right-most boundary of the domain

Line 3 - nzone integers

field 1 : the initial number of nodes in the left-most zone

field nzone: the initial number of nodes in the right-most zone

Line 4 - one integer, two real numbers

field 1: the maximum level of mesh refinement (zero indicates the default value of six)

field 2: mesh refinement tolerance (zero takes the default)

field 3: mesh point removal tolerance (zero takes the default)

Lines 5 through 5 +nzone - each line contains the diffusion coefficients for each component in the zone where zones are defined from left to right (i.e., zone 1 is the left-most zone)

Example: Line 5

field 1: diffusion coefficient for component 1 in zone 1

field 2: diffusion coefficient for component 2 in zone 1 
field ncomp: diffusion coefficient for component ncomp in zone 1

Repeat the above line for each zone....

Next nzone-1 lines - each line contains the "fixed" concentration values for each component at the internal interface where internal interfaces are defined from left to right (i.e., internal interface 1 is the left-most interface)

Example: Line 1 of this set

field 1 : the fixed concentration value on the left side of the first internal interface for component 1

field 2: the fixed concentration value on the right side of the first internal interface for component 1

field 3: the fixed concentration value on the left side of the first internal interface for component 2 field 4: the fixed concentration value on the right side of the first internal interface for component 2

field ncomp*2-1: the fixed concentration value on the left side of the first internal interface for the last component, ncomp

field ncomp*2: the fixed concentration value on the right side of the first internal interface for the last component, ncomp

Repeat the above line for each internal interface....

Next line - nzone real numbers defining the bulk density for each zone

field 1: the bulk density for zone 1 (left-most zone)

field nzone: the bulk density for zone nzone (right-most zone)

Next nzone lines - each line contains the initial concentration for each component in a zone

Example: Line 1 of this set

field 1: initial concentration of component 1 in zone 1

field 2: initial concentration of component 2 in zone 1

field ncomp: initial concentration of component ncomp in zone 1 
Repeat the above line for each zone....

Next line - three real numbers, one integer to define simulation time and time step

field 1 : initial time

field 2: final time

field 3: maximum time step (delta time)

field 4: maximum number of time steps

Next line - two real numbers to control output frequency

field 1: time of first write to print/plot file

field 2: increment of time to write to print/plot 


\section{APPENDIX E: Sample Input File}

The following lines represent a sample input file. This particular case describes a $100 \% \mathrm{Sn}-\mathrm{Cu}$ system with two intermetallics as discussed in Section 5.0. The calculations are carried out to 400 days and are plotted in Figs. 10 and 11. A brief comment follows each input line; see Appendix D for a more detailed description.

$0,4,2,1$

$-1.0 \mathrm{e}-2,0.0,1.6 \mathrm{e}-4,2.5 \mathrm{e}-4,1.0 \mathrm{e}-2$

$10,10,10,100$

$0,1 . e-6,0$

$8.0 \mathrm{e}-7,0.0$

$0.0,0.0$

$0.0,0.0$

$1.0,1.0$

$4.3 \mathrm{e}-8,0.0$

$0.0,0.0$

$1.4 \mathrm{e}-7,0.0$

$3.8 \mathrm{e} 3,1.0$

$0.5 \mathrm{e}-7,0.0$

$0.0,0.0$

$1.7 \mathrm{e}-7,0.0$

$2.1 \mathrm{e} 3,1.0$

$8.0 \mathrm{e}-7,0.0$

$0.0,0.0$

$0.0,0.0$

$1.0,1.0$

$0.3,0.0$

1.e- $2,0.0$

$0.3,0.0$

1.e- $2,0.0$

$0.3,0.0$

1.e- $2,0.0$

$0.3,0.0$

1.e- $2,0.0$ igeom $(0=$ slab), nzone, ncomp, jcont

$x$ face (i.e., endpoints of zones)

nnodes in each zone

ilevmx, rtolref, rtolrec $==>$ defaults

Dm for components in zone 1

a for components in zone 1

Dp for components in zone 1

$\mathrm{xk}$ for components in zone 1

Dm for components in zone 2

a for components in zone 2

Dp for components in zone 2

$\mathrm{xk}$ for components in zone 2

Dm for components in zone 3

a for components in zone 3

Dp for components in zone 3

xk for components in zone 3

Dm for components in zone 4

a for components in zone 4

Dp for components in zone 4

$\mathrm{xk}$ for components in zone 4

$\mathrm{kl}$ (reaction rate coef) for components left end of zone 1

$\mathrm{kr}$ (reaction rate coef) for components right end of zone 1

$\mathrm{kl}$ (reaction rate coef) for components left end of zone 2

$\mathrm{kr}$ (reaction rate coef) for components right end of zone 2

$\mathrm{kl}$ (reaction rate coef) for components left end of zone 3

$\mathrm{kr}$ (reaction rate coef) for components right end of zone 3

$\mathrm{kl}$ (reaction rate coef) for components left end of zone 4

$\mathrm{kr}$ (reaction rate coef) for components right end of zone 4 
$1.0,0.623,0.0,1.0$

$0.605,0.410,1.0,1.0$

$0.400,0.0,1.0,1.0$

$8.9,9.0,8.37,7.29$

$1.0,0.0$

$0.605,1.0$

$0.4,1.0$

$0.0,1.0$

$1.0,401.0,0.1,41000$

$1.0,5.0$ wfix at left and right sides of first boundary for each component wfix at left and right sides of second boundary wfix at left and right sides of third boundary bulk density of each zone initial condition for zone 1 initial condition for zone 2 initial condition for zone 3 initial condition for zone 4 initial time, final time, delta time, max steps time of first print/plot, increment of print/plot time 


\section{DISTRIBUTION}

1 Iris Artaki

AT\&T Bell Laboratories

Engineering Research Center

P. O. Box 900

Princeton, NJ 08540

1 Gary Becka, AS/KCD

D/837, 2C43

P. O. Box 41959

Kansas City, MO 64141-6159

MS $03201011 \quad$ C. E. Meyers

MS $08411500 \quad$ D. J. McCloskey

MS $08361501 \quad$ C. W. Peterson

MS $0827 \quad 1502 \quad$ P. J. Hommert

MS $08271511 \quad$ J.S. Rottler

3 MS $0827 \quad 1511 \quad$ P. L. Hopkins

MS $0827 \quad 1511 \quad$ M. J. Martinez

MS $08341512 \quad$ A. C. Ratzel

MS $08341512 \quad$ M. R. Baer

3 MS $08341512 \quad$ K. L. Erickson

MS $0834 \quad 1512 \quad$ J. R. Torczynski

MS 08351513 R. E. Hogan

MS0336 $1700 \quad$ R. J. Eagan

$\begin{array}{lll}\text { MS } 0337 & 1800 \quad \text { A. D. Romig }\end{array}$

MS 03681815 E. P. Lopez

MS 03421822 M. J. Carr

MS 03421822 P. F. Hlava

MS $03421822 \quad$ A. C. Kilgo

MS $03401831 \quad$ M. J. Cieslak

MS $03401831 \quad$ F. M. Hosking

10 MS $0340 \quad 1831 \quad$ P. T. Vianco

MS 03401831 F. Yost

MS 03401832 D. R. Frear

MS 03401832 R. Salzbrenner

MS $03401832 \quad$ J. J. Stephens

MS $11341833 \quad$ J. L. Jellison

MS $09612402 \quad$ J. Ledman

$\begin{array}{lll}\text { MS } 0957 & 2411 & \text { G. L. Cessac }\end{array}$

MS 90438743 M. L. Callabresi

MS 90438745 S. K. Griffiths

5 MS $0899 \quad 13414 \quad$ Technical Library

1 MS 061913416 Technical Publications 
10 MS 0100 7613-2 Document Processing for DOE/OSTI

1 MS 9018 8523-2 Central Technical Files 